\title{
Design of Active Defects in Semiconductors: 3D Electron Diffraction Revealed Novel Organometallic Lead Bromide Phases Containing Ferrocene as Redox Switches
}

Nicole Fillafer ${ }^{1}$, Henning Kuper ${ }^{2}$, Andreas Schaate ${ }^{1}$, Sonja Locmelis ${ }^{1}$, Joerg August Becker², Yaşar Krysiak ${ }^{1 *}$ and Sebastian Polarz ${ }^{1 *}$

N. Fillafer, Dr. Y. Krysiak, Dr. A. Schaate, Dr. S. Locmelis, Prof. S. Polarz

Leibniz University of Hannover, Institute of Inorganic Chemistry, Callinstraße 9, 30167

Hannover, Germany

E-mail: sebastian.polarz@aca.uni-hannover.de, yasar.krysiak@aca.uni-hannover.de

H. Kuper, Prof. Dr. J. A. Becker

Leibniz University of Hannover, Institute of Physical Chemistry, Callinstraße 3-3a, 30167

Hannover, Germany

Keywords: semiconductors, hybrid perovskites, ferrocene materials, molecular switches, micro electron diffraction

\begin{abstract}
Once the optical, electronic or photocatalytic properties of a semiconductor are set by adjusting composition, crystal phase and morphology, one cannot change them anymore, respectively on demand. Materials enabling a post-synthetic and reversible switching of features such as absorption coefficient, band-gap or charge carrier dynamics represent are highly desired. Hybrid perovskites facilitate exceptional possibilities for progress in the field of smart semiconductors because active organic molecules become an integral constituent of the crystalline structure. We report the integration of ferrocene ligands into semiconducting 2D phases based on lead bromide. The complex crystal structures of the resulting, novel ferrovskite phases were determined by $3 \mathrm{D}$ electron diffraction. The ferrocene ligands exhibit strong structure-directing effects on the $2 \mathrm{D}$ hybrid phases, which is why the formation of exotic types of face- and edge-sharing lead bromide octahedra is observed. The band gap of
\end{abstract}


the materials ranges from $3.06 \mathrm{eV}$ up to $3.51 \mathrm{eV}$, depending on the connectivity of the octahedra. Deploying the redox features of ferrocene, one can create defect states or even a defect band leading to the control over the direction of exciton migration and energy transport in the semiconductor.

\section{Introduction}

Research in materials chemistry aims to control the properties of a material by precisely adjusting parameters such as composition, crystal structure or nanostructure. However, it is quite common that the obtained materials have more or less strongly changed or even unexpected properties because of the presence of defects. Although defects are enthalpically unfavorable, they occur due to the contribution of entropy to free energy. Their frequent statistical occurrence makes them difficult to localize and to quantify and cannot yet be used to influence the properties of a material by purpose. Ideally, a defect can be switched on and off as desired. Substitutional point-defects are of utmost importance in semiconductor materials as they have a direct consequence on doping, the number and type of mobile charge carriers and band gap engineering in general. ${ }^{[1,2]}$ Once a heteroatom is introduced at a defined concentration into classical semiconductors such as Si, II-VI (e.g. ZnO) or III-V (e.g. GaN) compounds, the properties associated to the degree of doping are set.

Imagine a material which ideally could change fast, reversibly and on demand from a doped to an undoped (= defect-free) state. The development of such responsive semiconductor materials stands at its very beginning. It is obviously hard to create the described type of active defects in traditional semiconductor solids. However, recently major scientific attention was devoted to a new class, the so-called hybrid perovskites materials. Easy processability and unique properties brought hybrid organic-inorganic perovskites to the forefront of semiconductor research. ${ }^{[3]}$ In the last decade, they emerged as a genuine alternative to silicon, 
especially in photovoltaic applications. ${ }^{[4,5]}$ But the ultra-low cost materials are not only used in photovoltaics. Exceptional properties such as long-range electron and hole transport lengths ${ }^{[6]}$, high absorption coefficients ${ }^{[7]}$, a variably band gap ${ }^{[8,9]}$ and high photoluminescence quantum yields ${ }^{[10]}$ promoted the development of optoelectronic devices as transistors, light-emitting diodes and photodetectors. ${ }^{[11]}$ One reason for the wide range of applications is the possibility to adjust the electro-optical properties by a specific compositions (e.g. anion exchange) and dopants (e.g. $\left.\mathrm{Bi}^{3+}, \mathrm{Au}^{3+}, \mathrm{In}^{3+}, \mathrm{Mn}^{2+}\right) \cdot{ }^{[12-15]}$

One of the most interesting and most important features of hybrid perovskites is that larger and functional organic molecules can be included as integral parts of the crystal lattice. A consequence is the reduction of the dimensionality of the inorganic lead halide network, respectively the formation of layered structures such as the Ruddlesden-Popper phases. ${ }^{[16,17]}$ With organic cations exceeding the space given by the perovskite structure, layered hybrid perovskites (LHPs) are obtained. The structural diversity of LHPs depends strongly on the organic cation that serves as a template, but also the choice of halide $\left(\mathrm{Cl}^{-}, \mathrm{Br}^{-}, \mathrm{I}^{-}\right){ }^{[18-20]}$ Sterically demanding cations or cations with a strong templating effect lead to more complex metal halide structures compared the classic arrangement of lead halide octahedra. ${ }^{[21]}$ Other than in perovskite-related structures, these phases feature not only corner-, but also edge- and face-sharing octahedra. These structures led to the so-called perovskitoids, perovskite-like structures, which show enhanced stability and are therefore highly attractive for photovoltaic applications. ${ }^{[22-24]}$ Reported are one dimensional (1D) perovskitoids, ${ }^{[25]}$ but as well 2D and 3D structures are already available. ${ }^{[32-34]}$ The electronic structure of the conduction and valence band is influenced by both constituents, the inorganic and the organic. ${ }^{[19,29]}$ Due to the confinement of the charge carriers, the inorganic layers behave like quantum wells. ${ }^{[30]}$ The role of the organic ligands is equally important. ${ }^{[31]}$ Conductive $^{[30,32]}$, polymerizable ${ }^{[33]}$ and photoactive ${ }^{[34]}$ organic functionalities have already been incorporated into LHPs. 
It has not yet been possible to incorporate a ligand with which the electro-optical properties e.g. the band gap or photoluminescence properties can actively be controlled. One might think that photoactive ligands are most suitable for this purpose, but electronically active transition states are quenched by the semiconductor. ${ }^{[34]}$ ZHANG et $a l$. presented a highly important paper on 1D lead halide phase containing ferrocene $(\mathrm{Fc})$ with exceptional piezoelectric properties. ${ }^{[35]}$ The paper envisions that the combination of organometallic compounds with the structurally diverse class of hybrid perovskites opens up novel possibilities. However, one of the most important functionalities of $\mathrm{Fc}$, its unique redox properties, was not addressed. This is surprising because Fc has proven to be a valuable building block in many other areas of material science research. Fc has already been used in battery materials, polymers $^{[36]}$ and metal organic frameworks (MOFs) to artificially create conductivity. ${ }^{[37]}$ In MOFs, which usually have localized electronic stages, charge transfer between the surface bound Fc-ligands could be observed during the oxidation. ${ }^{[38]}$ The fast redox reaction and adjustable optical and electronic properties ${ }^{[39]}$ make it a perfect candidate as an electro-optically active ligand.

We report here the targeted synthesis of novel layered hybrid lead halide phases containing layers of tailor-made ferrocene (Fc) derivatives (Scheme 1) which allow band gap tuning by the incorporation of active defects. The underlying idea is that doping of the perovskite material occurs when the number of oxidized ferrocenium $\left(\mathrm{Fc}^{+}\right)$species is low and suddenly cooperative effects, when the density of $\mathrm{Fc}^{+}$increases. For the comprehensive characterization of the structural properties, a combination of 3D electron diffraction $(\mathrm{ED})^{[40,41]}$, modelling, powder X-ray diffraction (PXRD) supported by DFT calculations, was used to enable the structure determination of the fine-crystalline powder materials. Subsequently, electronic, optical and redox properties were characterized using X-ray photoelectron spectroscopy (XPS) and PES on air (PESA), UV/Vis and photoluminescence. 
a

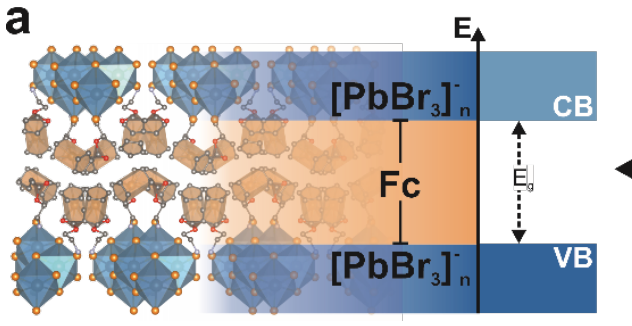

b
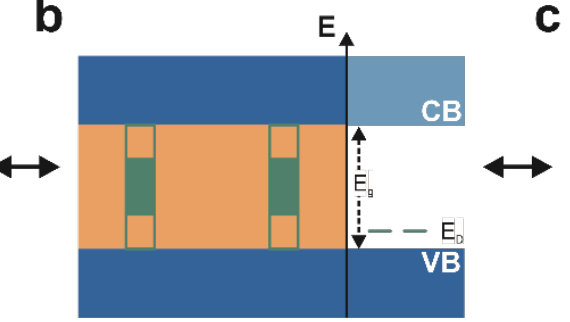

Scheme 1. Representation of a semiconductor crystal with integrated Fc and the band gap scheme in the intrinsic state (a), with a small amount of oxidized Fc-ligands causing defect states in the band gap $\mathrm{E}_{\mathrm{D}}(\mathrm{b})$, and with a high amount of oxidized Fc-ligands causing a new defect band in the band gap (c).

\section{Results and Discussion}

\subsection{Synthesis of Ferrovskites and crystal structure determination by 3D electron diffraction}

A systematic series of Fc-ligands capable of forming hybrid phases with lead halides was prepared first (Figure 1a, inset). The interaction of the Fc derivatives is achieved by an ammonium group. This head group can be attached to Fc-COOH by ester coupling chemistry as described in detail in the experimental section. The distance between the lead halide phase and Fc can be controlled by the adjustment of the length of the alkyl linker $\left(\mathrm{CH}_{2}\right)_{\mathrm{n}}(\mathrm{n}=2,4,6)$. The characterization of the molecular compounds was performed by standard techniques (see Figure S1-S4 Supporting Information). The described ligands are dissolved in dimethyl formamide (DMF) as a solvent together with a certain amount of lead bromide $\left(\mathrm{PbBr}_{2}\right)$, forming a precursor solution. The formation of the novel hybrid phases, which we designate ferrovskites, is initiated by an antisolvent method using dichloromethane (DCM) or toluene. The formation of a solid phase denoted as $\left[\mathrm{FcC}_{\mathrm{n}} \mathrm{Br}\right]^{\mathrm{Pb}}$ can be observed when the precursor solution is added to the antisolvent. 


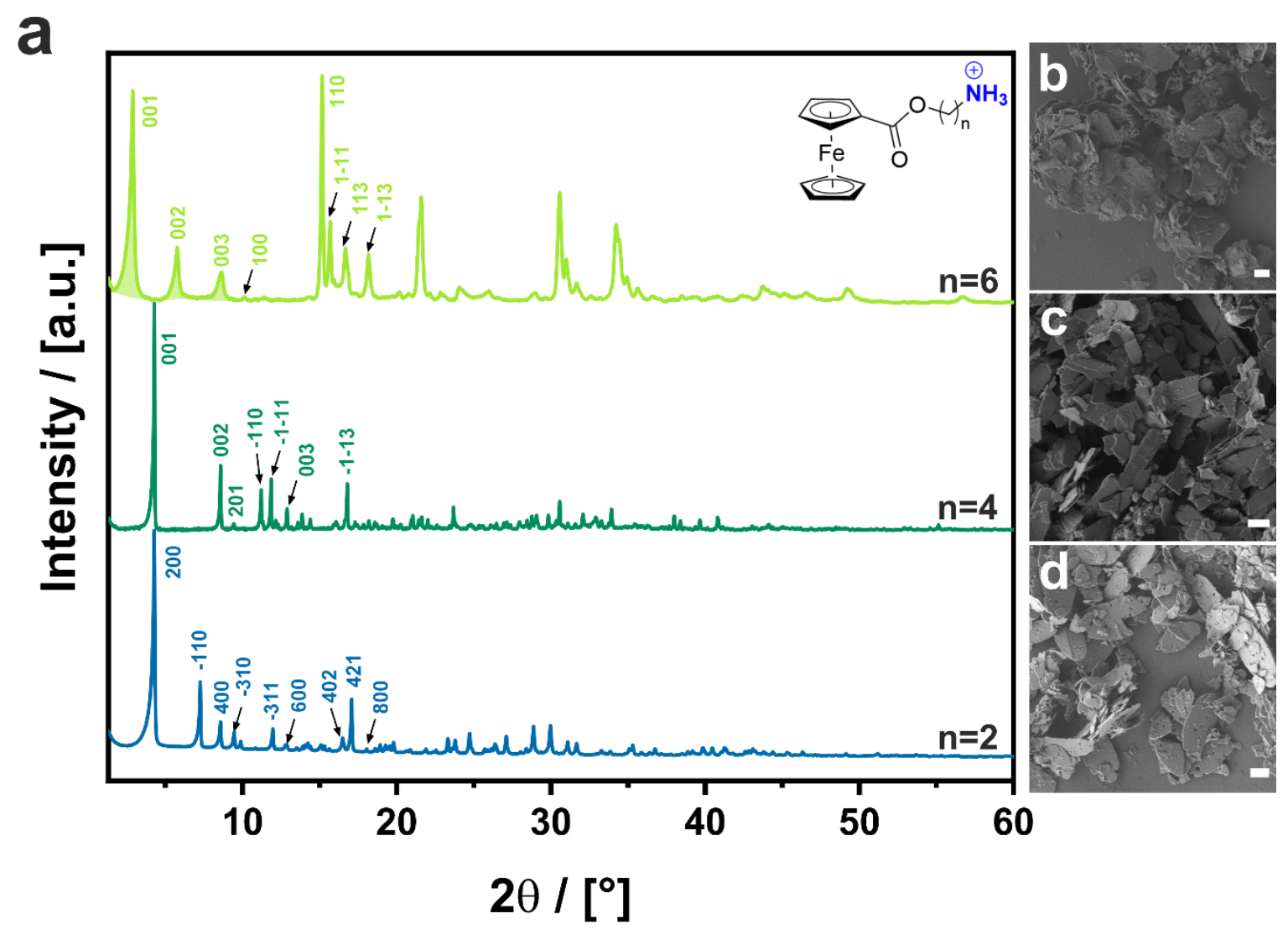

Figure 1. a) Experimental powder X-ray diffraction (PXRD) patterns for the reaction product of $\mathrm{FcC}_{\mathrm{n}} \mathrm{Br}$ and $\mathrm{PbBr}_{2}$ with chemical structure of the used $\mathrm{Fc}$-derivatives with alkyl linkers of the length $\left(\mathrm{CH}_{2}\right)_{n}(\mathrm{n}=2,4,6)$ as inset. Reflections were indicated based on crystal structure analysis, which will be discussed later. First three reflections (shaded in green) of $n=6$ have a FWHM values of approx. $0.26^{\circ}, 0.30^{\circ}$ and $0.40^{\circ} 2 \theta$. Scanning electron microscopy (SEM) images of the crystals formed with $\mathrm{PbBr}_{2}$ and b) $\mathrm{FcC}_{6} \mathrm{Br}$, c) $\mathrm{FcC}_{4} \mathrm{Br}$ and d) $\mathrm{FcC}_{2} \mathrm{Br}$. Scalebar $=2 \mu \mathrm{m}$.

The investigation of the precipitates by scanning electron microscopy (SEM) illustrates that small crystals form for all Fc-ligands (Figure 1b-d). The significant difference between the lateral extension of those crystals (several $\mu \mathrm{m}$ ) compared to their thickness (nm range) is a first indication for the formation of layered, respectively $2 \mathrm{D}$ phases. The lamellar nature of all three phases $\left[\mathrm{FcC}_{\mathrm{n}} \mathrm{Br}\right]^{\mathrm{Pb}}(\mathrm{n}=2,4,6)$ can in principal be confirmed by PXRD as shown in Figure 1a by the first strong reflections ((001) and (200), respectively), that can be assigned to the basal distances. However, the PXRD patterns are too complex to achieve an unambiguous characterization of the crystal structures. The crystals (Figure 1b-d) obtained in the antisolvent process are also too thin to perform classical single-crystal X-ray diffraction (SCXRD). 
With such hybrid materials, it is essential to know the short and especially the long-range order to understand the interplay of structure and function. With the recent developed method 3D electron diffraction (3D ED) it is now possible to overcome the limitation of small crystal sizes and to solve structures of even nanocrystals. ${ }^{[42-44]}$ In several cases it could be demonstrated that beyond the structure solution, the consideration of dynamical scattering effects allows a precise structure refinement and the detection of hydrogen atoms. ${ }^{[45,46]}$ In favorable cases it even approaches the accuracy of SCXRD and furthermore enables a robust determination of the absolute structure. ${ }^{[47,48]}$ One challenge that still needs to be overcome is the beam sensitivity of some materials, which can make a structure analysis difficult or impossible. It could be shown that the development of fast acquisition protocols ${ }^{[44,49]}$ allows the use of this technique with various transmission electron microscopes (TEMs) even for very beam sensitive materials. ${ }^{[41,50]}$ Nevertheless, especially in hybrid layered systems, besides beam sensitivity, stacking disorder is another difficulty that often requires a combination of several methods such as 3D ED, PXRD, modelling/simulation and DFT calculations. ${ }^{[41,51]}$

The solid phases of $\mathrm{FcC}_{2} \mathrm{Br}$ and $\mathrm{FcC}_{4} \mathrm{Br}$ have been investigated with $3 \mathrm{D} \mathrm{ED}$, resulting in the composition $\left(\mathrm{FcC}_{2}\right) \mathrm{PbBr}_{3}$ and $\left(\mathrm{FcC}_{4}\right)_{4} \mathrm{~Pb}_{3} \mathrm{Br}_{10}$, respectively. The crystallographic details of all three phases are summarized in Figure 2 and Table 1 and will be discussed here in detail. In case of $\left(\mathrm{FcC}_{2}\right) \mathrm{PbBr}_{3}$ the structure analysis was attempted purely based on 3D ED data. Three crystals (Figure S5a-c Supporting Information) have been measured with a very low accumulated electron dose ${ }^{[52,53]}$ of approx. $2.5 \mathrm{e}^{-/} \mathrm{A}^{2}$ for each dataset. The structure can be described in the monoclinic space group $C 2 / c$ with the lattice constants given in Table $\mathrm{S} 1$. In order to reduce dynamical scattering effects and to improve therewith the reflection statistics, three datasets were merged to be one $\left(R_{\text {int }}=10.6 \%\right)$. The structure could be solved ab initio based on each single dataset and enabled a clear identification of all non-hydrogen atoms (see Figure S7a-c Supporting Information). The following kinematical refinement converged to a 
fairly low $R_{1}(\mathrm{obs})$-value of $14.9 \%$. As can be seen from the successful Rietveld refinement, the structure completely describes the crystalline parts of the sample (Figure S10a Supporting Information). The overall crystallinity (Figure S8a Supporting Information) and the resolution of the diffraction data was high enough to perform a dynamical refinement of the structure model resulting in an excellent overall $R_{1}$-value of $9.4 \%$ for all observed reflections with highly improved geometry of the structure model compared to the kinematical refinement. This made it even possible to detect most of the hydrogen positions by the difference Fourier synthesis above the $3 \sigma$-level of the electrostatic difference potential map $[\Delta V(\mathbf{r})]$ as shown in Figure S9.
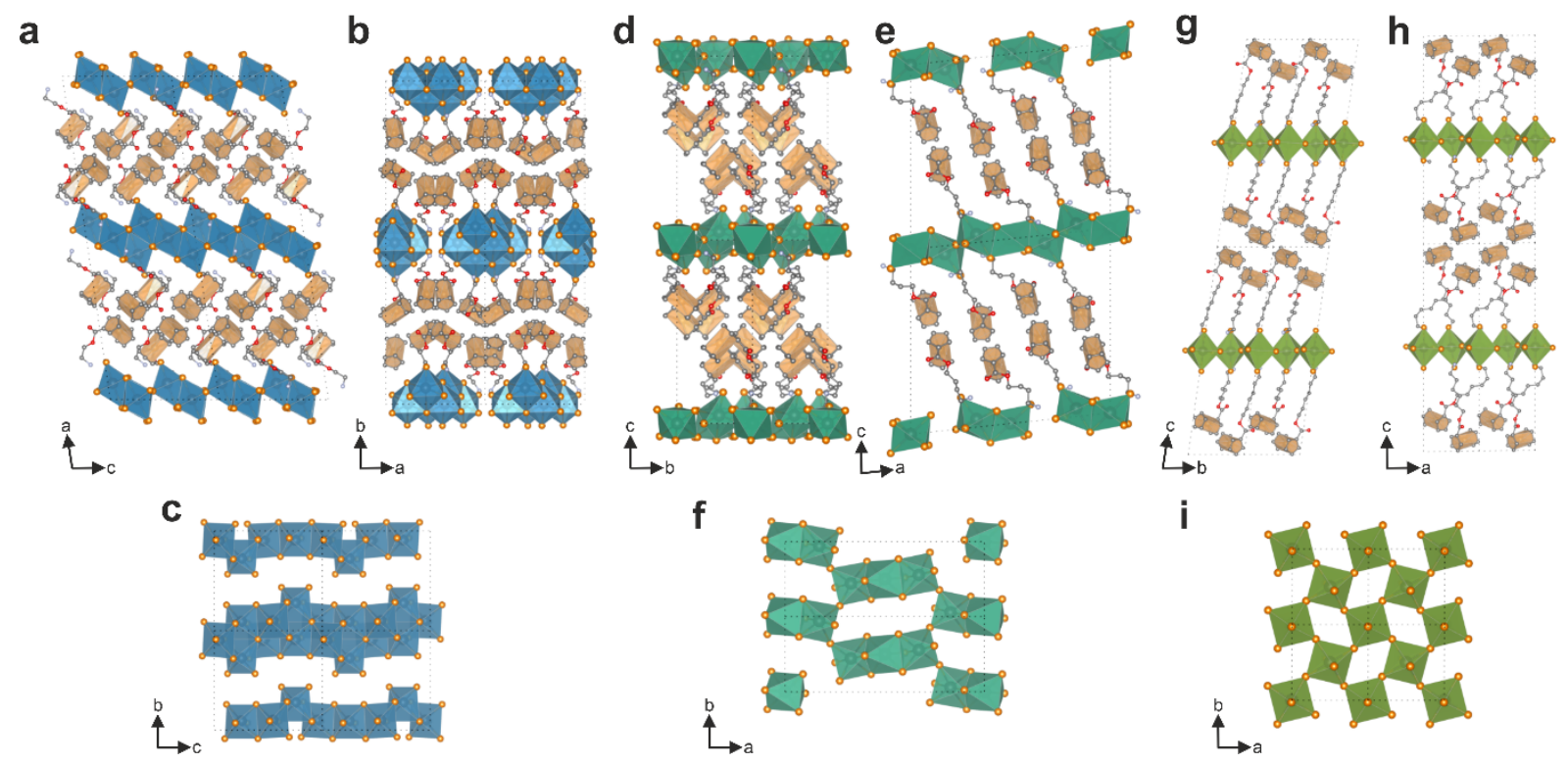

Figure 2. Crystal structures of a,b,c) $\left(\mathrm{FcC}_{2}\right) \mathrm{PbBr}_{3}$ with edge-sharing octahedra in blue, d,e,f) $\left(\mathrm{FcC}_{4}\right)_{4} \mathrm{~Pb}_{3} \mathrm{Br}_{10}$ with face- and corner-sharing octahedra in dark green and g,h,i) $\left(\mathrm{FcC}_{6}\right)_{2} \mathrm{PbBr}_{4}$ corner-sharing octahedra in light green. a,b,d,e,g,h) sideview of the phases $c, f, i)$ topview of the octahedra without Fc-ligands. Orange polyhedral represent the Fc-moieties. Hydrogen atoms have been removed for clarity.

The unit cell and symmetry of $\left(\mathrm{FcC}_{4}\right)_{4} \mathrm{~Pb}_{3} \mathrm{Br}_{10}$ could as well be determined based on 3D ED and matches the PXRD data (see Figure $1 \mathrm{a}, \mathrm{n}=4$ ). The structure crystallizes in the monoclinic space group $P 22_{1} / a$. Five datasets needed to be merged in order to solve the structure $a b$ initio. Beside the unambiguous determination of the lead bromide network, the ferrocene positions could also be indicated (see Figure S7d-f Supporting Information). The best diffraction 
pattern out of three datasets were used to perform a kinematical refinement that converged to $R_{1}(\mathrm{obs})=18.3 \%$. The same data was used to perform a dynamical refinement resulting in an overall $R_{1}$-value of $11.7 \%$ for all observed reflections. Even though the error values of structure refinement based on electron diffraction appear subordinate, the low completeness (Figure S6d-f Supporting Information) and overall data quality is too low (see Figure S8b Supporting Information) to verify the structure just based on 3D ED alone. Therefore, the structure has also been confirmed by a subsequent Rietveld refinement (Figure S10b Supporting Information). $15.2 \% \mathrm{PbBr}_{2}$ was detected as an impurity in the sample. In contrast to the phases $\left(\mathrm{FcC}_{2}\right) \mathrm{PbBr}_{3}$ and $\left(\mathrm{FcC}_{4}\right)_{4} \mathrm{~Pb}_{3} \mathrm{Br}_{10}$, the beam sensitivity of $\left[\mathrm{FcC}_{6} \mathrm{Br}\right]^{\mathrm{Pb}}$ is so much increased, that it wasn't possible to collect a single ED pattern before degeneration of the crystal structure. In addition, the strongly pronounced plate-like morphology as shown in the SEM image (Figure 1b) gives reason to assume weakened interactions between the layers. From the broadened reflections indicated by the large full width at half-maximum $(\mathrm{FWHM})$ of the first three reflections $\left(\mathrm{FWHM}>0.25^{\circ} 2 \theta\right)$ of the PXRD pattern (see Figure 1a, $n=6$ ), it can already be assumed that the amount of stacking faults is significantly increased at this chain length $\left(\mathrm{FcC}_{6}\right)$. However, from the intensity distribution of the profile in the $2 \theta$ range between $12^{\circ}$ and $40^{\circ}$ of the PXRD pattern (Figure $\mathrm{S} 11, \mathrm{n}=6$, Supporting Information), it can be deduced that $\left[\mathrm{FcC}_{6} \mathrm{Br}\right]^{\mathrm{Pb}}$ is a Ruddlesden-Popper phase with the composition $\left(\mathrm{FcC}_{6}\right)_{2} \mathrm{PbBr}_{4} \cdot{ }^{[34]}$ A structure was modelled and optimized by DFT-D (see Figure 2, Table 1; Figure S12, Supporting Information). 
Table 1. Crystal Data for hybrid lead bromide phases with $\mathrm{FcC}_{\mathrm{n}} \mathrm{Br}(\mathrm{n}=2,4$, 6), determined with 3D ED for $n=2,4$ and modelling for $n=6$. Lattice constants given here are based on Rietveld refinement and Pawley fit, respectively.

\begin{tabular}{|c|c|c|c|}
\hline & $\left(\mathrm{FcC}_{2}\right) \mathrm{PbBr}_{3}$ & $\left(\mathrm{FcC}_{4}\right)_{4} \mathrm{~Pb}_{3} \mathrm{Br}_{10}$ & $\left(\mathrm{FcC}_{6}\right)_{2} \mathrm{PbBr}_{4}$ \\
\hline precursor salt & $\prod_{\substack{F_{1}^{\prime} \\
1}}^{0}$ & $\underset{\mathrm{Fe}}{\mathrm{Fe}}$ & 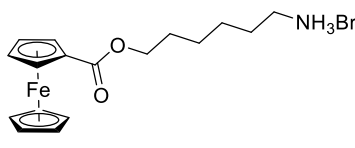 \\
\hline empirical formula & $\left(\mathrm{C}_{13} \mathrm{H}_{16} \mathrm{FeNO}_{2}\right) \mathrm{PbBr}_{3}$ & $\left(\mathrm{C}_{15} \mathrm{H}_{20} \mathrm{FeNO}_{2}\right)_{4} \mathrm{~Pb}_{3} \mathrm{Br}_{10}$ & $\left(\mathrm{C}_{17} \mathrm{H}_{24} \mathrm{FeNO}_{2}\right)_{2} \mathrm{PbBr}_{4}$ \\
\hline formula weight $(\mathrm{g} / \mathrm{mol})$ & 721.03 & 2630.44 & 1187.88 \\
\hline crystal system & Monoclinic & Monoclinic & Triclinic \\
\hline space group & $C 2 / c$ & $P 2_{1} / a$ & $P-1$ \\
\hline Z & 16 & 2 & 2 \\
\hline$a[\AA]$ & $41.6677(13)$ & $22.3384(10)$ & $8.287(5)$ \\
\hline$b[\AA]$ & $12.7153(4)$ & $8.43444(19)$ & $8.284(4)$ \\
\hline$c[\AA]$ & $14.0140(4)$ & $20.6965(7)$ & 31.09(3) \\
\hline$V\left[\AA^{3}\right]$ & $7333.9(4)$ & $3877.3(2)$ & 2113(3) \\
\hline$\alpha, \beta, \gamma\left[^{\circ}\right]$ & $90,98.9741(11), 90$ & 90, 96.109(3), 90 & $81.97(16), 90.62(9), 89.83(5)$ \\
\hline$\rho\left[\mathrm{g} / \mathrm{cm}^{3}\right]$ & 2.61 & 2.25 & 1.86 \\
\hline$\left.d_{\mathrm{Fe}-\mathrm{Fe}}[\AA]\right]$ & $6.35(5)^{\mathrm{a})}$ & $6.24(5)^{\text {a) }}$ & $6.14(4)$ \\
\hline$E_{\text {gap }}[\mathrm{eV}]$ & $3.51^{b)}$ & $3.27^{b)}$ & $3.06^{b)}$ \\
\hline
\end{tabular}

a) For the structure determination at $97 \mathrm{~K}$.

b) Energy of the band gap was determined by reflectance spectroscopy with a Kubelka-Munk plot provided in the Figure S13, Supporting Information.

Based on the crystal structure analysis, it can be confirmed that all phases are layered structures. In order to understand the electronic and optical properties of the materials, their crystalline structure is described in more detail below. In the structure of $\left(\mathrm{FcC}_{2}\right) \mathrm{PbBr}_{3}$, lead bromide octahedra are connected via their edges, forming a ribbon-like structure (Figure 2a-c). Four octahedra are connected to form a tetramer. A staggered arrangement of the tetramers leads to a zig-zag like structure of the $\left[\mathrm{PbBr}_{3}\right]^{-}$-ribbons, which extend along the c-axis. The structure complies with the $\left(\mathrm{NH}_{4}\right) \mathrm{CdCl}_{3}$ structure type, ${ }^{[54]}$ but it has not been 
observed before for any hybrid lead halide material. This unusual arrangement of the octahedra is obviously a consequence of the intermolecular interaction between the ferrocene groups and their resulting arrangement. Adjacent ferrocenes are positioned perpendicular to each other which is very similar to the arrangement in the crystal structure of nonfunctionalized $\mathrm{Fc}^{\left[{ }^{[5]}\right.}$ In addition, it can be observed that one of the ammonium head groups located above a $\left[\mathrm{PbBr}_{3}\right]^{-}$-ribbon are connected to the ester group of an adjacent ligand by hydrogen bonding (N1-H-O3) (see Figure S9, Supporting Information). The other ammonium head group (N2), on the other hand, adheres deeper in the $\left[\mathrm{PbBr}_{3}\right]^{-}$-ribbon and does not form an N-H-O hydrogen bond. Thus, there is an intramolecular competition for the interaction of the ammonium group with the lead bromide framework. Therefore, it can be concluded that $\mathrm{FcC}_{2} \mathrm{Br}$ acts as a strong structure-directing agent for the way the lead bromide octahedra are connected. The conformational flexibility is increasing for longer alkyl linkers of $\mathrm{FcC}_{\mathrm{n}} \mathrm{Br}$, and this will step-wise reduce the structure-directing character of the Fc constituent.

The reduced constraints in the packing of the ferrocene moieties allows the formation of a $2 \mathrm{D}$ structure in the lead bromide subphase in $\left(\mathrm{FcC}_{4}\right)_{4} \mathrm{~Pb}_{3} \mathrm{Br}_{10}$ (Figure $\left.2 \mathrm{~d}-\mathrm{f}\right)$. The inorganic layers contain trimers of face-sharing octahedra $\left[\mathrm{Pb}_{3} \mathrm{Br}_{10}\right]^{4-}$ linked through bridging bromides to adjacent trimers. The inorganic sublattice resembling the $\mathrm{Cs}_{4} \mathrm{Mg}_{3} \mathrm{~F}_{10}$ structure ${ }^{[56]}$ was reported before for other hybrid lead halides such as compounds containing phenyltrimethylammonium bromide $\left(\mathrm{C}_{6} \mathrm{H}_{5} \mathrm{~N}\left(\mathrm{CH}_{3}\right)_{3} \mathrm{Br}\right)^{[57]}$ or trimethylsulfonium bromide $\left(\left(\mathrm{CH}_{3}\right)_{3} \mathrm{SBr}\right) \cdot{ }^{[58]}$

If the alkyl linker becomes even longer such as in $\left(\mathrm{FcC}_{6}\right)_{2} \mathrm{PbBr}_{4}$ the ammonium is now fully available for the interaction with the inorganic phase because the formation of hydrogenbonding to the ester function is suppressed. In addition, the adjacent ferrocene groups can pack more efficiently. The latter can be seen by evaluating the increasing distance of two $\mathrm{Fe}^{\mathrm{II}}$ centers $\left(\mathrm{d}_{\mathrm{Fe}-\mathrm{Fe}}\right)$ between two neighboring Fc-ligands (Table 1). The described factors lead to the formation of a classical 2D perovskite, also known as Ruddlesden-Popper phases. ${ }^{[59]}$ The 
inorganic lattice consists of distorted corner-sharing octahedra (Figure 2g-i). A similar arrangement of the Fc-dumbbells is observed. This leads to an oblique, distorted position of the chain of every second ligand between the $\mathrm{PbBr}_{4}$-layers (Figure $2 \mathrm{~h}$ ). In addition, the longer alkyl chain now prevents the formation of hydrogen bonds, which results in a less densely packed structure.

\subsection{Electronic and Optical Properties of Ferrovskites}

Since it is known from the literature that the band gap strongly depends on the type of linkage of the $\left[\mathrm{PbBr}_{6}\right]^{4-}$ octahedra, ${ }^{[19,29]}$ following a trend of "corner-sharing $<$ edge-sharing $<$ face-sharing", we also expect such an effect for the ferrovskite phases described in the previous section. Optical reflectance spectroscopy (ORS) was used to determine the band gap of the resulting materials (Figure 3a; Figure S13, Supporting Information).
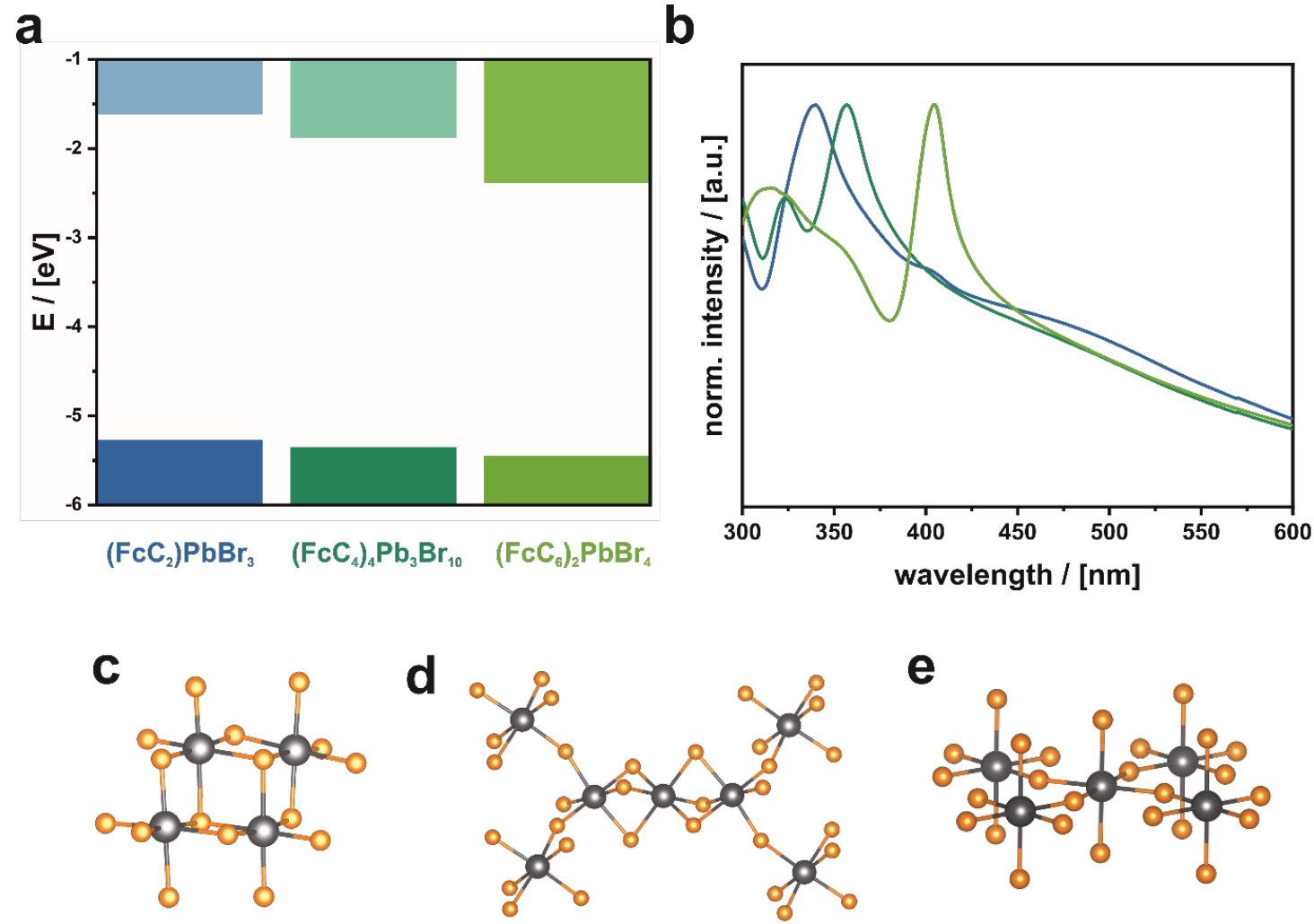

Figure 3. a) Band structure analysis determined from ORS/Kubelka Munk and PESA measurements on the different ferrovskite materials. b) Absorption spectra of the particles dispersed in toluene. Arrangement of lead halide octahedra in the different ferrovskite phases: c) $\left(\mathrm{FcC}_{2}\right) \mathrm{PbBr}_{3}$ with edge-sharing octahedra, d) $\left(\mathrm{FcC}_{4}\right)_{4} \mathrm{~Pb}_{3} \mathrm{Br}_{10}$ with face- and corner-sharing octahedra and e) $\left(\mathrm{FcC}_{6}\right)_{2} \mathrm{PbBr}_{4}$ with only corner-sharing octahedra. 
For $\left(\mathrm{FcC}_{2}\right) \mathrm{PbBr}_{3}$, which is composed of edge-sharing octahedra seen in Figure $3 \mathrm{c}$, the largest band gap is found with $3.51 \mathrm{eV}(\Rightarrow \lambda=353 \mathrm{~nm})$. For the phase $\left(\mathrm{FcC}_{4}\right)_{4} \mathrm{~Pb}_{3} \mathrm{Br}_{10}$, a band gap at $3.27 \mathrm{eV}(\Rightarrow \lambda=379 \mathrm{~nm})$ is found, which is in good agreement with the literature. ${ }^{[58]}$

Interestingly, the phase with a mixture of face- and corner-sharing octahedra (Figure 3d) has a smaller band gap than the edge-sharing $\left(\mathrm{FcC}_{2}\right) \mathrm{PbBr}_{3}$. As expected, the obtained Ruddlesden-Popper phase $\left(\mathrm{FcC}_{6}\right)_{2} \mathrm{PbBr}_{4}$, containing only corner-sharing octahedra (Figure $3 \mathrm{e}$ ) show the smallest band gaps with $3.06 \mathrm{eV}(\Rightarrow \lambda=405 \mathrm{~nm})$. These values are in good agreement with the literature. ${ }^{[60]}$ The relative energies of the valence band maximum (VBM) and conduction band minimum (CBM) were obtained from photoelectron spectroscopy in air (PESA) measurements (Figure S14, Supporting Information). The combined results are given in Figure 3a. The VBM is almost constant for all lead bromide phases with a slight trend towards lower energies from $\left(\mathrm{FcC}_{2}\right) \mathrm{PbBr}_{3}$ to $\left(\mathrm{FcC}_{6}\right)_{2} \mathrm{PbBr}_{4}$. Thus, it can be seen that the change of $E_{\text {gap }}$ is mainly an effect of the structure of the lead halide phase on the CBM, which decreases significantly in the given series (Figure 3a).

$\mathrm{UV}$-Vis absorption spectra can be recorded from a dispersion of the particles in toluene (Figure 3b). The advantage of toluene as a solvent is that its absorption bands are $\left(\lambda_{\mathrm{abs}}<\right.$ $280 \mathrm{~nm})$ are in a different region than $\mathrm{E}_{\mathrm{gap}}$, respectivel $\lambda_{\mathrm{abs}}\left(\mathrm{FcC}_{\mathrm{n}} \mathrm{Br}\right)$; see Supporting Information, Figure S4. Furthermore, the ferrocene ligands $\mathrm{FcC}_{\mathrm{n}} \mathrm{Br}$ are insoluble, and it can be assumed that they will remain in the ferrovskite crystals. Ferrocene has a very low extinction coefficient, which is why the absorption of the ligands is barely detected. ${ }^{[61]}$ Between $450 \mathrm{~nm}$ and $500 \mathrm{~nm}$ a slight shoulder of the Fc-ligands is found, which represents the HOMO $\rightarrow$ LUMO transition. Significantly stronger absorption is observed for the near-band-edge states with strong resonance peaks in all compounds. The absorption maximum but also the width of the absorption peaks provide information about the excitons and their binding energy. The peaks of the excitonic resonance are clearly separated from the continuous absorption, 
suggesting strongly bound excitons. Excitonic band gaps for $\left(\mathrm{FcC}_{2}\right) \mathrm{PbBr}_{3}$ showing a maximum at $337 \mathrm{~nm}$, for $\left(\mathrm{FcC}_{4}\right)_{4} \mathrm{~Pb}_{3} \mathrm{Br}_{10}$ with a maximum at $357 \mathrm{~nm}$ and $\left(\mathrm{FcC}_{6}\right)_{2} \mathrm{PbBr}_{4}$ with a maximum at $405 \mathrm{~nm}$ are found. Interestingly, $\left(\mathrm{FcC}_{4}\right)_{4} \mathrm{~Pb}_{3} \mathrm{Br}_{10}$ shows a blue shifted maximum at $323 \mathrm{~nm}$ which is attributed to material defects in the structure. ${ }^{[58]}$ It is noticeable that the peaks become narrower and sharper with a longer head group of the Fc-ligand. Mainly two effects define the excitonic binding energy in low-dimensional organic-inorganic materials: the quantum confinement and the dielectric confinement. From the ribbons of $\left(\mathrm{FcC}_{2}\right) \mathrm{PbBr}_{3}$, over the perovskite-like $\left(\mathrm{FcC}_{4}\right)_{4} \mathrm{~Pb}_{3} \mathrm{Br}_{10}$ to the Ruddlesden-Popper type $\left(\mathrm{FcC}_{6}\right)_{2} \mathrm{PbBr}_{4}$, the quantum confinement of the generated excitons shrinks. On the other hand, the Fc-ligands define the dielectric environment and influence the screening of the Coulombic attraction between the exciton's hole and electron. The length of the head group plays a crucial role for the proximity to the inorganic phase and thus also the influence of the dielectric constant of the organometallic molecules. The closer the Fc-ligands are to the inorganic phase, the stronger the confinement.

Up to this point, it seems that the ferrocene moiety is more or less inactive regarding the electronic properties of the phases. Is it just an overdone linker? A first indication that the ferrocene is more, comes from the photoluminescence (PL) spectra. Hybrid lead halide phases show intense PL because of their direct band gap character. The quantum confinement enables the formation of self-trapped excited states which show a strong Stokes-shift and broadband (white light) emission. ${ }^{[62,63]}$ However, we could not detect any PL signals for $\left(\mathrm{FcC}_{2}\right) \mathrm{PbBr}_{3}$ and $\left(\mathrm{FcC}_{4}\right)_{4} \mathrm{~Pb}_{3} \mathrm{Br}_{10}$; see for instance Figure $5 \mathrm{~d}$ for $\left(\mathrm{FcC}_{2}\right) \mathrm{PbBr}_{3}$. In agreement with studies on functional materials containing ferrocene in the literature ${ }^{[64]}$ the explanation for the effect is photoluminescence quenching by efficient photoinduced electron transfer (PET) to the ferrocene. The efficiency of PET depends on the distance between donator and acceptor. This distance is largest in the case of $\left(\mathrm{FcC}_{6}\right)_{2} \mathrm{PbBr}_{4}$, and actually a weak emission 
can be observed at $\lambda=416 \mathrm{~nm}\left(\mathrm{E}_{\mathrm{PL}}=2.98 \mathrm{eV}\right.$; data are shown in Figure S15, Supporting Information).

Because of the PET process, our hypothesis is that the optoelectronic properties of ferrovskites will change, if we change the electronic properties of the Fc entity. Because the vicinity between inorganic and metalorganic phase is closest for the new $\left(\mathrm{FcC}_{2}\right) \mathrm{PbBr}_{3}$ structure, we will concentrate our work on this compound from here on.

\subsection{Defect Creation by Redox-Chemistry and Electro-Spectroscopic Consequences}

An effective way to change the electronic property of the Fc building block is oxidation to ferrocenium $\left(\mathrm{Fc}^{+}\right)$. If only few ferrocenium molecules are oxidized, assuming there is an electronic communication between the subphases, a point-defect will be created which may induce doping or other electronic effects (see Scheme 1). Furthermore, it will be interesting to successively increase the fraction of $\mathrm{Fc}^{+}$. We hope that cooperative effects can occur at a critical density of $\mathrm{Fc}^{+}$and due to the periodic arrangement of the ligands.

Cyclic voltammograms $(\mathrm{CV})$ are recorded to study the oxidation of Fc-containing materials, as they provide information about the redox process of the Fc-ligands and the electronic processes in the material. A suitable electrolyte for the electrochemical characterization of hybrid perovskites is a mixture hydrofluoroether (HFE) and diethyl carbonate (DEC) with Lithium bistrifluoromethane sulfonimidate (LiTFSI), proposed by Hasan et al. ${ }^{[65]}$ The lithium containing electrolyte is commonly used for lithium ion batteries and does not dissolve $\left(\mathrm{FcC}_{2}\right) \mathrm{PbBr}_{3}$. In the initial material the ligand is present in pure, non-oxidized form according to Mößbauer spectroscopy (Figure S16, Table S3, Supporting Information). Figure 4a shows the recorded $\mathrm{CV}$ of $\left(\mathrm{FcC}_{2}\right) \mathrm{PbBr}_{3}$ drop casted on ITO (in 0.1 M) LiTFSI in HFE:DEC=(97:3), scan speed $10 \mathrm{mV} / \mathrm{s}$ after purging with $\mathrm{N}_{2}$ to remove dissolved oxygen). ITO was measured as a reference, which shows that the substrate is electrochemically inactive under chosen 
conditions (Figure 4a, light blue). The $\mathrm{CV}$ measured for $\left(\mathrm{FcC}_{2}\right) \mathrm{PbBr}_{3}$ fits well to reports in the literature about other functional materials containing ferrocene. ${ }^{[37,66]}$ Redox peaks centered at $\mathrm{E}_{1 / 2}=0.45 \mathrm{~V}$ are found, indicating that the Fc-ligands are electrochemically addressable. The signal of the oxidation at $0.65 \mathrm{~V}$ as well as the signal of the reduction at $0.24 \mathrm{~V}$ show no asymmetries, which indicates an ordinary electron transfer between the electrolyte and Fc-ligand. ${ }^{[67]}$ Because there are no additional signals, we assume that the inorganic $\left[\mathrm{PbBr}_{3}\right]^{-}$ constituent is electrochemically inactive in the relevant voltage range.
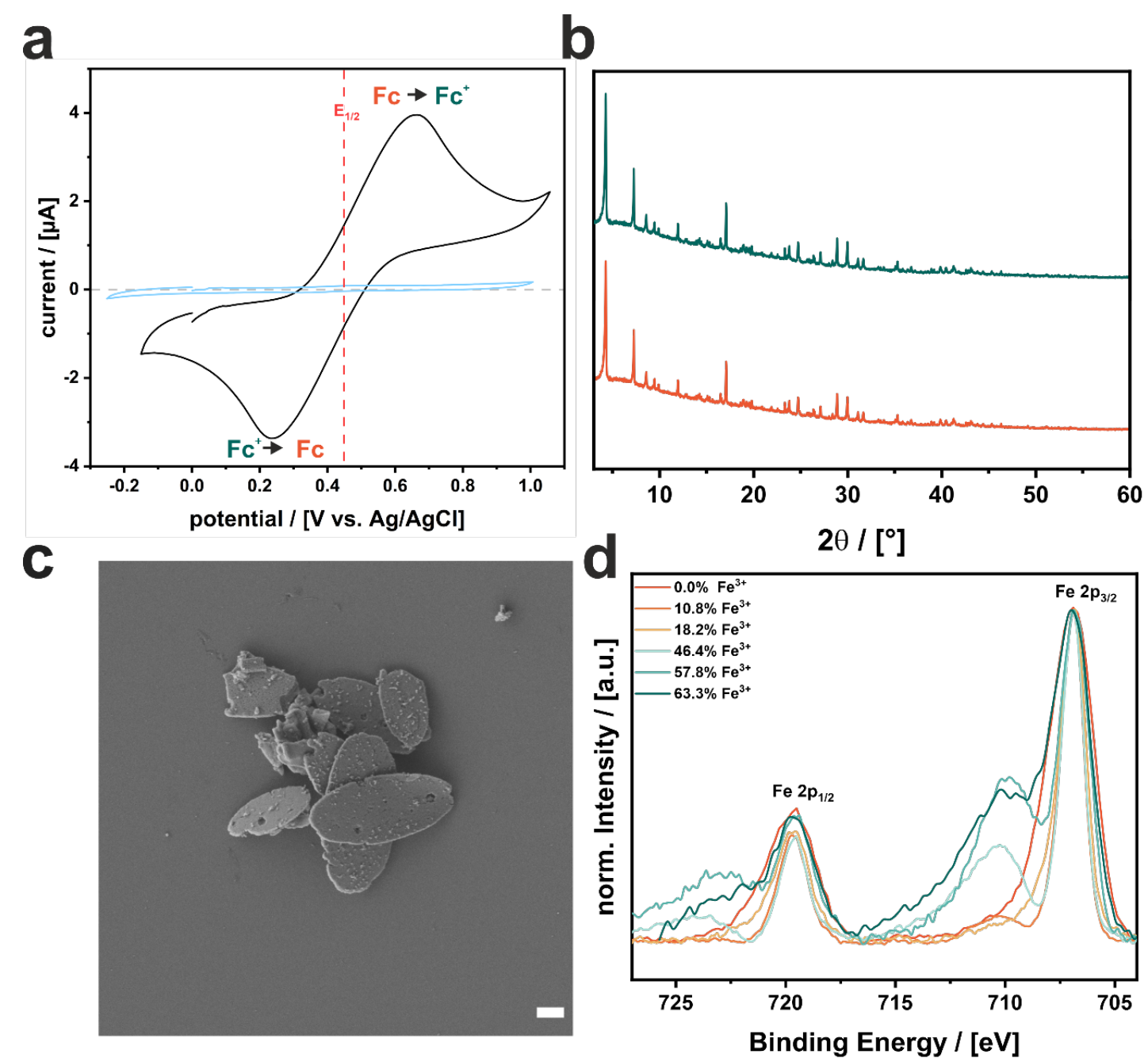

Figure 4. a) Cyclic voltammogram (CV) of $\left(\mathrm{FcC}_{2}\right) \mathrm{PbBr}_{3}$ (black) on ITO (lightblue) at scan speed of $10 \mathrm{mV} / \mathrm{sec}$ in $0.1 \mathrm{~m}$ LiTFSI in HFE:DEC $=(97: 3)$, a halfwave potential at $\mathrm{E}_{1 / 2}=0.45 \mathrm{~V}$ is found. For a detailed description of the measurement, we refer to the experimental section. b) PXRD measurement of the particles before oxidation (bottom) and after oxidation (top) with $57.8 \% \mathrm{Fe}^{3+}$. c) SEM image of the particles after oxidation with $57.8 \% \mathrm{Fe}^{3+}$. d) Normed X-ray photon spectroscopy (XPS) measurements for Fe $2 \mathrm{p}_{1 / 2}$ and $\mathrm{Fe} 2 \mathrm{p}_{3 / 2}$ of oxidized particles with increasing $\mathrm{Fe}^{3+}$-content. For the quantitative evaluation of the signals we refer to Figure S19, Supporting Information. The color coding of the varying $\mathrm{Fe}^{3+}$ contents is used for further diagrams and is no longer specified there. 
While the electrochemical methodology $(\mathrm{CV})$ is suitable to clarify the redox activity of $\mathrm{Fc}$ in the ferrovskites, only a very small amount of sample is affected and the ratio of oxidation to $\mathrm{Fc}^{+}$is hard to control because of an ill-defined contact of the $\left(\mathrm{FcC}_{2}\right) \mathrm{PbBr}_{3}$ particles with the electrode. Therefore, the chemical oxidation of dispersed $\left(\mathrm{FcC}_{2}\right) \mathrm{PbBr}_{3}$ particles in a solvent using perchlorate $\left(\mathrm{ClO}_{4}^{-}\right)$was attempted. A detailed description of the oxidation is given in the experimental section and in the Supplementary Information (Figure S17+S18). The investigation of the samples before and after oxidation by PXRD (Figure $4 \mathrm{~b}$ ) and SEM (Figure 4c; compare to Figure 1d) shows no changes indicating that the ferrovskite is stable. Whether oxidation has occurred and whether the $\mathrm{Fc}^{+} / \mathrm{Fc}$ ratio can be controlled by the amount of oxidant used were verified by X-ray photoelectron spectroscopy (XPS) shown in Figure 4d. It is obvious that the signals for $\mathrm{Fe}^{3+}$ e.g. $\mathrm{E}\left(\mathrm{Fe}-2 \mathrm{p}_{3 / 2}\right)=710.25 \mathrm{eV}$ becomes more and more intense. The quantification of the XPS spectra reveals that the $\mathrm{Fc}^{+} / \mathrm{Fc}$ ratio ranges from 0 \%-63.3 \%; see Supporting Information Figure S19. A higher oxidation degree is not possible because the samples seem to restructure if even more perchlorate is used.

\subsection{Defect-Density/ Optoelectronic Correlations in Ferrovskites}

Ferrocenium has a different color than ferrocene. Due to the oxidation, an electron of the $\mathrm{e}_{2 \mathrm{~g}}$ molecular orbital in $\mathrm{Fc}$ is removed. A ligand-to-metal charge-transfer transition occurs in $\mathrm{Fc}^{+}$, resulting in an absorption band at $631 \mathrm{~nm}(1.97 \mathrm{eV})$ and a color change from orange to green/blue (see Figure S20a, Supporting Information). ${ }^{[68]}$ Therefore, it is not surprising that also the ferrovskite samples have a different color after oxidation (Figure 5a). Their appearance changes from orange to green. However, the important question is, if there is some sort of coupling of the electronic states of $\mathrm{Fc}^{+}$with the inorganic subphase.

Optoelectronic properties of $\left(\mathrm{FcC}_{2}\right) \mathrm{PbBr}_{3}$ were examined with a combination of optical absorption/reflectance and photoluminescence spectroscopy. Our data show that it is 
necessary to distinguish between samples with a low content of $\mathrm{Fc}^{+}$(Scheme 1b) and a high content (Scheme 1c).

a

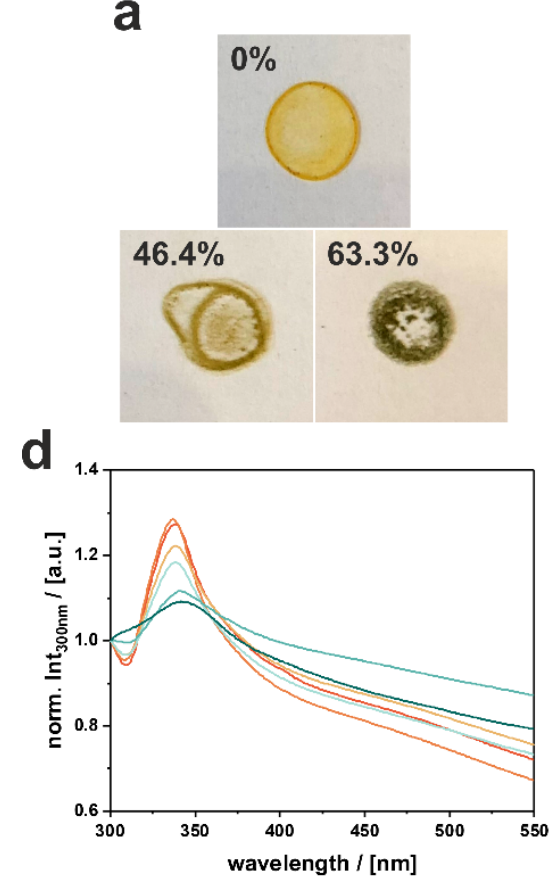

b

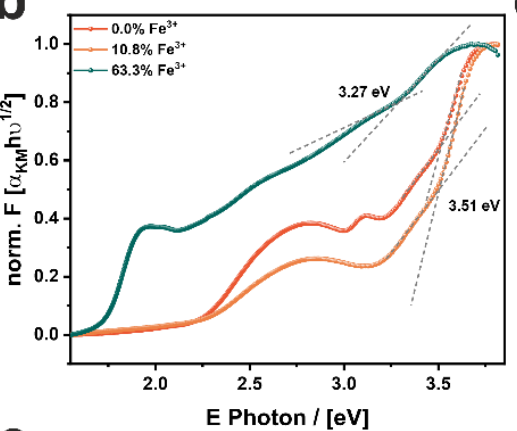

e

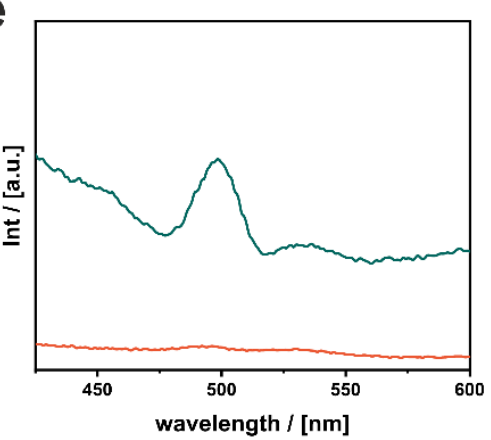

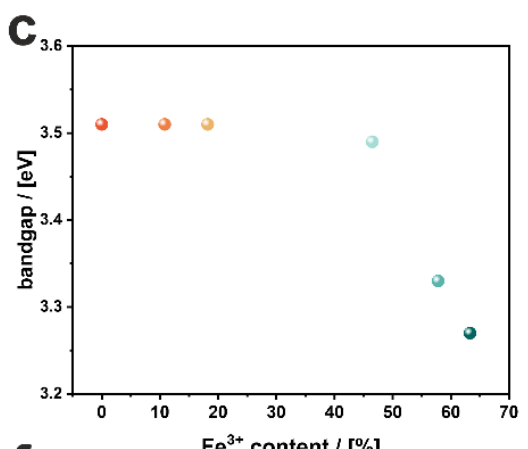

f

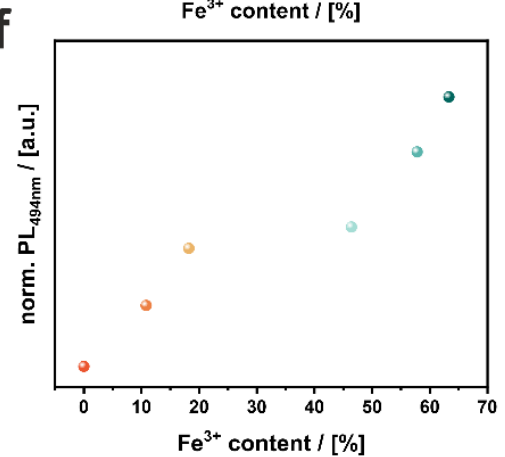

Figure 5. a) Photograph of drop casted particles with varying $\mathrm{Fe}^{3+}$-content. b) Normalized Kubelka-Munk $(\mathrm{KM})$ plot of $\left(\mathrm{FcC}_{2}\right) \mathrm{PbBr}_{3}$ before and after oxidation. Other KM-plots are shown in Figure S21, Supporting Information. c) Band gap determined from KM of $\left(\mathrm{FcC}_{2}\right) \mathrm{PbBr}_{3}$ with increasing $\mathrm{Fe}^{3+}$-content. d) Optical absorption of particles dispersed in toluene. e) Photoluminescence signal before (orange) and after (green) oxidation of the particles with excitation at $310 \mathrm{~nm}$ and $\mathrm{f}$ ) photoluminescence of normed PL-intensity at $494 \mathrm{~nm}$ with varying $\mathrm{Fe}^{3+}$-content.

If the $\mathrm{Fc}^{+} / \mathrm{Fc}$ ratio is low, ferrocenium is a point defect randomly distributed in the $\left(\mathrm{FcC}_{2}\right) \mathrm{PbBr}_{3}$ phase. The band gap energy of the samples was obtained from ORS measurements of the dried powder samples (Figure 5b; Figure S21 Supporting Information). It can be seen that the band gap remains constant at $\approx 3.5 \mathrm{eV}$ (Figure $5 \mathrm{c}$ ) up to $\mathrm{Fc}^{+} / \mathrm{Fc}=45 \%$. Optical absorption spectra were recorded for a dispersion of the oxidized ferrovskite particles. The results are shown in Figure $5 \mathrm{~d}$. The increase of the absorption in the range $\lambda>425 \mathrm{~nm}$ is caused by the presence of the oxidized species $\mathrm{Fc}^{+}$. There are also some effects on the excitonic peak of the lead bromide subphase at $337 \mathrm{~nm}$. The excitonic peak is broadened, which can be explained by the change of the dielectric environment. ${ }^{[58]}$ Oxidation results in a 
change in polarization and the excitons become even more confined as the relative permittivity of the ligand alters. However, not only a color change is observed, after the oxidation $\left(\mathrm{FcC}_{2}\right) \mathrm{PbBr}_{3}$ shows an emission at $494 \mathrm{~nm}$ with excitation at $310 \mathrm{~nm}$, presented in Figure 5e. The intensity of the signal increases for an increasing oxidation degree (Figure 5f). The resulting luminescence peak is attributed to the oxidized Fc-ligand, which shows emission at $514 \mathrm{~nm}$ in solution (Figure S20b, Supporting Information). We were also able to demonstrate this effect by electrochemical oxidation, shown in Figure S22+S23, Supporting Information. The excitation spectrum recorded for $\left[\mathrm{FcC}_{2} \mathrm{Br}\right]^{+}$as a reference shown in the Supporting Information, Figure S20b demonstrates that this fluorescence cannot be stimulated by excitation at $310 \mathrm{~nm}$. Therefore, we assume that there is an electron transfer from the semiconductor to the $\mathrm{Fc}^{+}$-ligand with subsequent radiative recombination. To support this assumption, we determined the relative energies of $\mathrm{HOMO}$ and $\mathrm{LUMO}$ of $\mathrm{FcC}_{2} \mathrm{Br}$ before oxidation using a combination of UV/Vis spectroscopy and PESA (see Figure S4a and S20c, Supporting Information). Figure 6 shows the alignment of the bands and MOs before (d) and after oxidation at low $\mathrm{Fc}^{+} / \mathrm{Fc}$ ratio (e). The step-like arrangement of energies before oxidation shows well why PET is observed. The LUMO of the Fc-ligand is below the CBM, which is why excited electrons move to the acceptor level. The recombination of charge carriers is non-radiative because the hole from the CBM cannot move to the HOMO. After oxidation, the situation changes. The oxidation only affects the position of the emerging single occupied molecular orbital $\left(\mathrm{SOMO} ; \mathrm{e}_{2 \mathrm{~g}}\right)$, which now has a higher energy than the previous $\mathrm{HOMO}\left(\mathrm{a}_{1 \mathrm{~g}}\right.$, which is now below $\mathrm{e}_{2 \mathrm{~g}}$. ${ }^{[69]} \mathrm{We}$ assume that the position of the LUMO does not change and determine the position of the SOMO from the observed photoluminescence. Again, the excitation of the semiconductor at $310 \mathrm{~nm}$ transfers an electron from the CBM to the LUMO, but since the SOMO is now above the CBM, the generated hole can be transferred as well. As the MO arrangement changes, their energies now lie favorably within the band gap ${ }^{[30]}$, thus, radiative recombination is observed. 


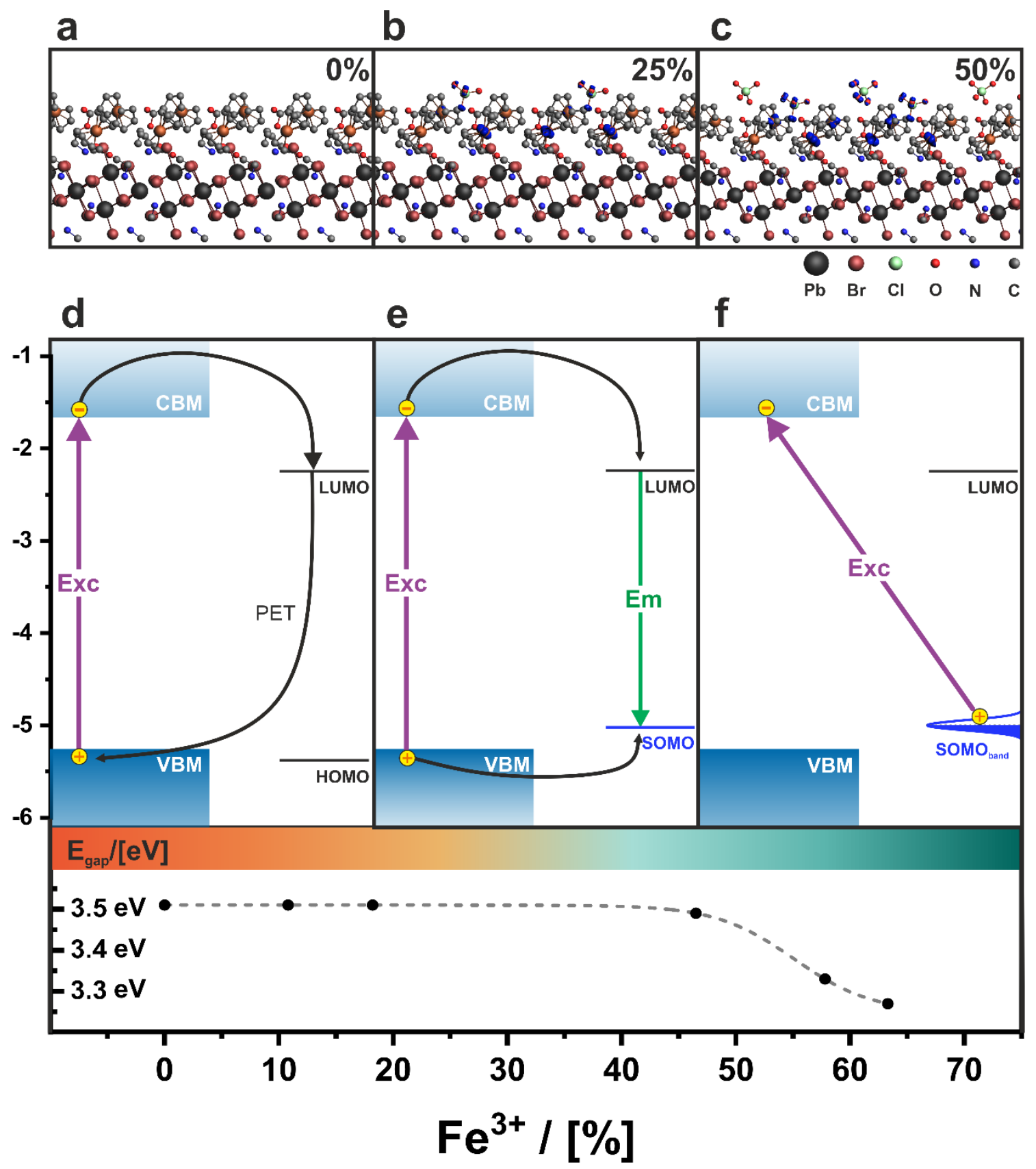

Figure 6. Representation of the $a b$ initio calculations using the BAND code for a) the intrinsic $\left.\left(\mathrm{FcC}_{2}\right) \mathrm{PbBr}_{3}, \mathrm{~b}\right)$ with $25 \%$ of the ligands oxidized with $\left(\mathrm{ClO}_{4}\right)^{-}$, c) with $50 \%$ of the ligands oxidized with $\left(\mathrm{ClO}_{4}\right)^{-}$. The location of the unpaired paramagnetic spin was calculated and made visible in spin density (blue isosurface). Hydrogen atoms were removed for clarity; Experimentally determined band structure of $\left.\left(\mathrm{FcC}_{2}\right) \mathrm{PbBr}_{3} \mathrm{~d}\right)$ in the intrinsic state showing why PET occurs upon excitation (Exc) at $310 \mathrm{~nm}$, e) after the oxidation with $\left(\mathrm{ClO}_{4}\right)^{-}$at low oxidation degrees (radiative recombination/emission $(\mathrm{Em})$ occurs due to the new energy alignment of the single occupied molecular orbital (SOMO) and e) at high oxidation degrees with the emergence of the new $\mathrm{SOMO}_{\text {band. }}$

There is a critical value in $\mathrm{Fe}^{3+}$ content, when the optical absorption of the material changes more severely. The $\mathrm{KM}$ plots for $\left(\mathrm{FcC}_{2}\right) \mathrm{PbBr}_{3}$ with $\mathrm{Fc}^{+} / \mathrm{Fc}=63.3 \%$ derived from the optical 
measurements are shown in Figure $5 \mathrm{~b}$ (green). There is a fundamental change compared to the native $\left(\mathrm{FcC}_{2}\right) \mathrm{PbBr}_{3}$ and the weakly oxidized samples (Figure $\left.5 \mathrm{~b}, 10.8 \% \mathrm{Fe}^{3+}\right)$. A new feature at $2.0 \mathrm{eV}$ appears, which can be assigned to the large number of $\mathrm{Fc}^{+}$species. The band gap, given by the inorganic lead-bromide network can be determined by the intersection of two linear regression lines. Interestingly, a flattening of the slope and a narrowing of the band gap is observed above an $\mathrm{Fe}^{3+}$-content of about $50 \%$ (Figure $5 \mathrm{c}$ ). Band gap narrowing is usually observed in heavily doped semiconductors, where discrete impurity levels in the band gap of the semiconductor evolve an impurity band, which can overlap with the CB or VB. ${ }^{[12,70,71]}$ Here it seems that the electronic situation of the semiconductor changes abruptly as soon as enough Fc-ligands have been oxidized. Essentially, our measurements show that the material with a high number of $\mathrm{Fc}^{+}$defects is an entirely different semiconductor. We assume that one possible effect are intramolecular interactions between the $\mathrm{Fe}^{2+} / \mathrm{Fe}^{3+}$ centers. To study this effect, we have performed calculations of the structure in the ground state and in the oxidized state.

Electron hopping between the $\mathrm{Fe}^{2+}$ and $\mathrm{Fe}^{3+}$ sites of the ligands is an interesting but difficult theoretical topic. It should be noted that quantum chemical calculations have been published in the literature for the electron transfer from surfaces in ligands with ferrocene moieties from C60 ${ }^{[72]}$, diamond ${ }^{[73]}$ or semiconductor colloids. ${ }^{[74]}$ Tarafder et al. have studied hole transfer from a photoexcited CdSe nanorod to a single Fc-ligand tethered to its surface. They discussed the results by quantum chemical calculations based on DFT using GW corrections within a Marcus charge transfer model. ${ }^{[75]}$ However, less is known about quantum chemical based charge transfer calculations within a layer of ligands as in our systems.

To simplify the theoretical model structure of the $\left(\mathrm{FcC}_{2}\right) \mathrm{PbBr}_{3}$ surface shown in Figure 6a, we extracted a layer from the experimentally determined unit cell consisting of $\left[\mathrm{PbBr}_{3}\right]^{-}-$-ribbons and surrounding Fc-ligands. This structure can serve as a surface model for the crystals. The surface with eight $\left[\mathrm{PbBr}_{3}\right]^{-}$units surrounded by four Fc-ligands on one side of the ribbon and 
four methylammonium ligands on the other side could represent a kind of Helmholtz bilayer structure if perchlorate units are added to the outside of the ferrocene ligand layer, as illustrated in Figure $6 b+c$. In a simple physicochemical picture, the perchlorate forms an adsorbed anion of an outer Helmholtz layer, while the nearest $\mathrm{Fe}^{3+}$ is supposed to balance the negative charge.

Our quantum chemical calculations within the SCM modeling suite using the BAND code on PBE (Perdew-Burk Ernzerhof) and non-relativistic double zeta theory level ${ }^{[76-78]}$ indeed showed enhanced positive Hirshfeld charges at the closest Fe site, but also at the neighboring Fe centers, as will be discussed in detail below. Furthermore, the delocalization effect can be visualized by spin density calculations, shown in Figure $6 \mathrm{~b}+\mathrm{c}$. The spin density is not localized at a single Fe center, as would be expected for a single $\mathrm{Fe}^{3+}$ with spin $1 / 2$ but partially distributed over the neighboring centers.

For an unoxidized system, the Hirshfeld charges (in units of e) at the Fe centers of the four ligands are $0.021 \pm 0.005$. With one $\left(\mathrm{ClO}_{4}\right)^{-}$anion, the Hirshfeld charge of the nearest Fe center is increased by 0.043 , relative to the unoxidized atom with a distance between $\mathrm{Cl}$ and the Fe atom of $4.94 \AA$. All of the other three Fc-ligands have roughly the same Cl-Fe-distance of about $6.48 \pm 0.15 \AA$ and the Hirshfeld charges are increased by $0.016 \pm 0.006$ (see Figure S24, Supporting Information). Hence, the nearest ferrocene moiety carries a maximum positive charge on its Fe center, but there is considerable charge delocalization across the group of neighboring Fe centers.

The charge delocalization is almost uniformly distributed over the Fe centers when a second perchlorate is added to our model surface (Figure 6c). The Hirshfeld charges for all four ferrocene ligands are increased by $0.040 \pm 0.005$ relative to the unoxidized state. One might speculate that the delocalized charge and spin density in the ground state might correspond to a significant electron transfer for an electron that should be ideally localized at a ferrocene fragment with $\mathrm{Fe}^{2+}$ to the oxidized ferrocenium $\mathrm{Fe}^{3+}$ fragment. This could be expressed with a 
Marcus model ${ }^{[75]}$, which states that if the charge is initially confined in the Marcus model fragment, substantial transition integrals to an adjacent fragment will occur, promoting lateral charge transfer rates within the interface layer. Calculating the electron transfer integral values $\mathrm{V}$ between neighboring sites is the first step in theoretically quantifying an electron hopping rate within the ligand layer using a Marcus electron transfer model. However, for such a model, these considerable reorganization energies must be calculated for a ligand structure in the layer. Alternatively, one might choose a solid-state polaron model ${ }^{[79]}$, although a more chemical model with hopping between fragment units is desirable. For a simple fragment-based charge transfer analysis ${ }^{[80-82]}$ within a model of two neighboring ferrocene ligands, a first DFT calculation using the ADF code on PBE and triple zeta level of theory ${ }^{[83]}$ yielded a value of $\mathrm{V}=0.0064 \mathrm{eV}$ for the charge transfer integral. Neglecting entropic contributions, one estimates an electron hopping rate of the order of $\mathrm{k}=1 * 10^{-10} \mathrm{~s}^{-1}$ from $\mathrm{Fe}^{2+}$ to $\mathrm{Fe}^{3+}$ sites at $\mathrm{T}=300 \mathrm{~K}$ using the calculated reorganization energies of $\lambda=0.32 \mathrm{eV}$ within the Marcus model. ${ }^{[75]}$ The Helmholtz layer model in Figure 6a-c can hence illustrate the ligand layer and allows electron hopping and delocalization to be discussed for the electronic ground state. A discussion of excited states with a strong coupling between the ligand layer and semiconducting $\left[\mathrm{PbBr}_{3}\right]^{-}$-ribbons would be ideal to study the optical properties of the system and could clarify electron and hole transfer between ribbon and Helmholtz layer. However, accurate quantum chemical calculations of the band structure in these extended complex systems, are already very difficult. ${ }^{[79]}$ For non-periodic systems such as semiconductor clusters with single ligands, HOMO-LUMO gaps can in principle be calculated by using DFT with the GW method ${ }^{[74]}$, but a complete ligand layer would be a much more challenging task. Therefore, for now, one must rely on an initial qualitative discussion of the gap as in Figure 6, which is consistent with the experimental data. 
We conclude that at low oxidation degrees local defect states are created, which result in radiative emission upon excitation of charge carriers in the semiconductor (Figure 6e). A charge carrier transfer from the electronic bands of the semiconducting lead bromide ribbons to the $\mathrm{Fc}^{+}$-ligands occurs, as the molecular orbitals lie favorable between the VBM and CBM. Accordingly, a higher degree of oxidation leads to delocalization of electrons over several ligands and electron hopping according to the Marcus theory (Figure 6f). Therefore, the formation of a novel electronic band $\mathrm{SOMO}_{\text {band }}$ is observed. Electrons from this band can now be transferred into the CBM by optical excitation, which is why a narrowing of the band gap is obtained. The new, indirect band gap is now $3.27 \mathrm{eV}$, which is $0.24 \mathrm{eV}$ smaller than for the unoxidized material.

\section{Conclusion}

Designing novel ligands for the synthesis of hybrid semiconductor materials is known to bear great potential, as it is possible to tailor electro-optical features. Ferrocene is not only interesting as a strongly structure-directing ligand, the oxidation also shows remarkable effects on the electronic situation in the semiconductor, as defect states in the band gap define the electro-optical properties.

In the current work, three novel Fc-ligands with suitable headgroup for the synthesis of hybrid lead bromide semiconductor particles were presented. The crystal structures of the resulting particles were determined by 3D ED and modelling. It is revealed that Coulombic attractions between the Fc-ligands as well as hydrogen bonds between the linking carboxyl group and the ammonium head group result in strong templating effects of the inorganic network. Therefore, the formation of more exotic inorganic structural motives from ribbons to $2 \mathrm{D}$ layered structures is observed. Depending on the connectivity of the octahedra the band gap decreases from $3.51 \mathrm{eV}$ to $3.06 \mathrm{eV}$ with increasing length of the headgroup. The packing of the ligands 
and thus the density and stability of the structure decreases with increasing layer-character of the phases.

Redox-activity of the Fc-ligands in the material was proven by $\mathrm{CV}$. Chemical oxidation was used to adjust the $\mathrm{Fc}^{+} / \mathrm{Fc}$ ratio and to observe alterations in optoelectronic properties.

Depending on the degree of oxidation, the material showed the formation of radiative defect states, which at a high degree of oxidation even resulted in the formation of a new electronic band. Ab initio calculations using the BAND code of the oxidized structure showed that the paramagnetic spins of the unpaired electron of the oxidized $\mathrm{Fe}^{3+}$-cations are delocalized between the Fc-ligands and may 'hop' between the Fe-central atoms. The lowest energy transition is thus no longer from the $\mathrm{VBM}$ to the $\mathrm{CBM}$, but an indirect transition from the new $\mathrm{Fe}^{3+}$-band to the $\mathrm{CBM}$, which is by $\Delta \mathrm{E}=0.24 \mathrm{eV}$ smaller than the initial band gap.

Our results suggest that ligand design is crucial for the formed crystal structure and thus desired properties such as stability and band gap of hybrid materials are highly tunable. Carboxyl groups have a great influence on the structure formation and could help to create tailor-made crystal structures with extraordinary properties. Also, the combination with a redox-active ligand offers a novel possibility to modify the optoelectronic properties of semiconductors. Furthermore, the successful oxidation of $\mathrm{Fe}^{2+}$ now also makes it possible to actively influence the magnetic properties of the semiconductors. The presence of a paramagnetic spin in the $\mathrm{Fe}^{3+}$ can lead to unusual effects in the magnetic field, so that these materials could become interesting in spintronics, for example. In the future, we want to focus on these investigations.

\section{Experimental Section and Methods}

Chemicals: Lead (II) bromide ( $\mathrm{PbBr}_{2}$, Sigma-Aldrich, $99.9 \%$ purity), methyl amine $\left(\mathrm{CH}_{3} \mathrm{NH}_{2} \cdot \mathrm{H}_{2} \mathrm{O}\right.$, Sigma Aldrich, $33 \mathrm{wt} \%$ in EtOH), hydrobromic acid (48 wt $\%$ in $\mathrm{H}_{2} \mathrm{O}$, Sigma-Aldrich), ferrocene carboxylic acid $\left(\mathrm{C}_{10} \mathrm{H}_{11} \mathrm{FeO}_{2}\right.$, Sigma-Aldrich, $96 \%$ purity), N-Boc ethanolamine $\left(\mathrm{C}_{7} \mathrm{H}_{15} \mathrm{NO}_{3}\right.$, Sigma Aldrich, 98 \% purity), 3-(Boc-amino)-1-propanol 
$\left(\mathrm{C}_{8} \mathrm{H}_{17} \mathrm{NO}_{3}\right.$, TCI chemicals, $96 \%$ purity), 4-(Boc-amino)-1-butanol $\left(\mathrm{C}_{9} \mathrm{H}_{19} \mathrm{NO}_{3}\right.$, TCI chemicals, $97 \%$ purity), 5-(Boc-amino)-1-pentanol $\left(\mathrm{C}_{10} \mathrm{H}_{21} \mathrm{NO}_{3}\right.$, TCI chemicals, $97 \%$ purity) 6-(Boc-amino)-1-hexanol $\left(\mathrm{C}_{11} \mathrm{H}_{23} \mathrm{NO}_{3}\right.$, Sigma Aldrich, $98 \%$ purity), 4-(dimethylamino) pyridine (DMAP, $\mathrm{C}_{7} \mathrm{H}_{10} \mathrm{~N}_{2}$, Sigma Aldrich), N-(3-Dimethylaminopropyl)-N'ethylcarbodiimide hydrochloride (EDC- $\mathrm{HCl}, \mathrm{C}_{8} \mathrm{H}_{17} \mathrm{~N}_{3}-\mathrm{HCl}$, TCI chemicals, $98 \%$ purity), trifluoroacetic acid (TFA, $\mathrm{C}_{2} \mathrm{HO}_{2} \mathrm{~F}_{3}$, Sigma Aldrich), hydrobromic acid $\left(\mathrm{HBr}, 48 \mathrm{wt} \%\right.$ in $\mathrm{H}_{2} \mathrm{O}$, Sigma Aldrich), diethyl carbonate (DEC, $\left(\mathrm{C}_{2} \mathrm{H}_{5} \mathrm{O}\right)_{2} \mathrm{CO}$, Sigma Aldrich, 99 \% purity), Bis(trifluoromethane)sulfonimide lithium salt (LiTFSI, $\mathrm{CF}_{3} \mathrm{SO}_{2} \mathrm{NLiSO}_{2} \mathrm{CF}_{3}$, Sigma Aldrich), Methoxyperfluorobutane (HFE-7100, Sigma Aldrich, $99 \%$ mixture of $n$ - and iso-butyl isomers), iron(III) perchlorate hydrate $\left(\mathrm{Fe}\left(\mathrm{ClO}_{4}\right)_{3} \cdot \mathrm{xH}_{2} \mathrm{O}\right.$, Sigma Aldrich).

Synthesis of $\mathrm{FcC}_{n} \mathrm{Br}(n=2,4,6)$ Starting from ferrocene carboxylic acid, Boc-protected amino alcohols were coupled to the carboxyl group via an ester coupling. $2.2 \mathrm{mmol}$ ferrocene carboxylic acid was dissolved in $50 \mathrm{~mL}$ dichloromethane (DCM) using ultrasound. Then $2.2 \mathrm{mmol}$ of the Boc-protected amine, $2.6 \mathrm{mmol} 4$-(dimethylamino) pyridine (DMAP) and $2.6 \mathrm{mmol} \mathrm{EDC}-\mathrm{HCl}$ were added to the mixture in this order. After addition of all reactants, any remaining solids should have dissolved. The mixture is then heated under reflux to $50^{\circ} \mathrm{C}$ for $16 \mathrm{~h}$ overnight. The solvent was removed and the brown solid was filtered with ethyl acetate over $\sim 4 \mathrm{~cm}$ of silica gel to give a yellow solution. The solvent was removed, giving a yellow to orange solid. (yield: $\mathrm{FcC}_{2}=95.5 \%, \mathrm{FcC}_{4}=68.3 \%, \mathrm{FcC}_{6}=76.3 \%$ )

To remove the Boc-protecting group, the solid was dissolved in DCM and deprotected with 30 eq TFA for $1 \mathrm{~h}$ at $50^{\circ} \mathrm{C}$ under reflux. The solvent was removed, giving a yellow to orange product. The deprotection was quantitative and was checked by thin film chromatography. All amines were further solved in 1,4-dioxane and treated with $\mathrm{HBr}$ (1.5 eq) to obtain the ammonium salt. The solvent was removed, the obtained brown solid was solved in sufficient EtOH and reprecipitated with diethyl ether $\left(\mathrm{Et}_{2} \mathrm{O}\right)$. The powder was filtrated, washed with $\mathrm{Et}_{2} \mathrm{O}$ and dried under reduced pressure. All products were characterized with ${ }^{1} \mathrm{H}-\mathrm{NMR}$, ${ }^{13} \mathrm{C}-\mathrm{NMR}$ (see Figure S1+S2, Supporting Information) and ESI-MS and further used for the material synthesis.

${ }^{1} \mathbf{H}-\mathrm{NMR}(400 \mathrm{MHz}, \mathrm{DMSO}-\mathrm{d} 6) \boldsymbol{n}=\mathbf{2}: \delta(\mathrm{ppm})=7.95\left(\mathrm{~s}, 3 \mathrm{H}, \mathrm{NH}_{3}\right), 4.87(\mathrm{t}, 2 \mathrm{H}, \mathrm{CH}), 4.50(\mathrm{t}$, $2 \mathrm{H}, \mathrm{CH}), 4.29\left(\mathrm{t}, 2 \mathrm{H}, \mathrm{CH}_{2}\right), 4.23$ (s, 5H, cp-ring) $3.16\left(\mathrm{t}, 2 \mathrm{H}, \mathrm{CH}_{2}\right) ; \boldsymbol{n}=4: \delta(\mathrm{ppm})=4.73(\mathrm{t}$, 2H, CH), 4.48 (t, 2H, CH), 4.22 (s, 5H, cp-ring), 4.16 (t, 2H, $\left.\mathrm{CH}_{2}\right), 2.85\left(\mathrm{~s}, 2 \mathrm{H}, \mathrm{CH}_{2}\right), 1.69$ $\left(\mathrm{m}, 4 \mathrm{H}, \mathrm{CH}_{2}\right) ; \boldsymbol{n}=6: \delta(\mathrm{ppm})=4.72(\mathrm{t}, 2 \mathrm{H}, \mathrm{CH}), 4.47(\mathrm{t}, 2 \mathrm{H}, \mathrm{CH}), 4.20(\mathrm{~s}, 5 \mathrm{H}, \mathrm{cp}-\operatorname{ring}), 4.14$ (t, 2H, $\left.\mathrm{CH}_{2}\right), 2.78\left(\mathrm{~s}, 2 \mathrm{H}, \mathrm{CH}_{2}\right), 1.64\left(\mathrm{p}, 2 \mathrm{H}, \mathrm{CH}_{2}\right), 1.55\left(\mathrm{~m}, 2 \mathrm{H}, \mathrm{CH}_{2}\right), 1.39\left(\mathrm{~m}, 6 \mathrm{H}, \mathrm{CH}_{2}\right)$ 
${ }^{13}$ C-NMR (400 MHz, DMSO-d6) $\boldsymbol{n}=\mathbf{2} \delta(\mathrm{ppm})=170.14(\mathrm{O}=\mathrm{C}-\mathrm{O}), 71.09$ (2C, CH-cp), 69.68 $\left(\mathrm{CH}_{2}\right) 69.66$ (2C, CH-cp) 69.27 (5C, CH-cp), $65.93\left(\mathrm{CH}_{2}\right) ; \boldsymbol{n}=4 \delta(\mathrm{ppm})=170.08(\mathrm{O}=\mathrm{C}-\mathrm{O})$, 70.85 (2C, CH-cp), 70.27 (1C, CH-cp) 69.19 (2C, CH-cp), 69.07 (5C, CH-cp), $62.61\left(\mathrm{CH}_{2}\right)$, $38.04\left(\mathrm{CH}_{2}\right), 24.93\left(\mathrm{CH}_{2}\right), 23.35\left(\mathrm{CH}_{2}\right) ; \boldsymbol{n}=\mathbf{6} \delta(\mathrm{ppm})=170.04(\mathrm{O}=\mathrm{C}-\mathrm{O}), 70.78(2 \mathrm{C}, \mathrm{CH}-$ cp), 70.40 (1C, CH-cp) 69.14 (2C, $\mathrm{CH}-\mathrm{cp}), 68.97$ (5C, $\mathrm{CH}-\mathrm{cp}), 62.63\left(\mathrm{CH}_{2}\right), 39.73\left(\mathrm{CH}_{2}\right)$, $27.65\left(\mathrm{CH}_{2}\right), 24.44\left(\mathrm{CH}_{2}\right)$

ESI-MS of $\boldsymbol{n}=\mathbf{2}$ Expected 275.05 Observed $275.13 ; \boldsymbol{n}=\mathbf{4}$ Expected 302.08 Observed 302.20; n=6 Expected 331.12 Observed 331.16

Synthesis of $\left(\mathrm{FcC}_{2}\right) \mathrm{PbBr}_{3}$ phase: For the material synthesis of $\left(\mathrm{FcC}_{2}\right) \mathrm{PbBr}_{3}$ a precursor solution with a concentration of $0.1 \mathrm{~m}$ in DMF was produced. 1 eq of $\mathrm{PbBr}_{2}$ and 1 eq of $\mathrm{FcC}_{2} \mathrm{Br}$ were dissolved in dryed DMF. Under vigorous stirring $0.2 \mathrm{~mL}$ of the precursor solution was added quickly into $30 \mathrm{~mL}$ DCM. The suspension was stirred for $1 \mathrm{~h}$, then the precipitation was centrifuged, washed three times with $3 \mathrm{~mL} \mathrm{DCM}$ and dried under reduced pressure. The samples were kept under nitrogen atmosphere to prevent decomposition.

Synthesis of $\left(\mathrm{FcC}_{4}\right)_{4} \mathrm{~Pb}_{3} \mathrm{Br}_{10}$ phase: For the material synthesis of $\left(\mathrm{FcC}_{4}\right)_{4} \mathrm{~Pb}_{3} \mathrm{Br}_{10}$ a precursor solution with a concentration of $0.1 \mathrm{M}$ in DMF was produced. Therefore, 3 eq of $\mathrm{PbBr}_{2}$ and 4 eq of $\mathrm{FcC}_{4} \mathrm{Br}$ were dissolved in dried DMF. Under vigorous stirring $0.2 \mathrm{~mL}$ of the precursor solution was added quickly into $30 \mathrm{~mL}$ DCM. The suspension was stirred for $1 \mathrm{~h}$, then the precipitation was centrifuged, washed three times with $3 \mathrm{~mL}$ DCM and dried under reduced pressure. The sample was kept under nitrogen atmosphere to prevent decomposition.

Synthesis of $\left(\mathrm{FcC}_{6}\right)_{2} \mathrm{PbBr}_{4}$ phases: For the material synthesis of $\left(\mathrm{FcC}_{6}\right)_{2} \mathrm{PbBr}_{4}$ a precursor solution with a concentration of $0.1 \mathrm{M}$ in DMF was produced. Therefore, 1 eq of $\mathrm{PbBr}_{2}$ and 2 eq of $\mathrm{FcC}_{6} \mathrm{Br}$ were dissolved in dried DMF. Under vigorous stirring $0.2 \mathrm{~mL}$ of the precursor solution was added quickly into $30 \mathrm{~mL}$ toluene. The suspension was stirred for $1 \mathrm{~h}$, then the precipitation was centrifuged, washed three times with $3 \mathrm{~mL} \mathrm{DCM}$ and dried under reduced pressure. The sample was kept under nitrogen atmosphere to prevent decomposition.

Oxidation of $\left(\mathrm{FcC}_{2}\right) \mathrm{PbBr}_{3}$ with iron(III) perchlorate hydrate: For the chemical oxidation of the $\left(\mathrm{FcC}_{2}\right) \mathrm{PbBr}_{3}$ particles, iron (III) perchlorate $\left(\mathrm{Fe}\left(\mathrm{ClO}_{4}\right)_{3}\right)$ was dried for $24 \mathrm{~h}$ at $60^{\circ} \mathrm{C}$ under reduced pressure. A stock solution of $\mathrm{Fe}\left(\mathrm{ClO}_{4}\right)_{3}$ in $\mathrm{CHCl}_{3}\left(10^{-3} \mathrm{M}\right)$ was prepared. $1 \mathrm{mg}$ of $\left(\mathrm{FcC}_{2}\right) \mathrm{PbBr}_{3}(1.4 \mu \mathrm{mol})$ were dispersed in $3 \mathrm{~mL}$ diluted solution of $\mathrm{Fe}\left(\mathrm{ClO}_{4}\right)_{3}$ with varying 
equivalents ( $0.1 \mathrm{eq}, 0.2 \mathrm{eq}, 0.5 \mathrm{eq}, 1.0 \mathrm{eq}$ and $2.0 \mathrm{eq}$ ) of oxidant and treated with ultrasound for 10 minutes. The particles were centrifuged, washed three times with $3 \mathrm{~mL} \mathrm{CHCl}_{3}$ and dried under reduced pressure. SEM images of the oxidized particles are provided in Figure S17. The samples were kept under nitrogen atmosphere to prevent decomposition. Cyclic voltammetry measurements: For CV measurements, $1.44 \mathrm{~g}$ LiTFSI (5 mmol; salt was stored in a glovebox) were solved in $48.5 \mathrm{~mL}$ HFE and $1.5 \mathrm{~mL}$ DEC. To remove dissolved oxygen, the solution was flushed with nitrogen for 10 minutes. ITO substrates were ultrasonically cleaned in a soap solution, ethanol and then acetone, 20 minutes each. The substrates were dried under a $\mathrm{N}_{2}$-stream. The coated ITO substrate was prepared by drop-casting a concentrated dispersion of the particles in toluene onto an area of about $1 \mathrm{~cm} \times 1 \mathrm{~cm}$. The solvent was evaporated on a heat-plate at $40^{\circ} \mathrm{C}$. The counter electrode, a Pt-plate, was cleaned in $\mathrm{H}_{2} \mathrm{SO}_{4} / \mathrm{H}_{2} \mathrm{O}_{2}$, washed with deionized water, ethanol and acetone. Before use, the Pt-plate was dried under a $\mathrm{N}_{2}$-stream. For the measurement, all electrodes were contacted with alligator clips and the electrodes were immersed in $30 \mathrm{~mL}$ of the electrolyte in a beaker. For oxidation experiments (30 minutes at $0.65 \mathrm{~V})$ the electrolyte was slightly stirred.

Three-dimensional electron diffraction (3D ED): All measurements of $\left(\mathrm{FcC}_{2}\right) \mathrm{PbBr}_{3}$ and $\left(\mathrm{FcC}_{4}\right)_{4} \mathrm{~Pb}_{3} \mathrm{Br}_{10}$ were carried out with a transmission electron microscope (TEM) FEI Tecnai F30 S-TWIN equipped with a field emission gun $(300 \mathrm{kV})$ or with a TEM FEI Tecnai 20 equipped with a LaB6 cathode $(200 \mathrm{kV})$, respectively. The powdered sample was dispersed in ethanol using an ultrasonic bath and sprayed on carbon coated copper grid using an ultrasound sonifier. ${ }^{[42]}$ The grid was plunged into liquid nitrogen and then transferred to the TEM. Measurements for $\left(\mathrm{FcC}_{2}\right) \mathrm{PbBr}_{3}$ were carried out with the FEI Tecnai F30, TEM images and ED patterns were acquired with a Gatan UltraScan4000 CCD camera (16-bit, 4096×4096 pixel) at hardware-binning of 4. Scanning transmission electron microscopy (STEM) images were collected by a FISCHIONE high-angular annular dark field (HAADF) detector and acquired by Emispec ES Vision software. 3D ED data were collected using the acquisition module Fast-ADT (FADT) ${ }^{[44]}$ developed for FEI and JEOL microscopes. A condenser aperture of $10 \mu \mathrm{m}$ and mild illumination settings (gun lens 8, spot size 6) were used in order to produce a semi-parallel beam of $550 \mathrm{~nm}$ in diameter $\left(0.090 \mathrm{e}^{-} \AA^{-2} \mathrm{~s}^{-1}\right)$. Crystal position tracking was performed in microprobe STEM mode. In case of $\left(\mathrm{FcC}_{4}\right)_{4} \mathrm{~Pb}_{3} \mathrm{Br}_{10}$ measurements were performed with the FEI Tecnai 20, TEM images and ED patterns were recorded using a single-electron ASI MEDIPIX detector ${ }^{[84]}$ (16-bit, $512 \times 512$ pixel). Mild illumination settings 
were used (condenser aperture of $10 \mu \mathrm{m}$ and spot size 8) in order to produce a semiparallel beam of $1050 \mathrm{~nm}$ in diameter $\left(0.060 \mathrm{e}^{-} \AA^{-2} \mathrm{~s}^{-1}\right)$. Three-dimensional electron diffraction data were collected using our own developed scripts in Olympus Soft Imaging Solutions iTEM software. The ED data were collected on both TEMs with electron beam precession (precession electron diffraction, PED) to improve reflection intensity integration quality. ${ }^{[42,85]}$ PED was performed using a Digistar unit developed by NanoMEGAS SPRL. The precession angle was kept at approx. $1^{\circ}$. The PETS2.0 software package ${ }^{[86]}$ was used for 3D ED data processing. Difference Fourier mapping and least-squares (dynamical) refinement were performed with the software JANA2006. ${ }^{[87]}$

Powder X-ray diffraction (PXRD): Measurements of the particles were obtained using an X-ray diffractometer with Debye-Scherrer setup (StadiP by Stoe) using monochromatic $\mathrm{CuK} \alpha_{1}$ radiation $(\lambda=1.54059 \AA)$. The diffractometer was equipped with a Mythen $1 \mathrm{~K}$ detector (Dectris) with an angular range of $12.5^{\circ}$. PXRD measurements of drop casted particles on ITO substrate were obtained using an X-ray diffractometer with Bragg-Brentano setup (ThetaTheta by Stoe) using $\mathrm{CuK} \alpha_{1}$ radiation $(\lambda=1.54059 \AA)$.

\section{Other Characterization:}

Scanning electron microscope (SEM) images and energy dispersive X-ray spectroscopy (EDX) of drop casted particles on silicon substrate were obtained using a Jeol JSM-6700F equipped with an Oxford Instruments INCA 300. UV/Vis measurements of drop casted particles on ITO substrate were acquired with an Agilent 8453 Carry 4000 with a praying mantis. UV/Vis measurements of drop casted particles on glass substrate were acquired with an Agilent 8453 Carry 5000 with an integrating sphere. For evaluation of the band gap the Kubelka-Munk method was used. UV/Vis measurements of particles in dispersion and the $\mathrm{FcC}_{\mathrm{n}} \mathrm{Br}$-ligands $(\mathrm{n}=2,4,6)$ in solution were obtained with an Agilent 8453 Carry 4000. Photon electron spectroscopy (on air; PESA) of drop casted particles on a glass substrate were acquired with a Riken Keiki AC-2 Photoelectron Spectrometer. X-ray photon spectroscopy (XPS) measurements were obtained with a Versaprobe III (Physical Electronics GmbH). Photoluminescence (PL) measurements of particles suspended in toluene were obtained using a Cary Eclipse (Agilent). Cyclic voltammetry measurements were obtained with a potentiostat (Autolab, PGSTAT101) from Metrohm.

\section{Supporting Information}


Supporting Information is available.

\section{Acknowledgements}

We thank the German Research Foundation for funding (project PO 780/22-1). The authors thank Ute Kolb for access to the transmission electron microscope FEI Tecnai F30 S-TWIN at the EM Center in Mainz (EZMZ) of the university Mainz. The authors are grateful to Lukás Palatinus for access to the TEM FEI Tecnai 20 at the Institute of Physics of the Czech Academy of Sciences. We thank Stefan Schupp for organizing the PESA measurements and Stephen Klimke for the Mößbauer analysis.

\section{Conflict of Intrest}

The authors declare no conflict of intrest.

\section{References}

[1] Y. Sun, J. A. Rogers, Adv. Mater. 2007, 19, 1897-1916.

[2] S. K. Garlapati, M. Divya, B. Breitung, R. Kruk, H. Hahn, S. Dasgupta, Adv. Mater. 2018, 30, 1707600.

[3] D. B. Mitzi, J. Mater. Chem. 2004, 14, 2355-2365.

[4] H. J. Snaith, J. Phys. Chem. Lett. 2013, 4, 3623-3630.

[5] N. Pellet, F. Giordano, M. Ibrahim Dar, G. Gregori, S. M. Zakeeruddin, J. Maier, M. Grätzel, Prog. Photovolt. Res. Appl. 2017, 25, 942-950.

[6] T. C. Sum, N. Mathews, G. Xing, S. S. Lim, W. K. Chong, D. Giovanni, H. A. Dewi, Acc. Chem. Res. 2016, 49, 294-302.

[7] J. S. Manser, J. A. Christians, P. V. Kamat, Chem. Rev. 2016, 116, 12956-13008.

[8] A. Amat, E. Mosconi, E. Ronca, C. Quarti, P. Umari, Md. K. Nazeeruddin, M. Grätzel, F. De Angelis, Nano Lett. 2014, 14, 3608-3616.

[9] M. R. Filip, G. E. Eperon, H. J. Snaith, F. Giustino, Nat. Commun. 2014, 5, 5757.

[10] S. Gonzalez-Carrero, R. E. Galian, J. Pérez-Prieto, J. Mater. Chem. A 2015, 3, 91879193.

[11] Y. Zhao, K. Zhu, Chem. Soc. Rev. 2016, 45, 655-89.

[12] A. L. Abdelhady, M. I. Saidaminov, B. Murali, V. Adinolfi, O. Voznyy, K. Katsiev, E. Alarousu, R. Comin, I. Dursun, L. Sinatra, E. H. Sargent, O. F. Mohammed, O. M. Bakr, J. Phys. Chem. Lett. 2016, 7, 295-301.

[13] D. M. Jang, K. Park, D. H. Kim, J. Park, F. Shojaei, H. S. Kang, J. P. Ahn, J. W. Lee, J. K. Song, Nano Lett. 2015, 15, 5191-9.

[14] S. Ji, X. Yuan, S. Cao, W. Ji, H. Zhang, Y. Wang, H. Li, J. Zhao, B. Zou, J. Phys. Chem. Lett. 2020, 11, 2142-2149.

[15] R. Begum, M. R. Parida, A. L. Abdelhady, B. Murali, N. M. Alyami, G. H. Ahmed, M. N. Hedhili, O. M. Bakr, O. F. Mohammed, J. Am. Chem. Soc. 2017, 139, 731-737.

[16] G. Grancini, C. Roldan-Carmona, I. Zimmermann, E. Mosconi, X. Lee, D. Martineau, S. Narbey, F. Oswald, F. De Angelis, M. Graetzel, M. K. Nazeeruddin, Nat. Commun. 2017, 8, 15684. 
[17] H. Tsai, W. Nie, J. C. Blancon, C. C. Stoumpos, R. Asadpour, B. Harutyunyan, A. J. Neukirch, R. Verduzco, J. J. Crochet, S. Tretiak, L. Pedesseau, J. Even, M. A. Alam, G. Gupta, J. Lou, P. M. Ajayan, M. J. Bedzyk, M. G. Kanatzidis, Nature 2016, 536, 312-6.

[18] E. R. Dohner, A. Jaffe, L. R. Bradshaw, H. I. Karunadasa, J. Am. Chem. Soc. 2014, 136, $13154-7$.

[19] L. Mao, P. Guo, M. Kepenekian, I. Hadar, C. Katan, J. Even, R. D. Schaller, C. C. Stoumpos, M. G. Kanatzidis, J. Am. Chem. Soc. 2018, 140, 13078-13088.

[20] M. D. Smith, B. A. Connor, H. I. Karunadasa, Chem. Rev. 2019, 119, 3104-3139.

[21] G.-E. Wang, C. Sun, M.-S. Wang, G.-C. Guo, Nanoscale 2020, 12, 4771-4789.

[22] T. Kong, H. Xie, Y. Zhang, J. Song, Y. Li, E. L. Lim, A. Hagfeldt, D. Bi, Adv. Energy Mater. 2021, 11, 2101018.

[23] F. Xu, Y. Li, N. Liu, Y. Han, M. Zou, T. Song, Crystals 2021, 11, 241.

[24] Y. Miao, X. Wang, H. Zhang, T. Zhang, N. Wei, X. Liu, Y. Chen, J. Chen, Y. Zhao, eScience 2021, 1, 91-97.

[25] A. F. Xu, R. T. Wang, L. W. Yang, V. Jarvis, J. F. Britten, G. Xu, Chem. Comm. 2019, 55, 3251-3253.

[26] C. Elliott, J. A. McNulty, D. B. Cordes, A. M. Z. Slawin, P. Lightfoot, J. Solid State Chem. 2021, 303, 122466.

[27] X. Li, Y. He, M. Kepenekian, P. Guo, W. Ke, J. Even, C. Katan, C. C. Stoumpos, R. D. Schaller, M. G. Kanatzidis, J. Am. Chem. Soc. 2020, 142, 6625-6637.

[28] P. Kour, M. Chenna Reddy, S. Pal, S. Sidhik, T. Das, P. Pandey, S. P. Mukherjee, S. Chakraborty, A. D. Mohite, S. Ogale, Angew. Chem. Int. Ed. 2021, 60, 18750-18760.

[29] C. C. Stoumpos, L. Mao, C. D. Malliakas, M. G. Kanatzidis, Inorg. Chem. 2017, 56, 5673.

[30] D. B. Mitzi, K. Chondroudis, C. R. Kagan, ACS Inorg. Chem. 1999, 38, 11.

[31] J. V. Milić, J. Mater. Chem. C 2021, 11428-11443.

[32] J. V. Passarelli, D. J. Fairfield, N. A. Sather, M. P. Hendricks, H. Sai, C. L. Stern, S. I. Stupp, J. Am. Chem. Soc. 2018, 140, 7313-7323.

[33] W. Chen, Y. Shi, J. Chen, P. Ma, Z. Fang, D. Ye, Y. Lu, Y. Yuan, J. Zhao, Z. Xiao, Adv. Mater. 2021, 33, 2104842.

[34] N. Fillafer, T. Seewald, L. Schmidt-Mende, S. Polarz, Beilstein J. Nanotechnol. 2020, $11,466-479$.

[35] Z.-X. Zhang, H.-Y. Zhang, W. Zhang, X.-G. Chen, H. Wang, R.-G. Xiong, J. Am. Chem. Soc. 2020, 142, 17787-17794.

[36] D. Astruc, Eur. J. Inorg. Chem. 2017, 2017, 6-29.

[37] Z. Huang, H. Yu, L. Wang, X. Liu, T. Lin, F. Haq, S. Z. Vatsadze, D. A. Lemenovskiy, Coord. Chem. Rev. 2021, 430, 213737.

[38] G. S. Mohammad-Pour, K. O. Hatfield, D. C. Fairchild, K. Hernandez-Burgos, J. Rodríguez-López, F. J. Uribe-Romo, J. Am. Chem. Soc. 2019, 141, 19978-19982.

[39] L. Fabbrizzi, ChemTexts 2020, 6, 22.

[40] M. Gemmi, E. Mugnaioli, T. E. Gorelik, U. Kolb, L. Palatinus, P. Boullay, S. Hovmöller, J. P. Abrahams, ACS Cent. Sci. 2019, 5, 1315-1329.

[41] Y. Krysiak, M. Maslyk, B. N. Silva, S. Plana-Ruiz, H. M. Moura, E. O. Munsignatti, V. S. Vaiss, U. Kolb, W. Tremel, L. Palatinus, Chem. Mater. 2021, 33, 3207-3219.

[42] E. Mugnaioli, T. Gorelik, U. Kolb, Ultramicroscopy 2009, 109, 758-765.

[43] U. Kolb, Y. Krysiak, S. Plana-Ruiz, Acta. Crystallogr. B. Struct. 2019, 75, 463-474.

[44] S. Plana-Ruiz, Y. Krysiak, J. Portillo, E. Alig, S. Estradé, F. Peiró, U. Kolb, Ultramicroscopy 2020, 211, 112951.

[45] L. Palatinus, P. Brázda, P. Boullay, O. Perez, M. Klementová, S. Petit, V. Eigner, M. Zaarour, S. Mintova, Science 2017, 355, 166-169. 
[46] D. Bowden, Y. Krysiak, L. Palatinus, D. Tsivoulas, S. Plana-Ruiz, E. Sarakinou, U.

Kolb, D. Stewart, M. Preuss, Nat. Commun. 2018, 9, 1-10.

[47] P. Brázda, L. Palatinus, M. Babor, Science 2019, 364, 667-669.

[48] P. Klar, Y. Krysiak, H. Xu, G. Steciuk, J. Cho, X. Zou, L. Palatinus, 2021.

[49] J. Simancas, R. Simancas, P. J. Bereciartua, J. L. Jorda, F. Rey, A. Corma, S.

Nicolopoulos, P. Pratim Das, M. Gemmi, E. Mugnaioli, J. Am. Chem. Soc. 2016, 138, 10116-10119.

[50] E. Mugnaioli, A. E. Lanza, G. Bortolozzi, L. Righi, M. Merlini, V. Cappello, L. Marini, A. Athanassiou, M. Gemmi, ACS Cent. Sci. 2020, 6, 1578-1586.

[51] Y. Krysiak, B. Marler, B. Barton, S. Plana-Ruiz, H. Gies, R. B. Neder, U. Kolb, IUCrJ 2020, 7, 522-534.

[52] M. J. de la Cruz, J. Hattne, D. Shi, P. Seidler, J. Rodriguez, F. E. Reyes, M. R. Sawaya, D. Cascio, S. C. Weiss, S. K. Kim, Nat. Methods 2017, 14, 399-402.

[53] J. Hattne, M. W. Martynowycz, P. A. Penczek, T. Gonen, IUCrJ 2019, 6, 921-926.

[54] C. Mac Gillavry, H. Nijveld, S. Dierdorp, J. Karsten, Rec. Trav. Chim. Pays Bas 1939, 58, 193-200.

[55] C. P. Brock, Y. Fu, Acta. Crystallogr. B. Struct. 1997, 53, 928-938.

[56] H. Steinfink, G. D. Brunton, Inorg. Chem. 1969, 8, 1665-1668.

[57] Th. Wiest, R. Blachnik, H. Reuter, Z. Naturforsch. 1999, 54 b, 1099-1102.

[58] M. D. Smith, B. L. Watson, R. H. Dauskardt, H. I. Karunadasa, Chem. Mater. 2017, 29, 7083-7087.

[59] B. Saparov, D. B. Mitzi, Chem. Rev. 2016, 39.

[60] N. Kitazawa, Mater. Sci. Eng., B 1997, 49, 233-238.

[61] A. Paul, R. Borrelli, H. Bouyanfif, S. Gottis, F. Sauvage, ACS Omega 2019, 4, 1478014789.

[62] M. D. Smith, H. I. Karunadasa, Acc. Chem. Res. 2018, 51, 619-627.

[63] Z. Yuan, C. Zhou, Y. Tian, Y. Shu, J. Messier, J. C. Wang, L. J. van de Burgt, K. Kountouriotis, Y. Xin, E. Holt, K. Schanze, R. Clark, T. Siegrist, B. Ma, Nat. Commun. 2017, 8, 14051.

[64] S. Fery-Forgues, B. Delavaux-Nicot, J. Photochem. Photobiol. 2000, 132, 137-159.

[65] M. Hasan, S. Venkatesan, D. Lyashenko, J. D. Slinker, A. Zakhidov, Anal. Chem. 2017, 89, 9649-9653.

[66] N. G. Tsierkezos, J. Solut. Chem. 2007, 36, 289-302.

[67] R. H. Palmer, J. Liu, C.-W. Kung, I. Hod, O. K. Farha, J. T. Hupp, Langmuir 2018, 34, 4707-4714.

[68] R. Prins, J. Chem. Soc. D 1970, 280b-2281.

[69] M. Rowe, A. McCaffery, J. Chem. Phys. 1973, 59, 3786-3794.

[70] K.-F. Berggren, B. E. Sernelius, Phys. Rev. B 1981, 24, 1971.

[71] V. Palankovski, G. Kaiblinger-Grujin, S. Selberherr, Mater. Sci. Eng. B 1999, 66, 46-49.

[72] C. Stangel, C. Schubert, S. Kuhri, G. Rotas, J. T. Margraf, E. Regulska, T. Clark, T.

Torres, N. Tagmatarchis, A. G. Coutsolelos, Nanoscale 2015, 7, 2597-2608.

[73] R. E. Ruther, Q. Cui, R. J. Hamers, J. Am. Chem. Soc. 2013, 135, 5751-5761.

[74] K. Tarafder, Y. Surendranath, J. H. Olshansky, A. P. Alivisatos, L.-W. Wang, J. Am. Chem. Soc. 2014, 136, 5121-5131.

[75] R. A. Marcus, Rev. Mod. Phys. 1993, 65, 599.

[76] G. Te Velde, E. Baerends, Phys. Rev. B 1991, 44, 7888.

[77] J. P. Perdew, K. Burke, M. Ernzerhof, Phys. Rev. Lett. 1996, 77, 3865.

[78] G. Philipsen, G. te Velde, E. J. Baerends, J. A. Berger, P. L. de Boeij, M. Franchini, J. A. Groeneveld, E. S. Kadantsev, R. Klooster, F. Kootstra, M. C. W. M. Pols, P.

Romaniello, M. Raupach, D. G. Skachkov, J. G. Snijders, C. J. O. Verzijl, J. A. Celis 
Gil, J. M. Thijssen, C. A. Peeples, G. Schreckenbach, T. Ziegler, BAND 2021.1, SCM, Http://Www.Scm.Com, 2020.

[79] E. Welch, L. Scolfaro, A. Zakhidov, AIP Advances 2016, 6, 125037.

[80] K. Senthilkumar, F. Grozema, F. Bickelhaupt, L. Siebbeles, J. Chem. Phys. 2003, 119, 9809-9817.

[81] K. Senthilkumar, F. C. Grozema, C. F. Guerra, F. M. Bickelhaupt, F. D. Lewis, Y. A. Berlin, M. A. Ratner, L. D. Siebbeles, J. Am. Chem. Soc. 2005, 127, 14894-14903.

[82] S.-H. Wen, A. Li, J. Song, W.-Q. Deng, K.-L. Han, W. A. Goddard III, J. Phys. Chem. B 2009, 113, 8813-8819.

[83] G. Te Velde, F. M. Bickelhaupt, E. J. Baerends, C. Fonseca Guerra, S. J. van Gisbergen, J. G. Snijders, T. Ziegler, J. Comp. Chem. 2001, 22, 931-967.

[84] D. Georgieva, J. Jansen, I. Sikharulidze, L. Jiang, H. Zandbergen, J. Abrahams, J. Instrum. 2011, 6, C01033.

[85] R. Vincent, P. Midgley, Ultramicroscopy 1994, 53, 271-282.

[86] L. Palatinus, P. Brázda, M. Jelínek, J. Hrdá, G. Steciuk, M. Klementová, Acta. Crystallogr. B. Struct. 2019, 75, 512-522.

[87] V. Petř́iček, M. Dušek, L. Palatinus, Z. Kristallogr. Cryst. Mater. 2014, 229, 345-352.

[88] L. Palatinus, G. Chapuis, J. Appl. Cryst. 2007, 40, 786-790.

[89] P. t Doyle, P. Turner, Acta Crystallogr. A 1968, 24, 390-397.

[90] L. Palatinus, V. Petříček, C. A. Corrêa, Acta Crystallogr. A 2015, 71, 235-244.

[91] A. A. Coelho, J. Appl. Cryst. 2018, 51, 210-218.

[92] A. Boultif, D. Louër, J. Appl. Cryst. 1991, 24, 987-993.

[93] M. Meunier, S. Robertson, Molecular Simulation 2021, 47, 537-539.

[94] S. Grimme, J. Antony, S. Ehrlich, H. Krieg, J. Chem. Phys. 2010, 132, 154104. 
Supporting Information

Design of Active Defects in Semiconductors: 3D Electron Diffraction Revealed Novel Organometallic Lead Bromide Phases Containing Ferrocene as Redox Switches

Nicole Fillafer ${ }^{1}$, Henning Kuper ${ }^{2}$, Andreas Schaate ${ }^{1}$, Sonja Locmelis ${ }^{1}$, Joerg August Becker ${ }^{2}$, Yaşar Krysiak ${ }^{l *}$ and Sebastian Polarz ${ }^{1 *}$
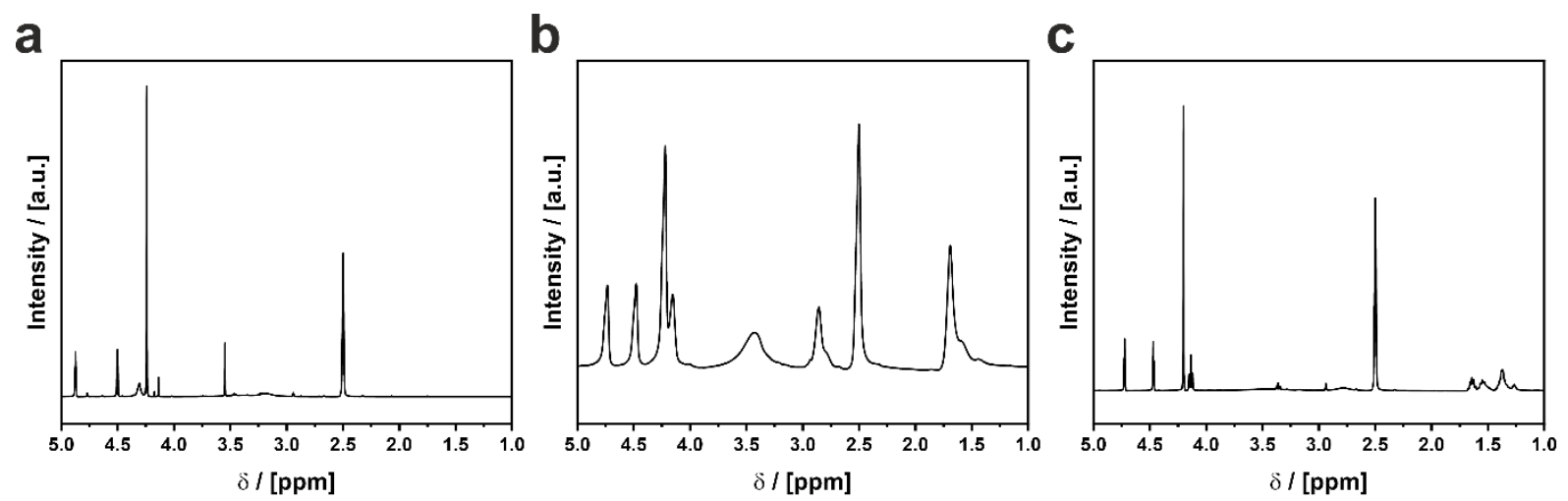

Figure S1. ${ }^{1} \mathrm{H}-\mathrm{NMR}$ of a) $\mathrm{C}_{13} \mathrm{H}_{15} \mathrm{BrFeNO}_{2}\left(=\mathrm{FcC}_{2} \mathrm{Br}\right)$, b) $\mathrm{C}_{15} \mathrm{H}_{20} \mathrm{BrFeNO}_{2}(=\mathrm{FcC} 4 \mathrm{Br})$ and c) $\mathrm{C}_{17} \mathrm{H}_{24} \mathrm{BrFeNO}_{2}\left(=\mathrm{FcC}_{6} \mathrm{Br}\right)$. For evaluation of the spectra we refer to the experimental section.

a

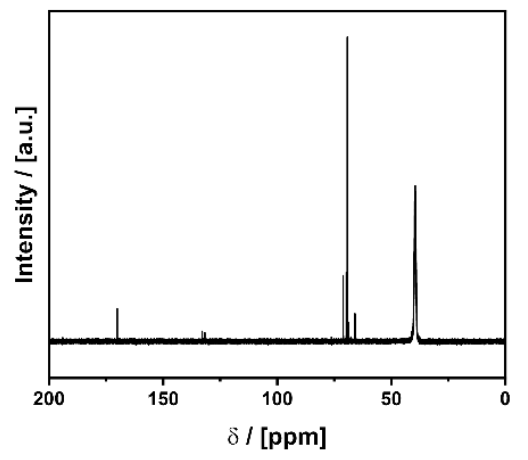

b

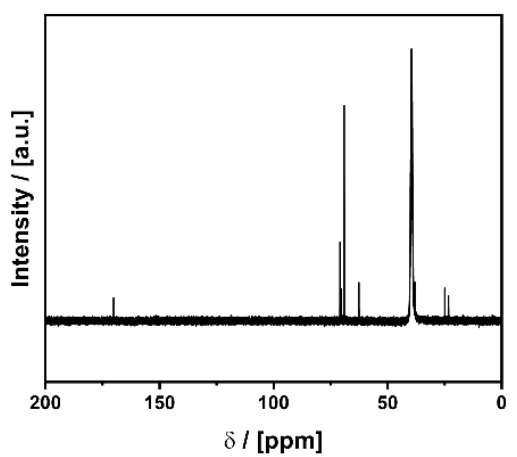

C

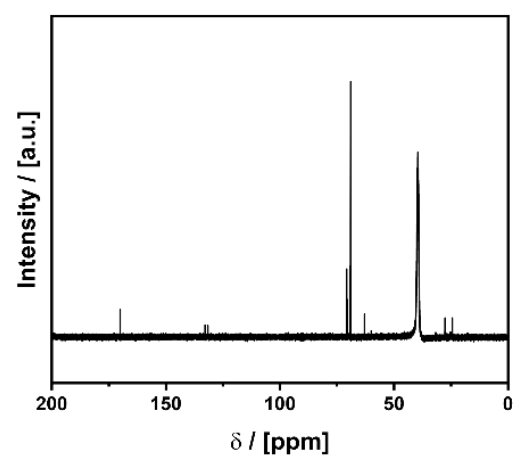

Figure S2. ${ }^{13} \mathrm{C}-\mathrm{NMR}$ of a) $\mathrm{C}_{13} \mathrm{H}_{15} \mathrm{BrFeNO}_{2}\left(=\mathrm{FcC}_{2} \mathrm{Br}\right)$, b) $\mathrm{C}_{15} \mathrm{H}_{20} \mathrm{BrFeNO}_{2}\left(=\mathrm{FcC}{ }_{4} \mathrm{Br}\right)$ and c) $\mathrm{C}_{17} \mathrm{H}_{24} \mathrm{BrFeNO}_{2}\left(=\mathrm{FcC}_{6} \mathrm{Br}\right)$. For evaluation of the spectra we refer to the experimental section. 

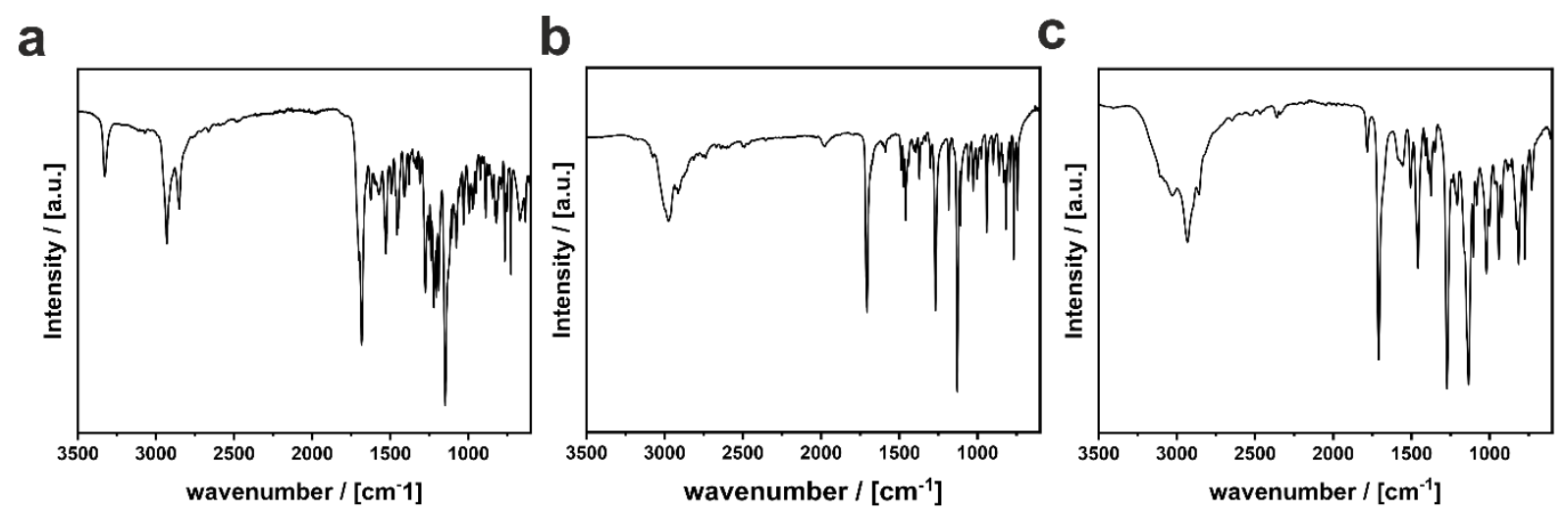

Figure S3. IR transmission spectra of a) $\mathrm{FcC}_{2} \mathrm{Br}$ with significant vibrations at $2930-2850 \mathrm{~cm}^{-1}\left(\mathrm{NH}_{3}\right.$ stretching vibration), $1683 \mathrm{~cm}^{-1}$ (C=O stretching vibration), $1526 \mathrm{~cm}^{-1}$ (O- $\mathrm{CH}_{2}$ deformation vibration), $1273 \mathrm{~cm}^{-1}$ (O-C=O stretching vibration), $1144 \mathrm{~cm}^{-1}$ (O-C=O stretching vibration), $767 \mathrm{~cm}^{-1}+728 \mathrm{~cm}^{-1}$ (cp C-H out-of-plane vibration), b) $\mathrm{FcC}_{4} \mathrm{Br}$ with significant vibrations at $2970 \mathrm{~cm}^{-1}\left(\mathrm{NH}_{3}\right.$ stretching vibration), $1706 \mathrm{~cm}^{-1}(\mathrm{C}=\mathrm{O}$ stretching vibration), $1459 \mathrm{~cm}^{-1}$ (O-CH 2 deformation vibration), $1269 \mathrm{~cm}^{-1}$ (O-C=O stretching vibration), $1129 \mathrm{~cm}^{-1}$ (O-C=O stretching vibration), $769 \mathrm{~cm}^{-1}$ ( $\mathrm{cp} \mathrm{C-H} \mathrm{out-of-plane} \mathrm{vibration)}$ and c) $2931 \mathrm{~cm}^{-1}\left(\mathrm{NH}_{3}\right.$ stretching vibration), $1711 \mathrm{~cm}^{-1}$ (C=O stretching vibration), $1458 \mathrm{~cm}^{-1}$ (O- $\mathrm{CH}_{2}$ deformation vibration) $1273 \mathrm{~cm}^{-1}\left(\mathrm{O}-\mathrm{C}=\mathrm{O}\right.$ stretching vibration), $1134 \mathrm{~cm}^{-1}(\mathrm{O}-\mathrm{C}=\mathrm{O}$ stretching vibration), $773 \mathrm{~cm}^{-1}$ (cp C-H out-of-plane vibration).

a

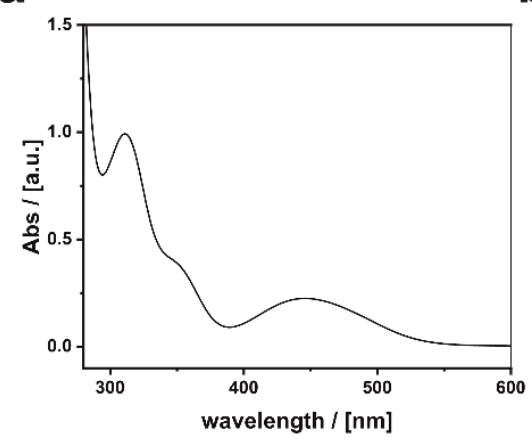

b

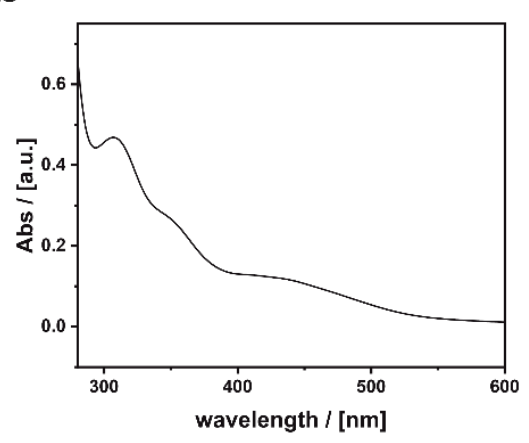

C

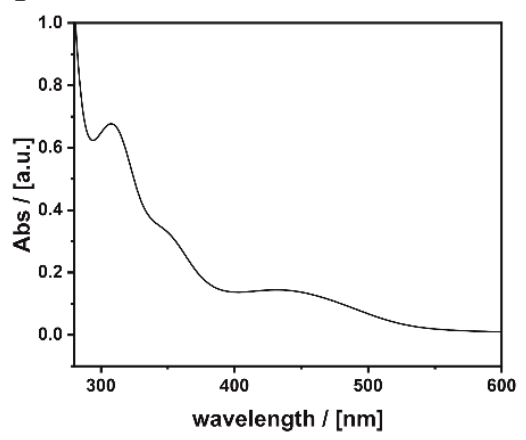

Figure S4. UV/Vis absorption spectra in $\mathrm{MeOH}$ of a) $\mathrm{FcC}_{2} \mathrm{Br}$ with three local absorption maxima at $446 \mathrm{~nm}$ (Еномо-Lumo; $2.78 \mathrm{eV}), 349 \mathrm{~nm}(3.55 \mathrm{eV})$ and $311 \mathrm{~nm}(3.98 \mathrm{eV}), \mathrm{b})$ $\mathrm{FcC}_{4} \mathrm{Br}$ with three local absorption maxima at $431 \mathrm{~nm}$ (Eномо-Lumo; $2.88 \mathrm{eV}$ ), $350 \mathrm{~nm}$ $(3.54 \mathrm{eV})$ and $307 \mathrm{~nm}(4.04 \mathrm{eV})$ and c) $\mathrm{FcC}_{6} \mathrm{Br}$ with three local absorption maxima at $431 \mathrm{~nm}$ (Еномо-цuмо; $2.88 \mathrm{eV}), 350 \mathrm{~nm}(3.54 \mathrm{eV})$ and $308 \mathrm{~nm}(4.02 \mathrm{eV})$. 


\section{D electron diffraction data reconstruction}

PETS2.0 ${ }^{[86]}$ was used to process three $\left(\mathrm{FcC}_{2}\right) \mathrm{PbBr}_{3}$ and five $\left(\mathrm{FcC}_{4}\right)_{4} \mathrm{~Pb}_{3} \mathrm{Br}_{10} 3 \mathrm{D}$ electron diffraction datasets. First, each dataset was processed separately to determine the individual orientation matrices. A reference dataset and thus a reference orientation matrix was defined for each compound. In a next step, the position angles of the other datasets were transformed to match the reference orientation matrix. In a final step, the orientation and distortion of each individual frame had to be carefully refined for the respective merged data sets before the intensities were extracted. In this way, inaccuracies in the lattice constants can be minimized and the statistics for the individual measured reflections can be considerably improved, as well as multiple scattering effects are reduced by averaging. The space groups were identified to be $C 2 / c$ and $P 2_{1} / a$ for the setting chosen presented in Table $\mathrm{S} 1$. In case $\left(\mathrm{FcC}_{4}\right)_{4} \mathrm{~Pb}_{3} \mathrm{Br}_{10}$ we preferred a monoclinic setting with a $\beta$-angle close to $90^{\circ}$. Thus, in the case of $\left(\mathrm{FcC}_{2}\right) \mathrm{PbBr}_{3}$ a merging error of $R_{\text {int }}=10.6 \%$ and in case of $\left(\mathrm{FcC}_{4}\right)_{4} \mathrm{~Pb}_{3} \mathrm{Br}_{10} R_{\text {int }}=9.9 \%$ could be achieved for the data reconstruction assuming in both cases the Laue class $2 / m$.

\section{Structure solution}

Ab initio structure solution of $\left(\mathrm{FcC}_{2}\right) \mathrm{PbBr}_{3}$ and $\left(\mathrm{FcC}_{4}\right)_{4} \mathrm{~Pb}_{3} \mathrm{Br}_{10}$ were performed assuming the kinematic approximation $I \sim\left|F_{\mathrm{hkl}}\right|^{2}$ by SUPERFLIP ${ }^{[88]}$ implemented in the program JANA2006. ${ }^{[87]}$ Scattering factors for electrons were taken from Doyle and Turner. ${ }^{[89]}$ The potential maps were interpreted with the help of JANA2006 and can be accessed via the following links: xplor-files.

\section{Structure refinement of $\left(\mathrm{FcC}_{2}\right) \mathrm{PbBr}_{3}$}

The fractional coordinates of the structure model were first shifted by the vector $\left[\begin{array}{lll}0 & 0 & 1 / 2\end{array}\right]$. All hydrogens were added in a chemically sensible way. For $\mathrm{C}, \mathrm{N}$ and $\mathrm{O}$ atoms the displacement parameters were set to be independent and isotropic. In case of the heavier atoms $\mathrm{Pb}, \mathrm{Br}$ and Fe the displacement parameters were refined anisotropic. The hydrogen positions were constrained in relation to the nearest chemical environment. The distance between hydrogen and non-hydrogen was set to $1.09 \AA$ and the isotropic displacement parameters were set to twice the displacement parameters to the nearest atom. The residuals and parameters of the kinematical refinement are listed in Table S1.

The following dynamical refinement was carried out based on three single datasets.

Therefore, a standard procedure was followed which is described in Palatinus et al., in more detail. $^{[86,90]}$ Additional parameters for the dynamical refinement are the scaling factors of each 
frame and typically one average thickness value per dataset. Diffraction patterns with less than 10 reflections, resolution lower than $0.9 \AA^{-1}$ and recorded from multiple domains, were not considered. Out of 333 images, 326 were left out for refinement.

\section{Structure refinement of $\left(\mathrm{FcC}_{4}\right)_{4} \mathrm{~Pb}_{3} \mathrm{Br}_{10}$}

The fractional coordinates of the structure model were first shifted by the vector $\left[\begin{array}{lll}1 / 2 & 0 & 1 / 2\end{array}\right]$. First, all hydrogens were added in a chemically sensible way. The displacement parameters of all carbons forming the cyclopentadiene ring were set to be the same and isotropic. The displacement parameters of the atoms forming the functional groups of the substituted cyclopentadiene rings were as well fixed to be the same. The isotropic displacement parameters of $\mathrm{Pb}, \mathrm{Br}$ and $\mathrm{Fe}$ atoms were refined independently. The hydrogen positions were constrained in relation to the nearest chemical environment. The distance between hydrogen and non-hydrogen was set to $1.09 \AA$ and the isotropic displacement parameters were set to twice the displacement parameters to the nearest atom. Bond angles and lengths of $\left[\mathrm{FeCp}_{2} \mathrm{COOC}_{4} \mathrm{H}_{8} \mathrm{NH}_{3}\right]^{+}$were restrained. The refinement didn't converge well and the resulting geometry of the ferrocene derivatives was heavily distorted. Therefore, for a new data reconstruction, only the first 50-60 diffraction images of the best three data sets were considered in order to exclude the diffraction images in which denaturation by the electron beam was already advanced. Out of 415 images, 173 were left out for refinement. This reduces the theoretical data completeness from $80 \%$ to $47 \%$. The geometry of the ferrocene ligands has been restrained with the help of dummy atoms Fix11, Fix12, Fix21 and Fix22 located in the middle of the Cp-rings forming a linear molecule with Fe. The bond angle of $\angle$ (Fix11-Fe1-Fix12) and $\angle$ (Fix21-Fe2-Fix22) was fixed to $180^{\circ}$ with a standard uncertainty of $0.4^{\circ}$. A following dynamical refinement was carried out on the basis of 173 diffraction patterns using the same structural restraints and constraints. The residuals and parameters of the kinematical refinement are listed in Table S1.

\section{Rietveld refinement of $\left(\mathrm{FcC}_{2}\right) \mathrm{PbBr}_{3}$ and $\left(\mathrm{FcC}_{4}\right)_{4} \mathrm{~Pb}_{3} \mathrm{Br}_{10}$}

The structures of $\left(\mathrm{FcC}_{2}\right) \mathrm{PbBr}_{3}$ and $\left(\mathrm{FcC}_{4}\right)_{4} \mathrm{~Pb}_{3} \mathrm{Br}_{10}$ were refined against the PXRD data using TOPAS V6 ${ }^{[91]}$, based on the structure models as determined by the 3D ED method. Bond angles and lengths of $F_{c} C_{n} B r(n=2,4)$ were restrained. Isotropic displacement parameters $\mathrm{B}_{\text {iso }}$ were fixed to be the same for identical atom types and $\mathrm{C}, \mathrm{N}$ and $\mathrm{O}$. The isotropic displacement parameters of the hydrogen atoms were set to $1.2 \mathrm{x}$ the displacement parameters to the nearest atom. Anisotropic Lorentzian peak broadening modelled by using spherical harmonics $(9$ 
parameters for $\left(\mathrm{FcC}_{2}\right) \mathrm{PbBr}_{3}$ and 4 parameters for $\left.\left(\mathrm{FcC}_{4}\right)_{4} \mathrm{~Pb}_{3} \mathrm{Br}_{10}\right) . \mathrm{PbBr}_{2}$ had to be considered in case of the Rietveld refinement of $\left(\mathrm{FcC}_{4}\right)_{4} \mathrm{~Pb}_{3} \mathrm{Br}_{10}$. The amount of $\mathrm{PbBr}_{2}$ converged to $15.2 \%$. The Rietveld refinements converged to the residuals $\mathrm{R}_{\exp }=2.3 \%, \mathrm{R}_{\mathrm{wp}}=3.1 \%, \mathrm{R}_{\mathrm{p}}=$ $2.4 \%, G O F=1.35$ for $\left(\mathrm{FcC}_{2}\right) \mathrm{PbBr}_{3}$ and $\mathrm{R}_{\text {exp }}=2.3 \%, \mathrm{R}_{w p}=2.5 \%, \mathrm{R}_{p}=1.9 \%, G O F=1.11$ for $\left(\mathrm{FcC}_{4}\right)_{4} \mathrm{~Pb}_{3} \mathrm{Br}_{10}$.

\section{Modelling of $\left(\mathrm{FcC}_{6}\right)_{2} \mathrm{PbBr}_{4}$}

Several attempts to index the PXRD diagram with DICVOL91 ${ }^{[92]}$ failed. Besides the obvious basal spacing around $30 \AA$, some indexing results repeated with the typical spacing around $8.3 \AA$ for one or sometimes two lattice constants. These distances were used as starting values for the construction of a unit cell in which the corner-linked $\left[\mathrm{PbBr}_{6}\right]^{4-}$ octahedra corresponding to a typical RPP phase were placed in the space group $P-1$ with $\mathrm{Pb}$ atoms on a special position. BIOVIA Materials Studio $2020^{[93]}$ was used to build the structure. The linker molecules were also constructed and two symmetry-independent ones were placed in the unit cell so that the respective ammonium head group extend into the octahedral void. The alkyl chain was aligned so that the iron atoms, with the cyclopentadienyl rings, form their own layer parallel to the octahedral layer. Care was taken to ensure that the iron atoms have a distance of around $6 \AA$ from each other. The angles of the unit cell was adjusted so that the reflections of the simulated PXRD roughly matched that of the experimental powder diagram. The geometry of the structure was optimized with fixed lattice constants using FORCITE implemented in Materials Studio in default settings.

\section{Geometry optimization by dispersion-corrected DFT calculations}

The calculation $\left(\mathrm{FcC}_{6}\right)_{2} \mathrm{PbBr}_{4}$ were performed under periodic boundary conditions and plane wave functions as basis set. The Perdew-Burke-Ernzerhof $(\mathrm{PBE})^{[77]}$ functional was used with a dispersion correction by Grimme et al. ${ }^{[94]}$ The plane-wave cut-off energy was $490 \mathrm{eV}$, the k-point spacing approximately $0.04 \AA^{-1}$. The unit cell was kept fixed and the convergence criterion for the energy minimizations was set to $0.002 \AA$ for the atomic displacement. The optimized structure was then refined against the experimental PXRD data by applying hard restrains for the geometry. The fractional coordinates are given in Table S2. 

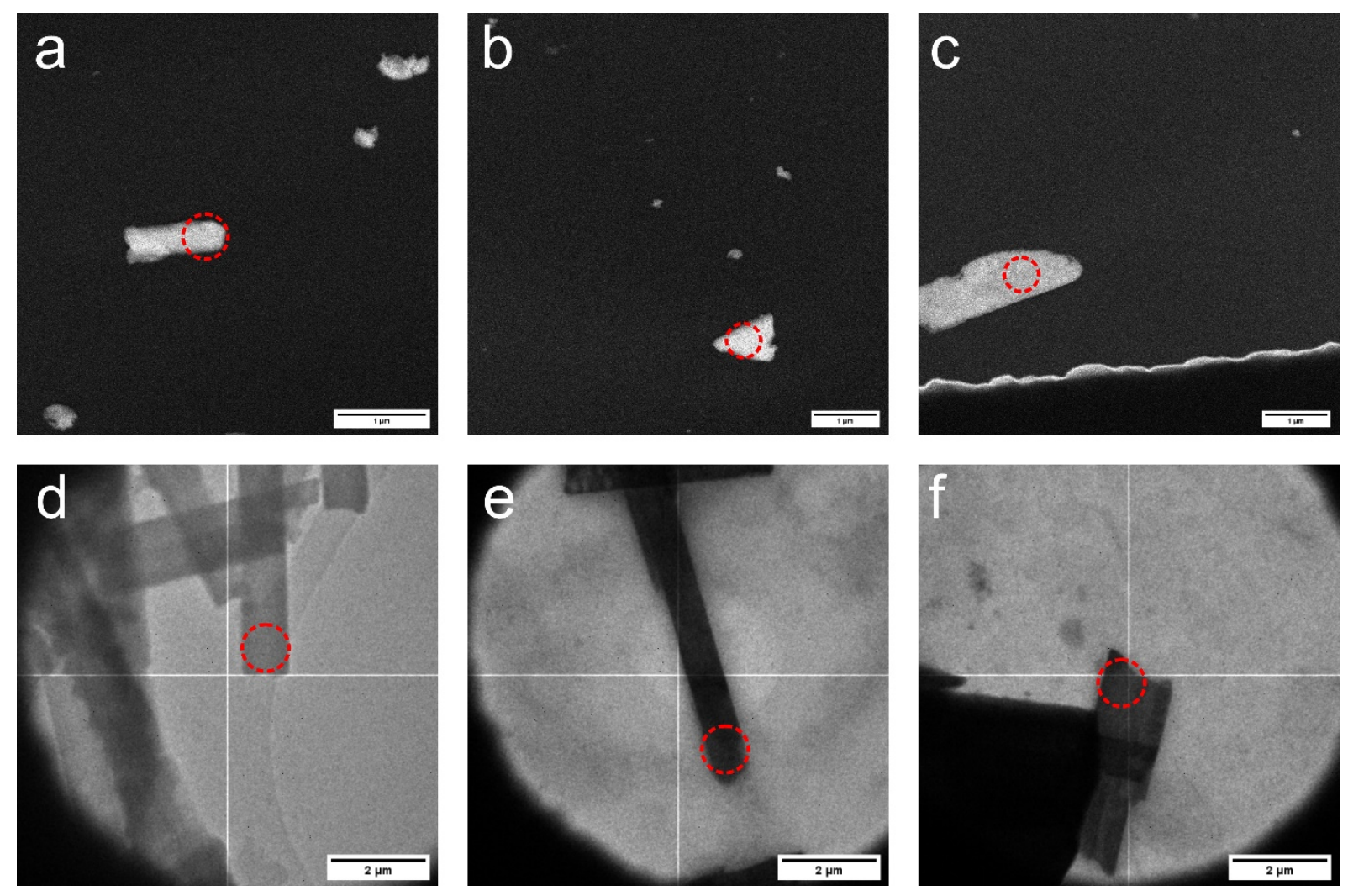

Figure S5. STEM images (a-c) of $\left(\mathrm{FcC}_{2}\right) \mathrm{PbBr}_{3}$ crystals and TEM images (d-f) of $\left(\mathrm{FcC}_{4}\right)_{4} \mathrm{~Pb}_{3} \mathrm{Br}_{10}$ crystals selected for 3D ED measurements. Beam positions for 3D ED experiments are marked by red circles.
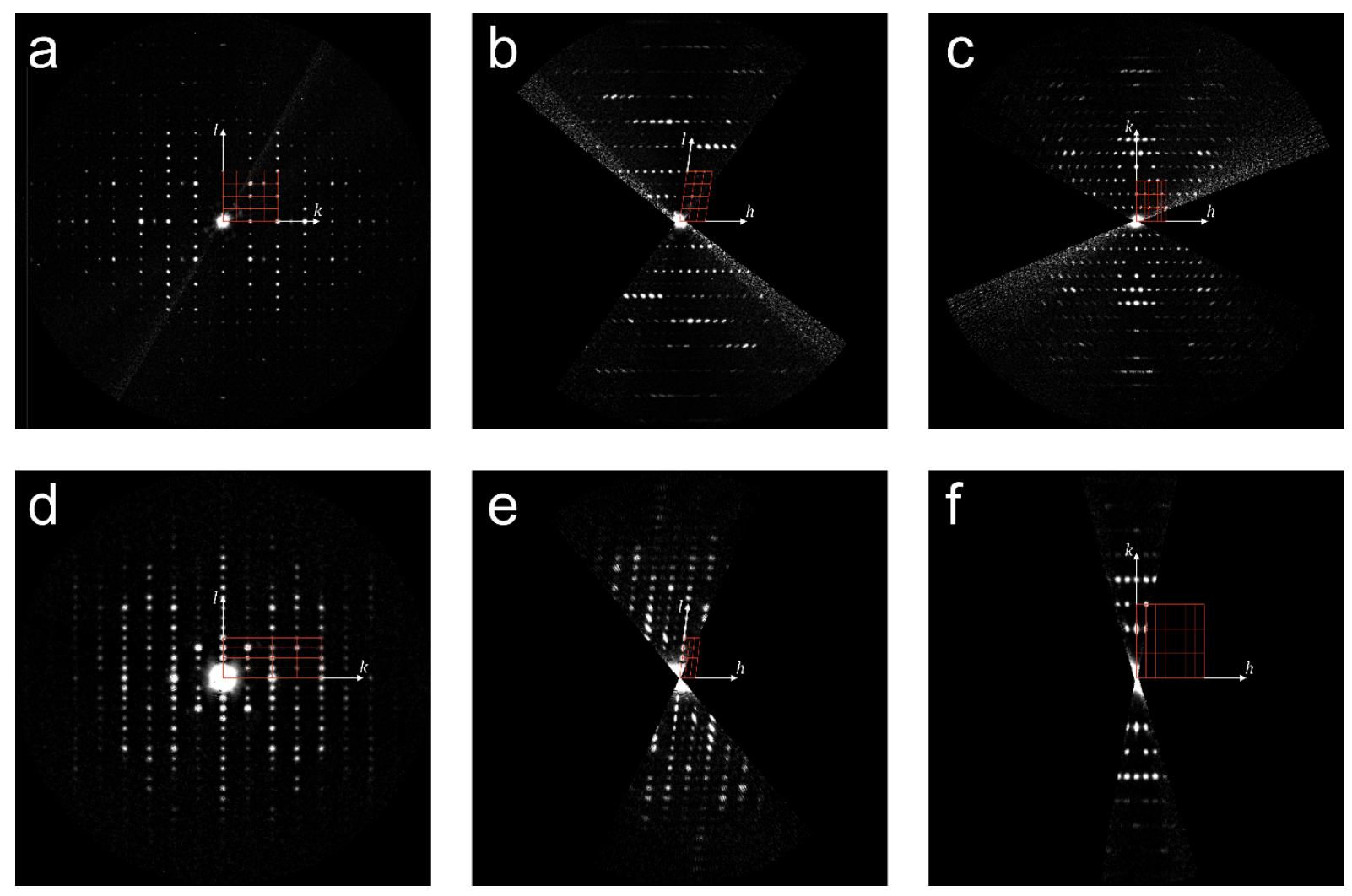
Figure S6. Reconstructed sections $h 0 l, 0 k l$ and $h k 0$ (a-c) of $\left(\mathrm{FcC}_{2}\right) \mathrm{PbBr}_{3}$ and (d-f) $\left(\mathrm{FcC}_{4}\right)_{4} \mathrm{~Pb}_{3} \mathrm{Br}_{10}$ recorded with 3D ED.

a

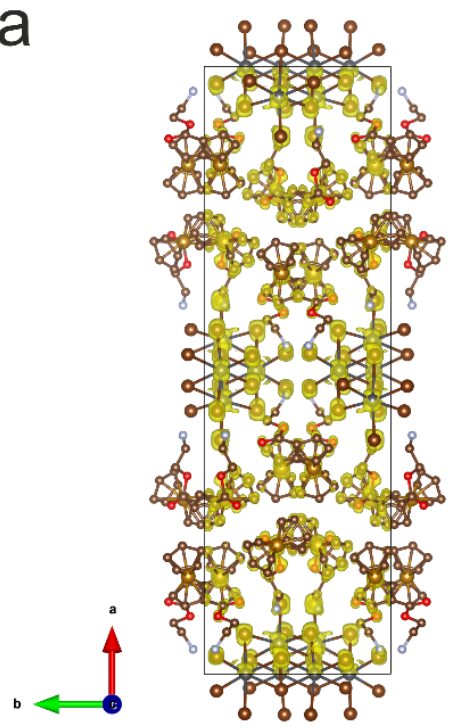

b

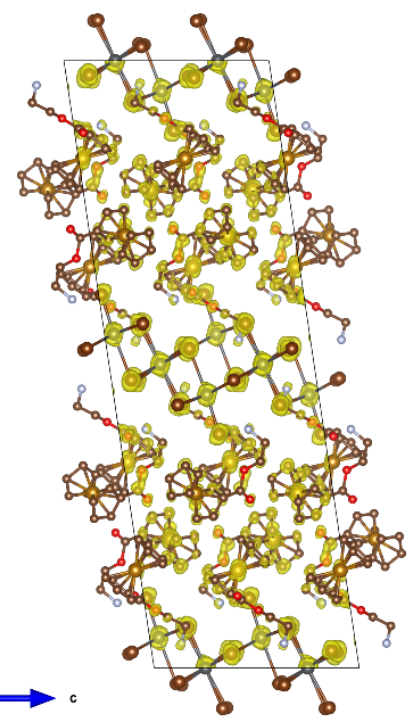

C

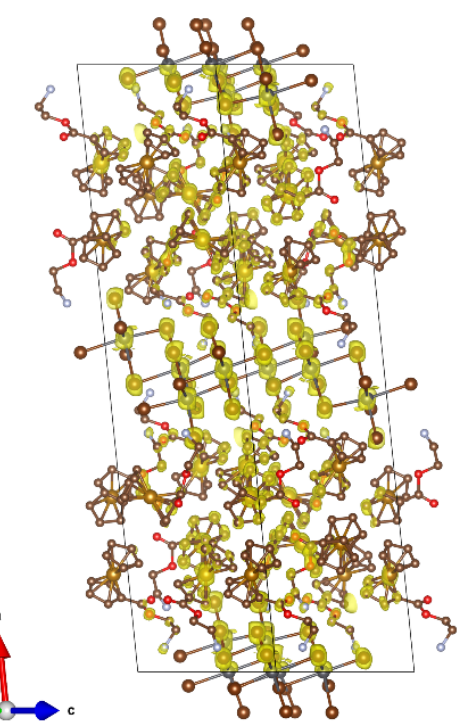

d
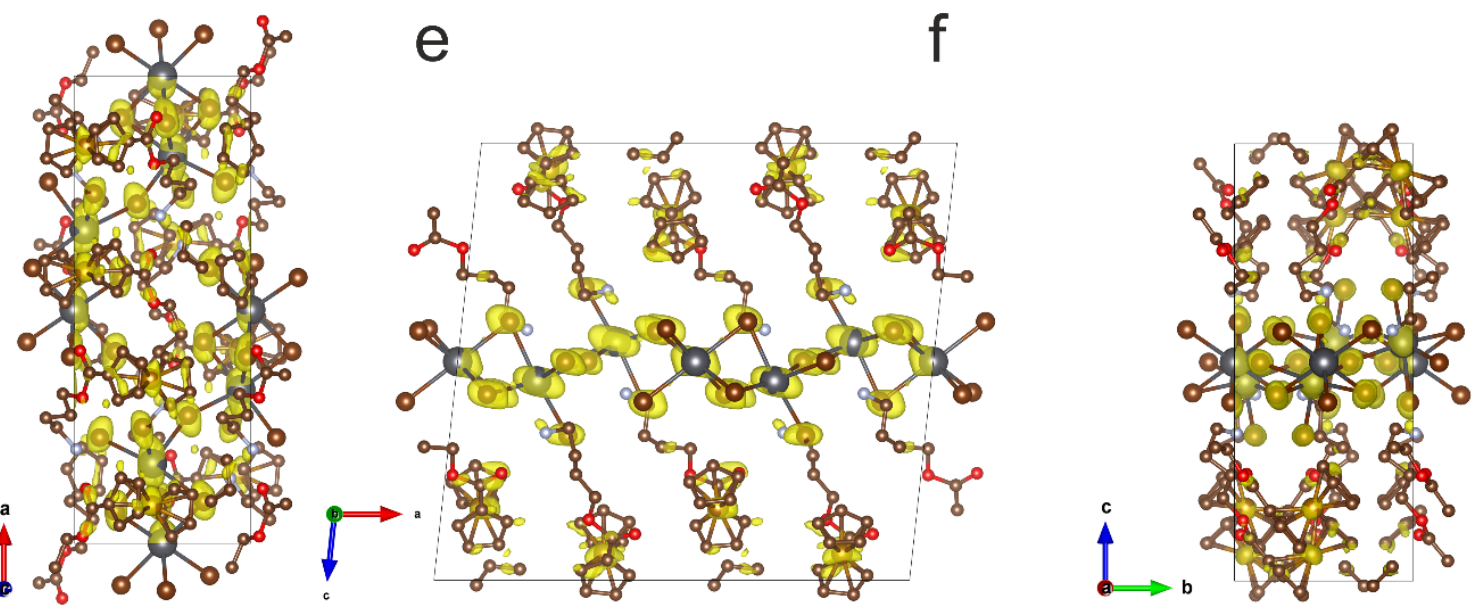

Figure S7. Results of ab initio structure solutions plotted using VESTA. Potential maps $(\Delta V)$ based on structure solution performed in Superflip for $\left(\mathrm{FcC}_{2}\right) \mathrm{PbBr}_{3}$ (a-c) in space group $C 2 / c$. Crystal structure plotted with view along a) [001] , b) [010] and c) [011]. (d-f) $\left(\mathrm{FcC}_{4}\right)_{4} \mathrm{~Pb}_{3} \mathrm{Br}_{10}$ solved in space group $P 2{ }_{1} / a$. Crystal structure plotted with view along a) [001], b) [010] and c) [100]. Transparent yellow potentials are plotted using $1.5 \sigma(\Delta V)$ threshold ( $\sigma$ is the standard deviation of map values). Lead atoms are shown in metallic grey, bromine in brown, iron in orange, carbon in brown, oxygen in red and nitrogen in light blue. 
a

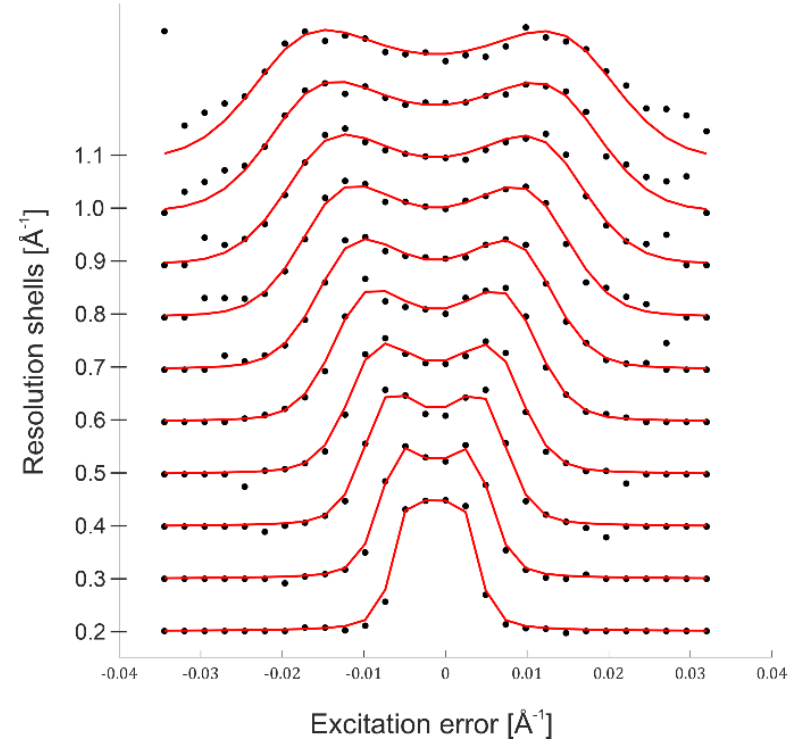

b

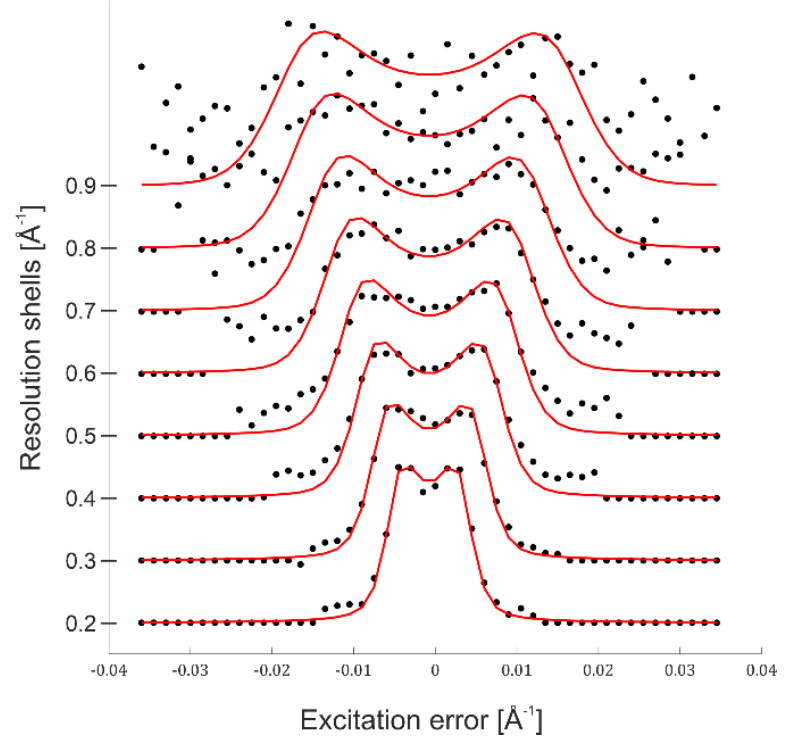

Figure S8. Averaged rocking-curves of the reflections at different diffraction data resolution intervals (black dots), fitted by the precession-dependent double-peaked profile (red curves). (a) Fit for $\left(\mathrm{FcC}_{2}\right) \mathrm{PbBr}_{3} 3 \mathrm{D} \mathrm{ED}$ data using the reflection width of $0.001 \AA^{-1}$, mosaicity of $0.25^{\circ}$, precession angle $0.94^{\circ}$ and for (b) $\left(\mathrm{FcC}_{4}\right)_{4} \mathrm{~Pb}_{3} \mathrm{Br}_{10}$ using the reflection width of $0.001 \AA^{-1}$, mosaicity of $0.20^{\circ}$, precession angle $1.00^{\circ}$.

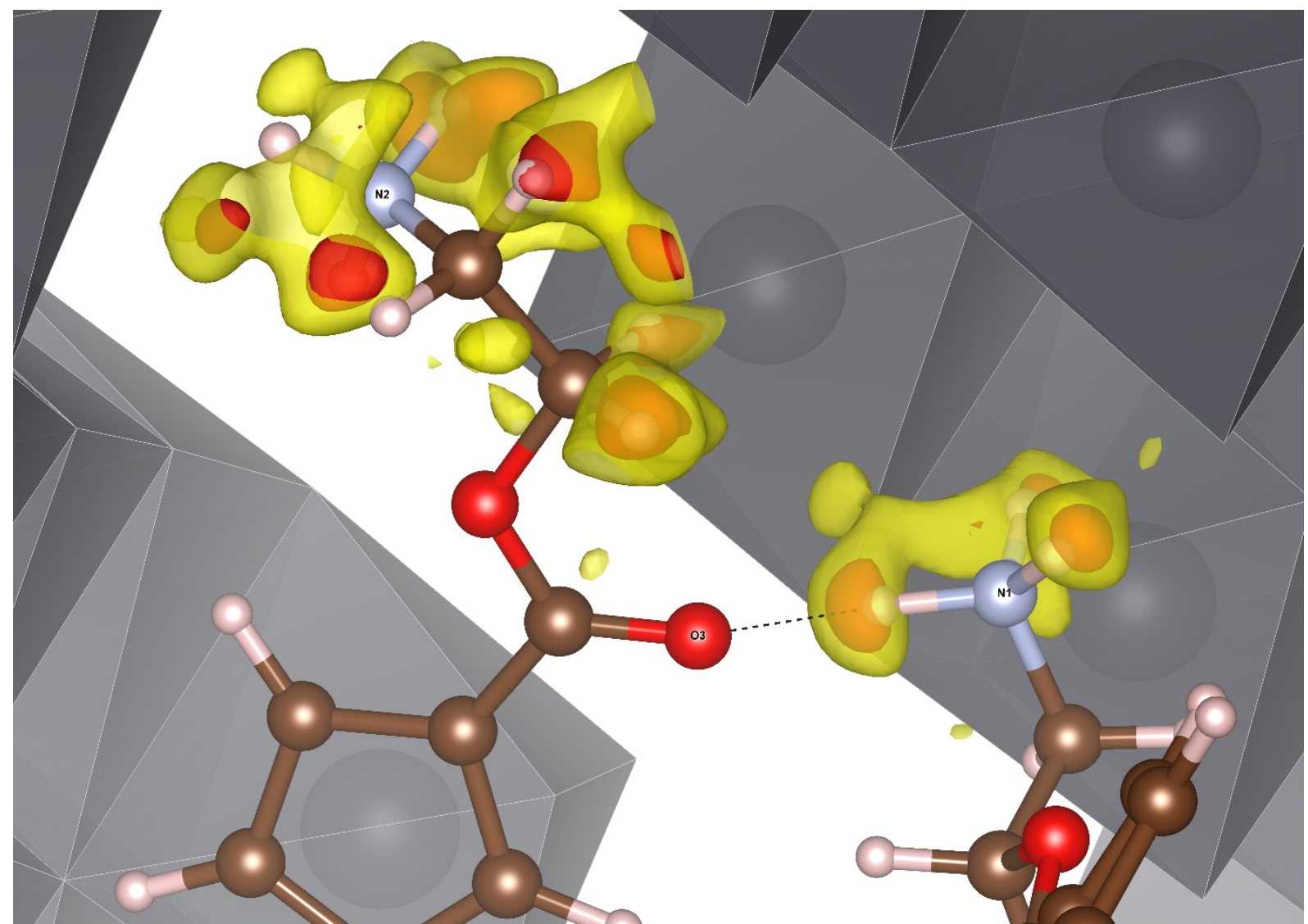

Figure S9. Difference potential maps of $\left(\mathrm{FcC}_{2}\right) \mathrm{PbBr}_{3}$ based on the final model with hydrogen atoms removed. Yellow isosurfaces correspond to the $2 \sigma[\Delta V(\mathbf{r})]$, red isosurfaces to the 
$3 \sigma[\Delta V(\mathbf{r})]$ level. The map is superimposed with the structure model and expected locations of some hydrogen sites.

Table S1. 3D ED parameters, residuals and crystallographic data for kinematical and dynamical refinement of $\left(\mathrm{FcC}_{2}\right) \mathrm{PbBr}_{3}$ and $\left(\mathrm{FcC}_{4}\right)_{4} \mathrm{~Pb}_{3} \mathrm{Br}_{10}$.

\begin{tabular}{|c|c|c|}
\hline & $\left(\mathrm{FcC}_{2}\right) \mathrm{PbBr}_{3}$ & $\left(\mathrm{FcC}_{4}\right)_{4} \mathrm{~Pb}_{3} \mathrm{Br}_{10}$ \\
\hline \multicolumn{3}{|l|}{ Crystal data } \\
\hline Crystal system, space group & monoclinic, $C 2 / \mathrm{c}$ & monoclinic, $P 22_{1} / a$ \\
\hline \multirow[t]{2}{*}{$a(\AA), \mathrm{b}(\AA), c(\AA), \beta\left(^{\circ}\right)$} & 41.504(8), 12.6538(12), & 22.479(13), 8.4216(11), \\
\hline & 13.8784(14), 98.458(12) & 20.698(4), 96.10(4) \\
\hline$V\left(\AA^{3}\right)$ & 7209.4(17) & $3896(2)$ \\
\hline Empirical formula & $\left(\mathrm{C}_{13} \mathrm{H}_{16} \mathrm{NO}_{2} \mathrm{Fe}\right) \mathrm{PbBr}_{3}$ & $\left(\mathrm{C}_{15} \mathrm{H}_{20} \mathrm{NO}_{2} \mathrm{Fe}\right)_{4} \mathrm{~Pb}_{3} \mathrm{Br}_{10}$ \\
\hline$Z$ & 16 & 2 \\
\hline \multicolumn{3}{|l|}{ Data collection } \\
\hline Radiation type & electrons, $300 \mathrm{kV}$ & electrons, $200 \mathrm{kV}$ \\
\hline Wavelength $(\AA)$ & 0.01970 & 0.02510 \\
\hline Temperature (K) & 97 & 97 \\
\hline Precession angle (deg.) & 0.94 & 1.0 \\
\hline Resolution $\left(\AA^{-1}\right)$ & 1.0 & 0.9 \\
\hline Tilt step (deg.) & 1 & 1 \\
\hline No. of frames & $329(326)^{b}$ & $415(173)^{b}$ \\
\hline Completeness (\%) & 88 & $80(47)^{b}$ \\
\hline \multicolumn{3}{|l|}{ Kinematical structure refinement } \\
\hline No. of used reflections (obs/all) & $2061 / 3321$ & $725 / 1850$ \\
\hline$R_{1}(\mathrm{obs}) / R_{1}(\mathrm{all}), w R_{1}(\mathrm{obs}) / w R_{1}$ (all) (\%) & $14.9 / 21.4,15.2 / 15.8$ & $18.3 / 32.2,14.7 / 16.3$ \\
\hline goodness of fit (obs/all) & $5.1 / 4.1$ & $4.2 / 2.9$ \\
\hline No. of refined parameters & 220 & 145 \\
\hline \multicolumn{3}{|l|}{ Dynamical structure refinement } \\
\hline No. of used reflections (obs/all) & $14578 / 47320$ & $4548 / 20971$ \\
\hline Average crystal thickness (nm) & 49 / 67 / 64 & $131 / 80 / 90$ \\
\hline$g_{\max }, S_{g_{\max }}(\operatorname{matrix}), \mathrm{RSg}_{\max }, \mathrm{DSg}_{\min }, \mathrm{N}($ IntSteps $)$ & $1.05,0.01,0.6,1.7 \mathrm{e}-3,120$ & $0.95,0.01,0.6,1.7 \mathrm{e}-3,120$ \\
\hline$R_{1}(\mathrm{obs}) / R_{1}(\mathrm{all}), w R_{1}(\mathrm{obs}) / w R_{1}$ (all) (\%) & $9.4 / 21.5,9.7 / 11.6$ & $11.7 / 32.8,10.9 / 13.1$ \\
\hline goodness of fit (obs/all) & $2.00 / 1.34$ & $2.66 / 1.48$ \\
\hline No. of refined parameters ${ }^{\mathrm{a}}$ & $222+326$ & $147+173$ \\
\hline
\end{tabular}

${ }^{a}$ Split into the terms of the sum structural parameters and scale factors.

${ }^{b}$ Number of frames used for structure solution and structure refinement in brackets. 

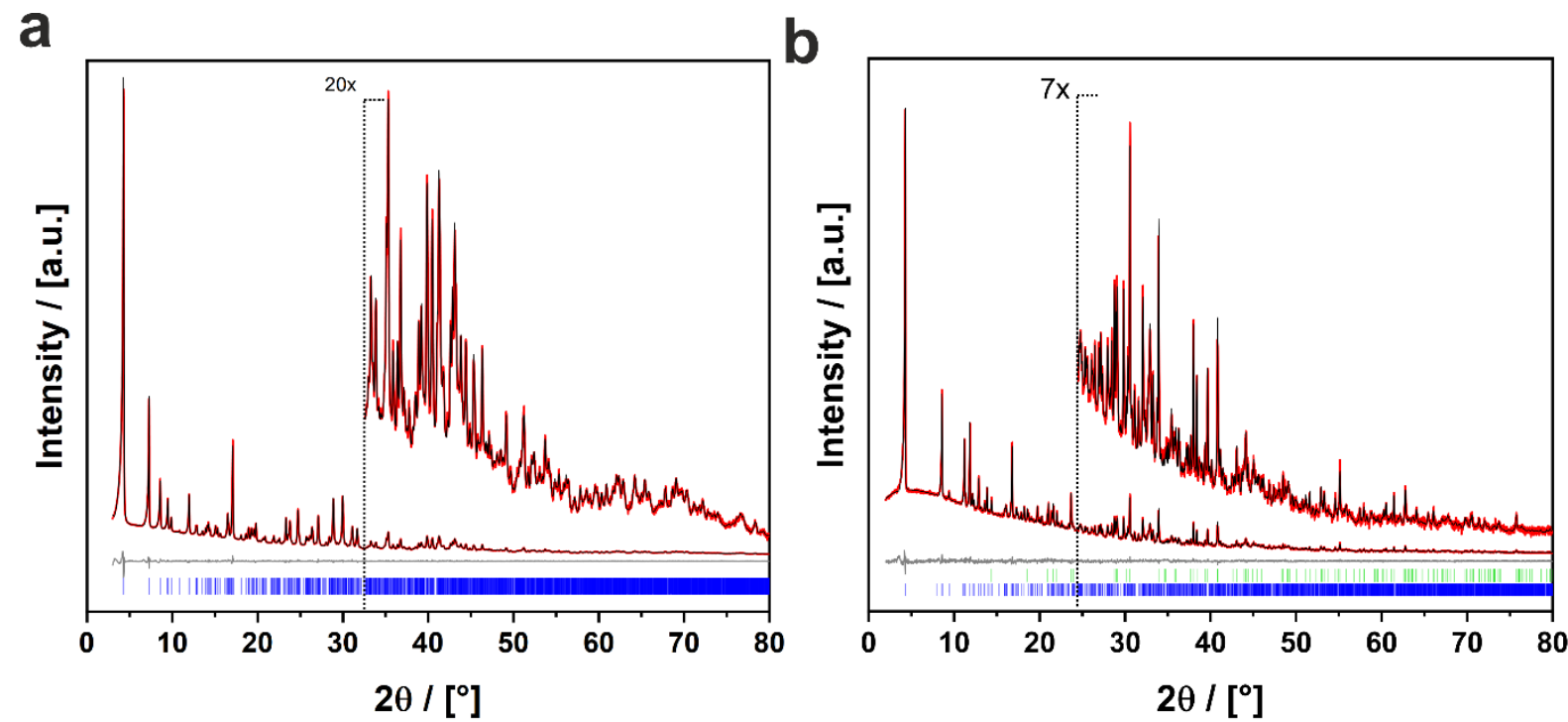

Figure S10. Rietveld refinement plot $(\lambda=1.54059 \AA)$ of a) $\left(\mathrm{FcC}_{2}\right) \mathrm{PbBr}_{3}$ and $\left.\mathrm{b}\right)$

$\left(\mathrm{FcC}_{4}\right)_{4} \mathrm{~Pb}_{3} \mathrm{Br}_{10}$. Red line for measured intensities $\left(I_{\mathrm{O}}\right)$, black line for fitted profile $\left(I_{\mathrm{C}}\right)$, and grey line for the difference $\left(I_{\mathrm{O}}-I_{\mathrm{C}}\right)$.
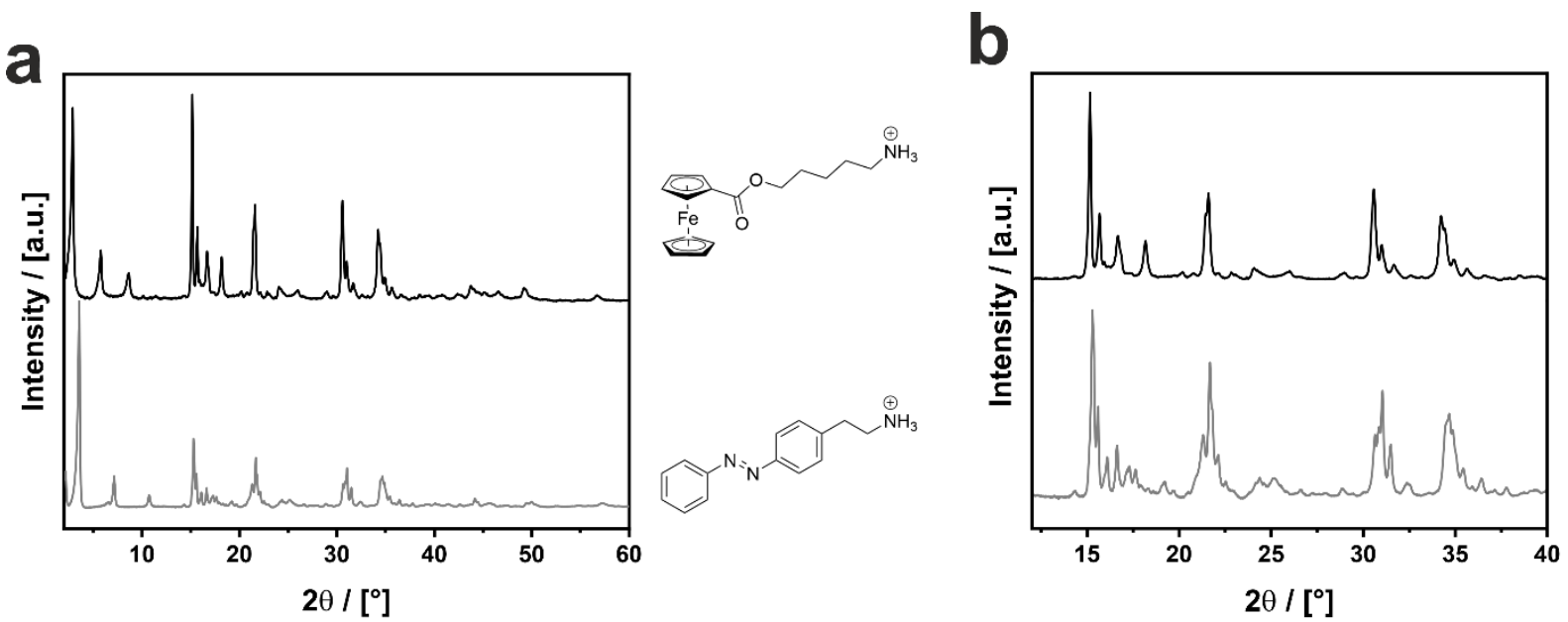

Figure S11. a) PXRD of $\left(\mathrm{FcC}_{6}\right)_{2} \mathrm{PbBr}_{4}$ (top) vs. the Ruddlesden-Popper phase with azobenzene ethylammonium bromide $\left(\mathrm{AzoC}_{2} \mathrm{Br}\right)$ from our latest publication. $\left.{ }^{[34]} \mathrm{b}\right)$ Enlargement of the range between $2 \Theta=12^{\circ}-40^{\circ}$. 


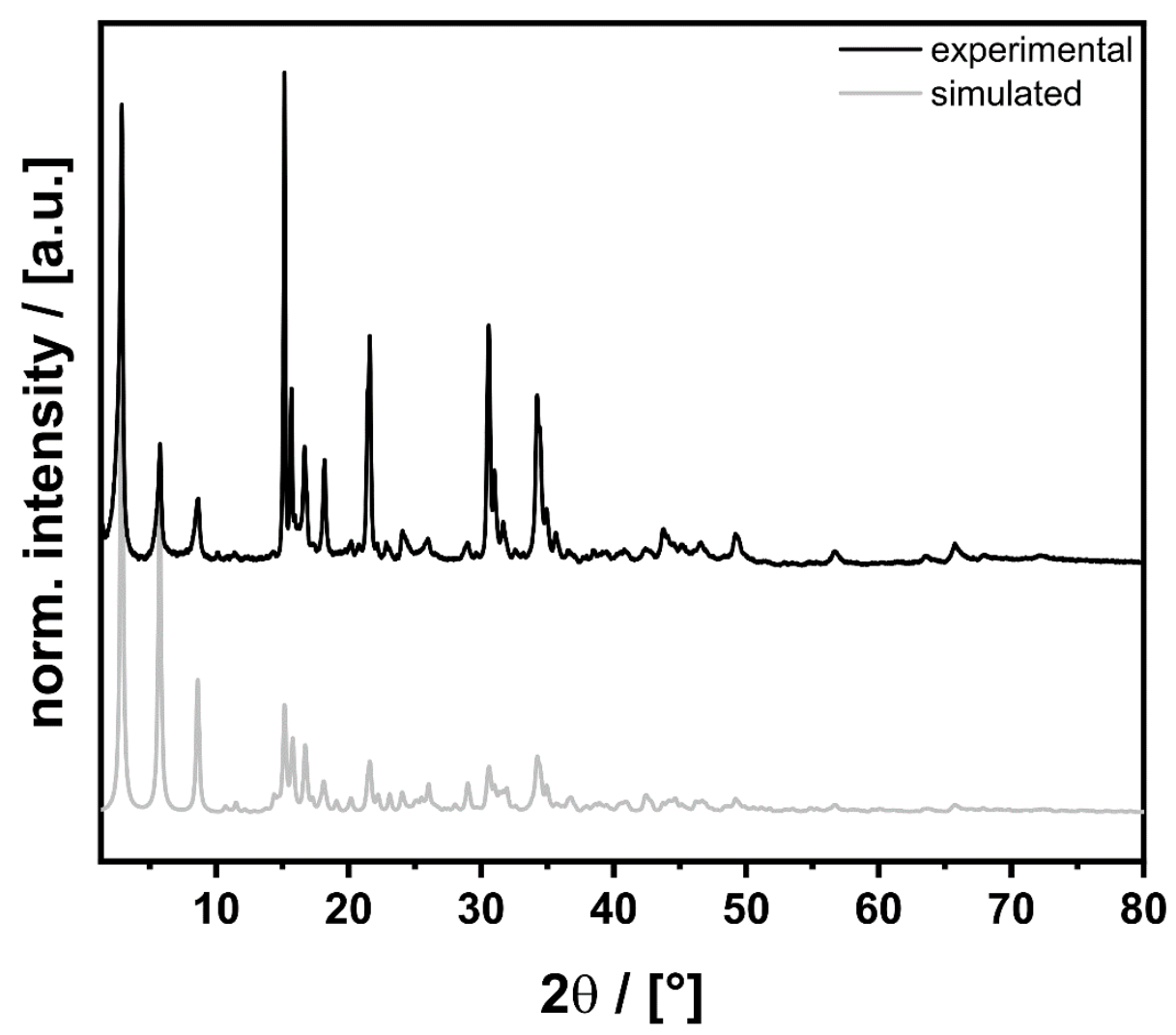

Figure S12. Experimental (black) and simulated (grey) PXRD pattern of $\left(\mathrm{FcC}_{6}\right)_{2} \mathrm{PbBr}_{4}$. Simulation is based on the geometry optimized DFT calculations of $\left(\mathrm{FcC}_{6}\right)_{2} \mathrm{PbBr}_{4}$.

Table S2. Fractional coordinates of modelled crystal structure of $\left(\mathrm{FcC}_{6}\right)_{2} \mathrm{PbBr}_{4}$.

\begin{tabular}{|l|l|l|l|l|l|}
\hline Site label & Atom type & $\mathbf{x}$ & $\mathbf{y}$ & $\mathbf{z}$ & $\boldsymbol{U}_{\text {iso }}\left[\AA^{2}\right]$ \\
\hline $\mathrm{Pb} 1$ & $\mathrm{~Pb}$ & 0.5 & 0.5 & 0.5 & 0.04142 \\
\hline $\mathrm{Pb} 2$ & $\mathrm{~Pb}$ & 1 & 0 & 0.5 & 0.04142 \\
\hline $\mathrm{Br} 1$ & $\mathrm{Br}$ & 0.44636 & 0.55072 & 0.40257 & 0.04085 \\
\hline $\mathrm{Br} 2$ & $\mathrm{Br}$ & 0.99712 & -0.02652 & 0.59812 & 0.04085 \\
\hline $\mathrm{Br} 3$ & $\mathrm{Br}$ & 0.68641 & 0.19098 & 0.49313 & 0.04085 \\
\hline $\mathrm{Br} 4$ & $\mathrm{Br}$ & 0.81479 & -0.31406 & 0.50223 & 0.04085 \\
\hline $\mathrm{Fe} 1$ & $\mathrm{Fe}$ & 0.733 & 0.2702 & 0.94657 & 0.09262 \\
\hline $\mathrm{Fe} 2$ & $\mathrm{Fe}$ & 0.77531 & 0.26886 & 0.14988 & 0.09262 \\
\hline $\mathrm{C} 1$ & $\mathrm{C}$ & 0.89221 & 0.41175 & 0.97244 & 0.13543 \\
\hline $\mathrm{C} 2$ & $\mathrm{C}$ & 0.80759 & 0.5052 & 0.93743 & 0.13543 \\
\hline $\mathrm{C3}$ & $\mathrm{C}$ & 0.83488 & 0.43097 & 0.89895 & 0.13543 \\
\hline $\mathrm{C} 4$ & $\mathrm{C}$ & 0.93716 & 0.29251 & 0.91002 & 0.13543 \\
\hline $\mathrm{C} 5$ & $\mathrm{C}$ & 0.97379 & 0.28062 & 0.95544 & 0.13543 \\
\hline $\mathrm{C} 6$ & $\mathrm{C}$ & 0.66918 & 0.03813 & 0.9668 & 0.13543 \\
\hline $\mathrm{C} 7$ & $\mathrm{C}$ & 0.61455 & 0.14191 & 0.99711 & 0.13543 \\
\hline $\mathrm{C} 8$ & $\mathrm{C}$ & 0.50993 & 0.26249 & 0.9745 & 0.13543 \\
\hline $\mathrm{C} 9$ & $\mathrm{C}$ & 0.5009 & 0.2346 & 0.93008 & 0.13543 \\
\hline $\mathrm{C} 10$ & $\mathrm{C}$ & 0.5984 & 0.09815 & 0.92524 & 0.13543 \\
\hline $\mathrm{C} 11$ & $\mathrm{C}$ & 0.71105 & 0.03066 & 0.88409 & 0.13543 \\
\hline $\mathrm{C} 12$ & $\mathrm{C}$ & 0.11361 & 0.80872 & 0.13543 \\
\hline
\end{tabular}




\begin{tabular}{|c|c|c|c|c|c|}
\hline C13 & C & 0.58285 & 0.06325 & 0.77859 & 0.13543 \\
\hline C14 & C & 0.64978 & 0.04189 & 0.73384 & 0.13543 \\
\hline C15 & C & 0.52154 & -0.01102 & 0.7032 & 0.13543 \\
\hline C16 & C & 0.59241 & -0.01466 & 0.65785 & 0.13543 \\
\hline C17 & C & 0.47724 & -0.07571 & 0.62584 & 0.13543 \\
\hline C18 & C & 0.8948 & 0.13731 & 0.20078 & 0.13543 \\
\hline C19 & C & 0.80031 & 0.03101 & 0.17835 & 0.13543 \\
\hline $\mathrm{C} 20$ & C & 0.85173 & 0.05099 & 0.13385 & 0.13543 \\
\hline $\mathrm{C} 21$ & C & 0.97847 & 0.16963 & 0.12871 & 0.13543 \\
\hline C22 & C & 1.00536 & 0.2226 & 0.17015 & 0.13543 \\
\hline $\mathrm{C} 23$ & C & 0.75826 & 0.51488 & 0.14251 & 0.13543 \\
\hline C24 & C & 0.74135 & 0.45599 & 0.10152 & 0.13543 \\
\hline $\mathrm{C} 25$ & C & 0.60494 & 0.34881 & 0.10444 & 0.13543 \\
\hline $\mathrm{C} 26$ & C & 0.53739 & 0.34083 & 0.14707 & 0.13543 \\
\hline C27 & C & 0.63007 & 0.44293 & 0.17025 & 0.13543 \\
\hline $\mathrm{C} 28$ & C & 0.60034 & 0.49316 & 0.21512 & 0.13543 \\
\hline $\mathrm{C} 29$ & C & 0.39501 & 0.47177 & 0.27063 & 0.13543 \\
\hline $\mathrm{C30}$ & C & 0.21555 & 0.43622 & 0.27287 & 0.13543 \\
\hline C31 & C & 0.13287 & 0.50235 & 0.31102 & 0.13543 \\
\hline C32 & C & -0.04398 & 0.45126 & 0.31626 & 0.13543 \\
\hline C33 & C & -0.14086 & 0.54044 & 0.34791 & 0.13543 \\
\hline C34 & C & -0.10216 & 0.49952 & 0.39614 & 0.13543 \\
\hline 01 & 0 & 0.69122 & -0.10201 & 0.88243 & 0.13543 \\
\hline 02 & 0 & 0.63968 & 0.15551 & 0.84883 & 0.13543 \\
\hline 03 & 0 & 0.68046 & 0.57506 & 0.23328 & 0.13543 \\
\hline 04 & 0 & 0.45341 & 0.4193 & 0.23066 & 0.13543 \\
\hline N1 & $\mathrm{N}$ & 0.5564 & -0.06885 & 0.58234 & 0.13543 \\
\hline N2 & $\mathrm{N}$ & 0.02657 & 0.60327 & 0.41138 & 0.13543 \\
\hline $\mathrm{H} 1$ & $\mathrm{H}$ & 0.89443 & 0.43498 & 1.00606 & 0.16251 \\
\hline $\mathrm{H} 2$ & $\mathrm{H}$ & 0.73548 & 0.61363 & 0.93953 & 0.16251 \\
\hline $\mathrm{H} 3$ & $\mathrm{H}$ & 0.78562 & 0.47345 & 0.86673 & 0.16251 \\
\hline $\mathrm{H} 4$ & $\mathrm{H}$ & 0.97956 & 0.21074 & 0.88791 & 0.16251 \\
\hline H5 & $\mathrm{H}$ & 1.0503 & 0.18832 & 0.97403 & 0.16251 \\
\hline $\mathrm{H} 6$ & $\mathrm{H}$ & 0.74965 & -0.06611 & 0.97417 & 0.16251 \\
\hline $\mathrm{H7}$ & $\mathrm{H}$ & 0.64753 & 0.13055 & 1.03144 & 0.16251 \\
\hline $\mathrm{H} 8$ & $\mathrm{H}$ & 0.44769 & 0.35838 & 0.9885 & 0.16251 \\
\hline $\mathrm{H} 9$ & $\mathrm{H}$ & 0.43154 & 0.30685 & 0.90444 & 0.16251 \\
\hline $\mathrm{H} 12-1$ & $\mathrm{H}$ & 0.772 & 0.22136 & 0.79287 & 0.16251 \\
\hline H12-2 & $\mathrm{H}$ & 0.79713 & 0.01438 & 0.81664 & 0.16251 \\
\hline H13-1 & $\mathrm{H}$ & 0.48922 & 0.15665 & 0.77432 & 0.16251 \\
\hline H13-2 & $\mathrm{H}$ & 0.53208 & -0.052 & 0.79326 & 0.16251 \\
\hline H14-1 & $\mathrm{H}$ & 0.74457 & -0.05037 & 0.73821 & 0.16251 \\
\hline $\mathrm{H} 14-2$ & $\mathrm{H}$ & 0.69948 & 0.15762 & 0.71908 & 0.16251 \\
\hline $\mathrm{H} 15-1$ & $\mathrm{H}$ & 0.4211 & 0.07496 & 0.70078 & 0.16251 \\
\hline H15-2 & $\mathrm{H}$ & 0.47966 & -0.13232 & 0.71606 & 0.16251 \\
\hline $\mathrm{H} 16-1$ & $\mathrm{H}$ & 0.69801 & -0.09403 & 0.66117 & 0.16251 \\
\hline H16-2 & $\mathrm{H}$ & 0.62772 & 0.10866 & 0.64477 & 0.16251 \\
\hline H17-1 & $\mathrm{H}$ & 0.36931 & 0.00049 & 0.62245 & 0.16251 \\
\hline
\end{tabular}




\begin{tabular}{|c|c|c|c|c|c|}
\hline H17-2 & $\mathrm{H}$ & 0.44486 & -0.20135 & 0.63749 & 0.16251 \\
\hline H18 & $\mathrm{H}$ & 0.88517 & 0.15166 & 0.23499 & 0.16251 \\
\hline H19 & $\mathrm{H}$ & 0.7063 & -0.05073 & 0.19244 & 0.16251 \\
\hline $\mathrm{H} 2 \mathrm{O}$ & $\mathrm{H}$ & 0.80264 & -0.01309 & 0.10835 & 0.16251 \\
\hline $\mathrm{H} 21$ & $\mathrm{H}$ & 1.04225 & 0.2117 & 0.09876 & 0.16251 \\
\hline $\mathrm{H} 22$ & $\mathrm{H}$ & 1.09408 & 0.3119 & 0.17729 & 0.16251 \\
\hline $\mathrm{H} 23$ & $\mathrm{H}$ & 0.85078 & 0.59826 & 0.15098 & 0.16251 \\
\hline $\mathrm{H} 24$ & $\mathrm{H}$ & 0.81768 & 0.4867 & 0.07329 & 0.16251 \\
\hline $\mathrm{H} 25$ & $\mathrm{H}$ & 0.56 & 0.28443 & 0.07856 & 0.16251 \\
\hline $\mathrm{H} 26$ & $\mathrm{H}$ & 0.43332 & 0.26894 & 0.15912 & 0.16251 \\
\hline H29-1 & $\mathrm{H}$ & 0.4574 & 0.40299 & 0.29825 & 0.16251 \\
\hline H29-2 & $\mathrm{H}$ & 0.41544 & 0.60156 & 0.27011 & 0.16251 \\
\hline $\mathrm{H} 30-1$ & $\mathrm{H}$ & 0.19952 & 0.30456 & 0.27656 & 0.16251 \\
\hline H30-2 & $\mathrm{H}$ & 0.15899 & 0.49219 & 0.24263 & 0.16251 \\
\hline H31-1 & $\mathrm{H}$ & 0.13799 & 0.63482 & 0.30548 & 0.16251 \\
\hline H31-2 & $\mathrm{H}$ & 0.19773 & 0.45626 & 0.34086 & 0.16251 \\
\hline H32-1 & $\mathrm{H}$ & -0.0473 & 0.32125 & 0.32784 & 0.16251 \\
\hline H32-2 & $\mathrm{H}$ & -0.10268 & 0.47546 & 0.28437 & 0.16251 \\
\hline H33-1 & $\mathrm{H}$ & -0.2684 & 0.51156 & 0.34346 & 0.16251 \\
\hline H33-2 & $\mathrm{H}$ & -0.12275 & 0.67036 & 0.33885 & 0.16251 \\
\hline H34-1 & $\mathrm{H}$ & -0.06339 & 0.3731 & 0.40269 & 0.16251 \\
\hline H34-2 & $\mathrm{H}$ & -0.21155 & 0.51666 & 0.41432 & 0.16251 \\
\hline H1n1 & $\mathrm{H}$ & 0.65977 & -0.14186 & 0.58509 & 0.16251 \\
\hline $\mathrm{H} 2 \mathrm{n} 1$ & $\mathrm{H}$ & 0.47706 & -0.11176 & 0.56008 & 0.16251 \\
\hline H3n1 & $\mathrm{H}$ & 0.58895 & 0.05014 & 0.57077 & 0.16251 \\
\hline H1n2 & $\mathrm{H}$ & -0.00867 & 0.725 & 0.40608 & 0.16251 \\
\hline $\mathrm{H} 2 \mathrm{n} 2$ & $\mathrm{H}$ & 0.0479 & 0.5699 & 0.44453 & 0.16251 \\
\hline H3n2 & $\mathrm{H}$ & 0.13282 & 0.58842 & 0.39481 & 0.16251 \\
\hline
\end{tabular}


a

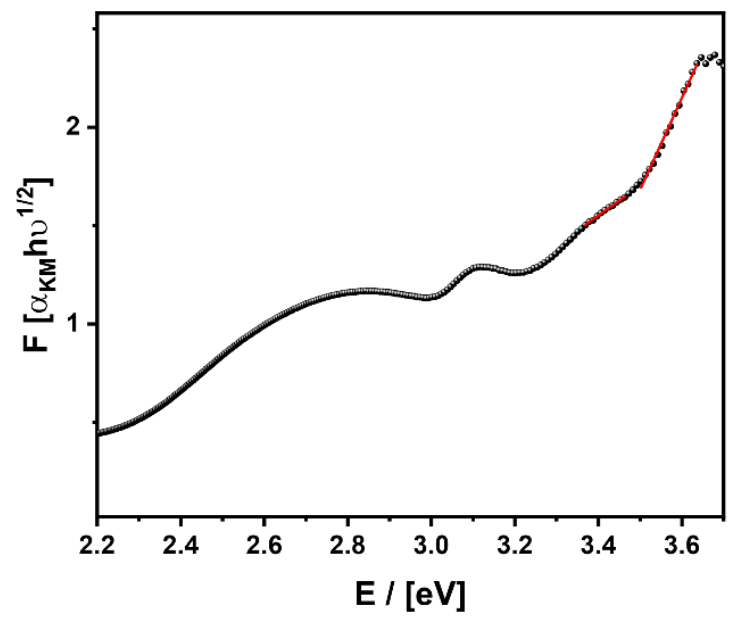

b

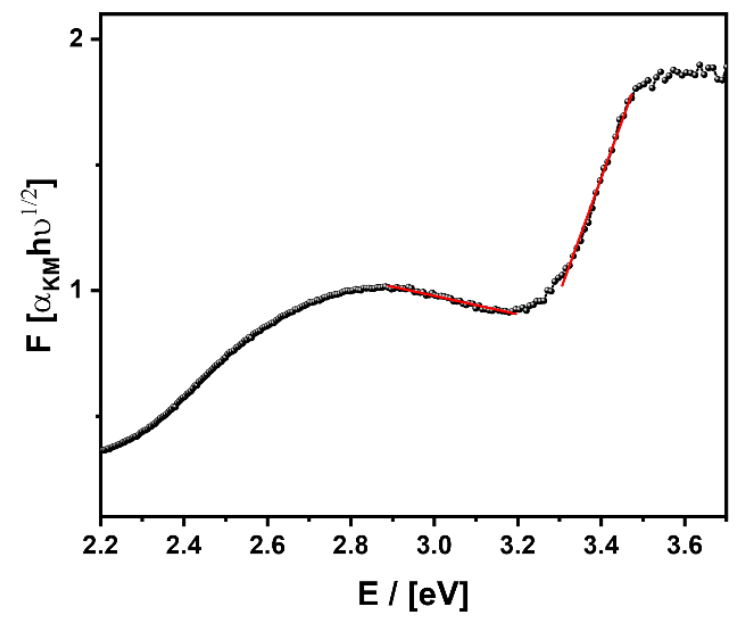

C

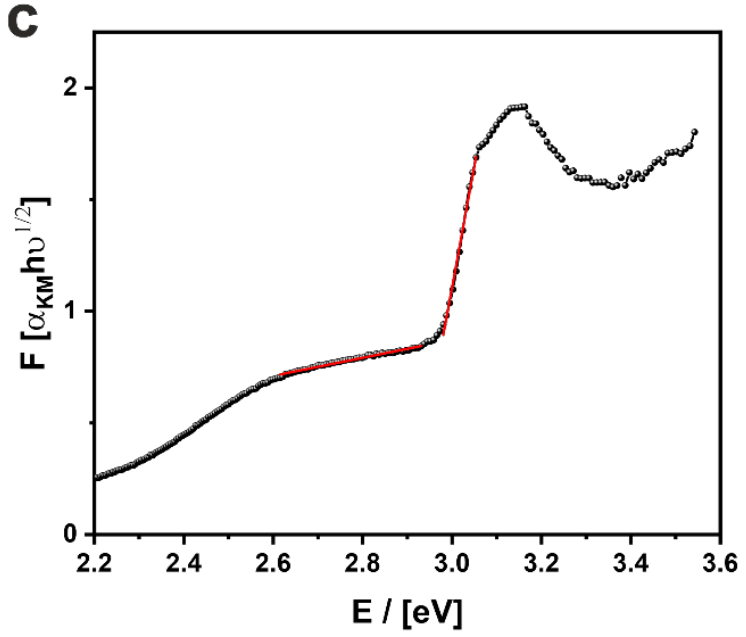

Figure S13. Kubelka-Munk plot of optical reflectance spectroscopy (ORS) for a)

$\left(\mathrm{FcC}_{2}\right) \mathrm{PbBr}_{3}$ with a band gap of $\left.\mathrm{E}_{\text {gap }}=3.51 \mathrm{eV}, \mathrm{b}\right)\left(\mathrm{FcC}_{4}\right)_{4} \mathrm{~Pb}_{3} \mathrm{Br}_{10}$ with a band gap of $E_{\text {gap }}=3.27 \mathrm{eV}$ and c) $\left(\mathrm{FcC}_{6}\right)_{2} \mathrm{PbBr}_{4}$ with a band gap of $\mathrm{E}_{\text {gap }}=3.06 \mathrm{eV}$. 


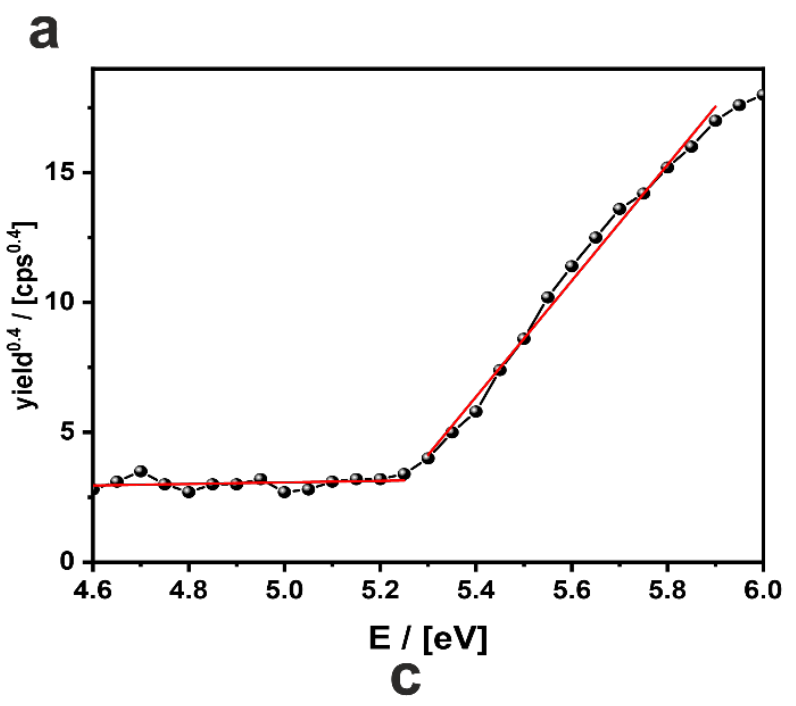

b
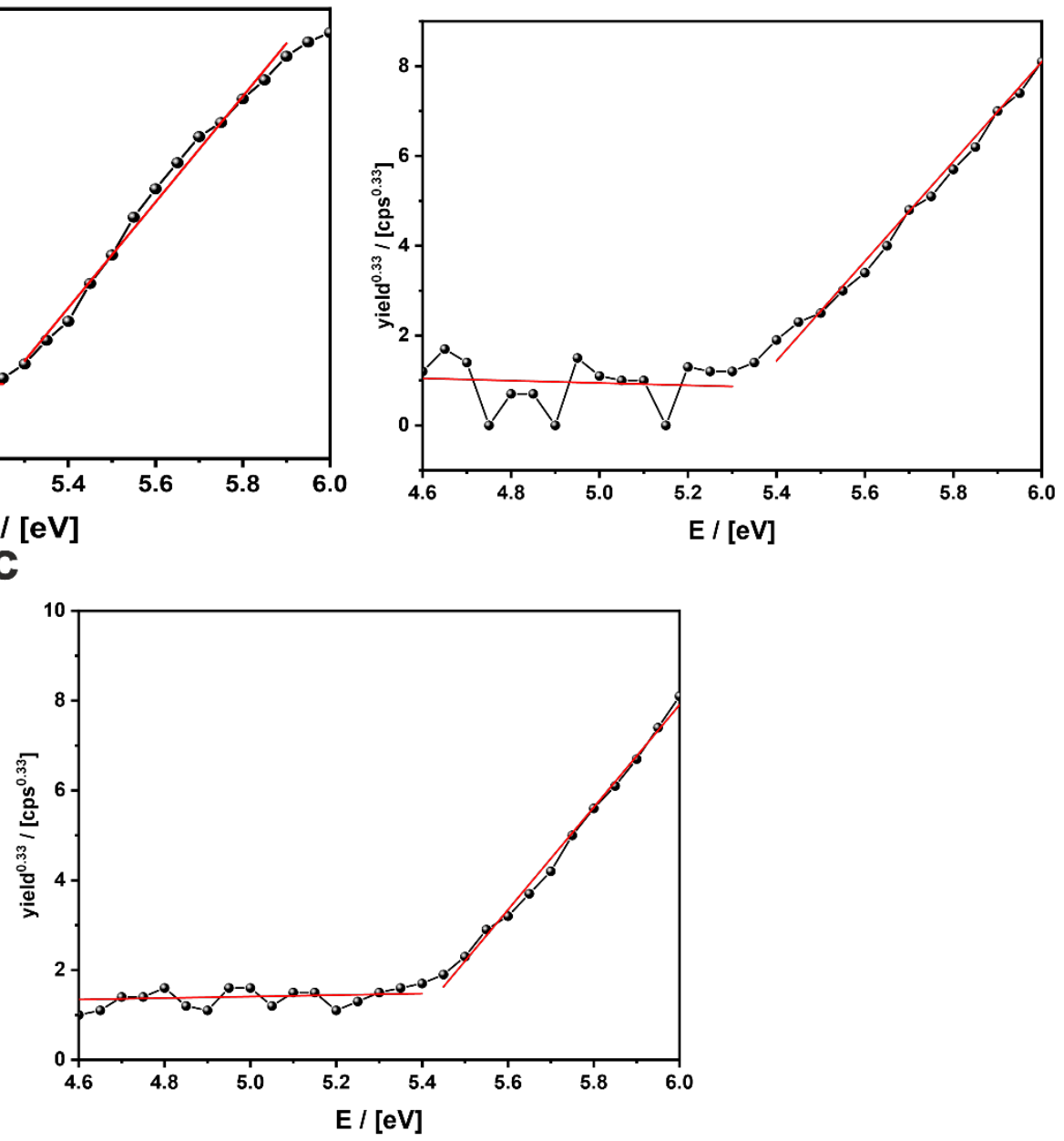

Figure S14. Photoelectron spectroscopy in air (PESA) of a) $\left(\mathrm{FcC}_{2}\right) \mathrm{PbBr}_{3}$ with $\left.\mathrm{E}_{\mathrm{VBM}}=-5.27 \mathrm{eV}, \mathrm{b}\right)\left(\mathrm{FcC}_{4}\right)_{4} \mathrm{~Pb}_{3} \mathrm{Br}_{10}$ with $\left.\mathrm{EVBM}_{\mathrm{VB}}=-5.35 \mathrm{eV}, \mathrm{c}\right)\left(\mathrm{FcC}_{6}\right)_{2} \mathrm{PbBr}_{4}$ with $\mathrm{E}_{\mathrm{VBM}}=-5.45 \mathrm{eV}$.

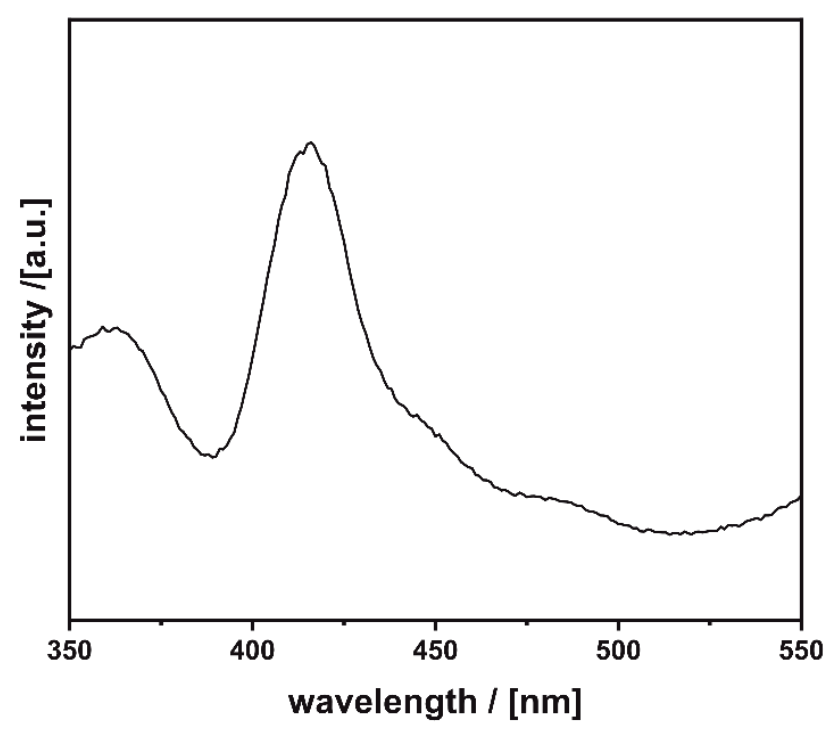

Figure S15. Photoluminescence (PL) spectra of $\left(\mathrm{FcC}_{6}\right)_{2} \mathrm{PbBr}_{4}$ dispersed in toluene with an excitation at $300 \mathrm{~nm}$. An emission maximum at $\lambda=416 \mathrm{~nm}\left(\mathrm{E}_{\mathrm{PL}}=2.98 \mathrm{eV}\right)$ is found. 

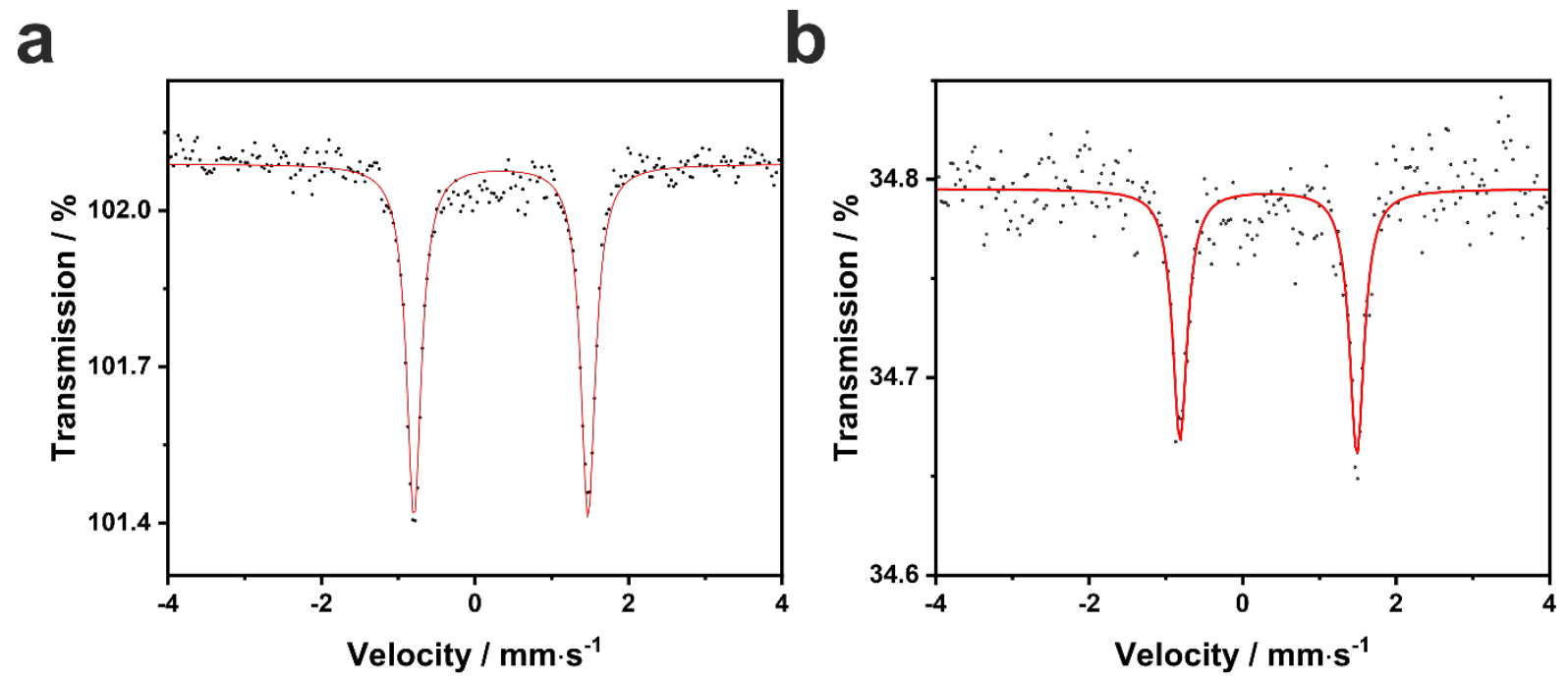

Figure S16. Fe $57 \mathrm{Mössbauer} \mathrm{spectra} \mathrm{of} \mathrm{a)} \mathrm{FcC}_{2} \mathrm{Br}$ and b) $\left(\mathrm{FcC}_{2}\right) \mathrm{PbBr}_{3}$ recorded at room temperature. No singlet proving the presence of $\mathrm{Fe}^{3+}$ can be detected (see Table S3).

Table S3. (Evaluation of Mössbauer spectra)

\begin{tabular}{|c|c|c|c|c|}
\hline Name & $d_{I S}$ & $\mathrm{D}_{\mathbf{Q}}$ & FWHM & Amount $\mathrm{Fe}^{2+}$ \\
\hline$/ \mathrm{mm} \cdot \mathrm{s}^{-1}$ & $/ \mathrm{mm} \cdot \mathrm{s}-1$ & $/ \mathrm{mm} \cdot \mathrm{s}^{-1}$ & $/ \mathrm{mm} \cdot \mathrm{s}^{-1}$ & $/ \%$ \\
\hline Doublet a) & $0.448(5)$ & $2.268(9)$ & $0.233(7)$ & 100 \\
\hline Doublet b) & $0.445(14)$ & $2.304(28)$ & $0.232(22)$ & 100 \\
\hline
\end{tabular}


a

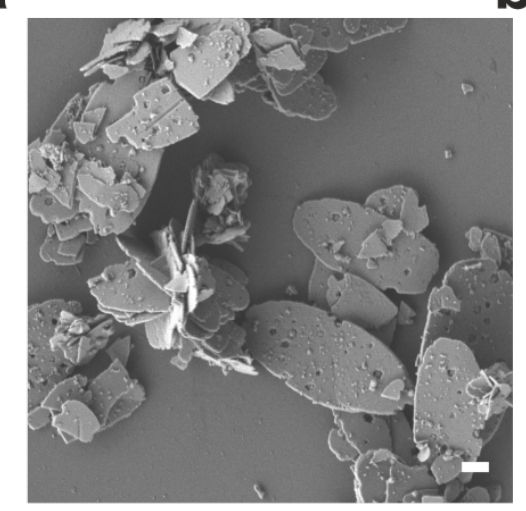

d

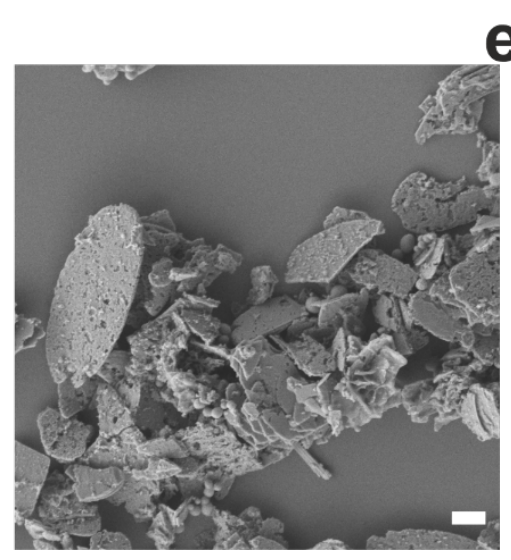

b

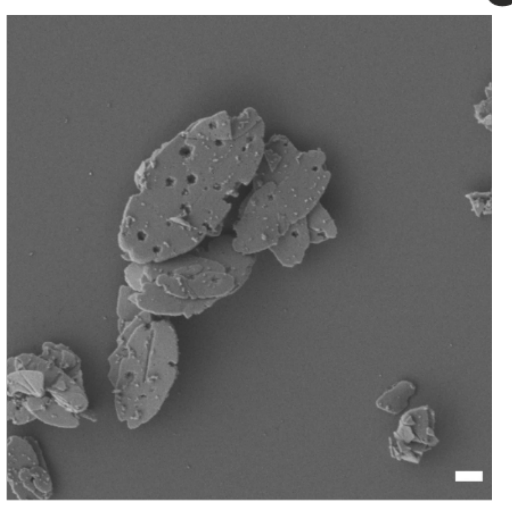

e

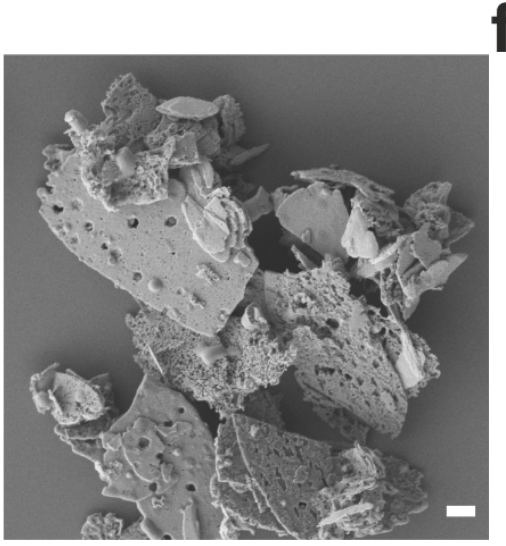

C

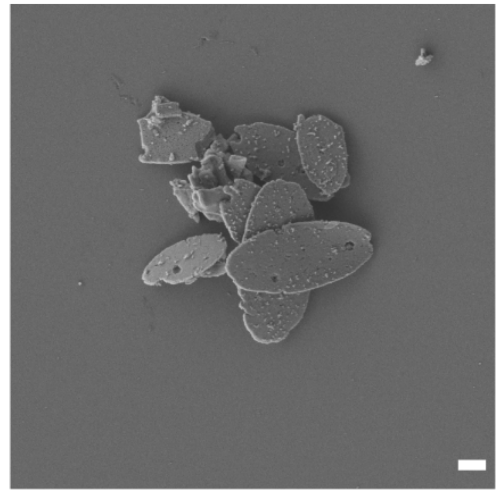

f

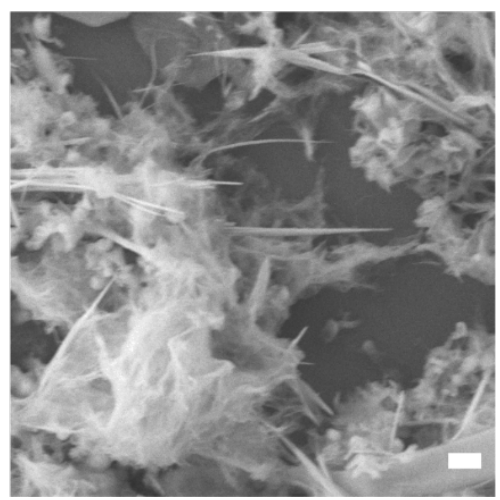

Figure S17. SEM images of particles oxidized with a) 0 eq, b) 0.1 eq c) 0.2 eq, d) 0.5 eq e) 1.0 eq and f) 2.0 eq of $\mathrm{Fe}\left(\mathrm{ClO}_{4}\right)_{3}$. a-e) scalebar $\left.=1 \mu \mathrm{m}, \mathrm{f}\right)$ scalebar $=2 \mu \mathrm{m}$. For detailed procedures of the oxidation, please refer to the experimental section. Note that the shape of the particles is preserved up to 1.0 equivalent of oxidant. At high concentrations, however, they lose their shape and form long needles. The ions of the oxidant can presumably intercalate into the structure, destroying the morphology of the particles. The oxidant enters the structure through a tunnel provided by the ferrocene molecules (see Figure 2a). As counter anions $\left(\mathrm{OCl}_{4}\right)^{-}$ are attached to the surface by the oxidation, they split the particles into long needles. However, phase and composition remain unaltered, proofed by PXRD and EDX, supporting our hypotheses of the intercalation process (Figure S18). 

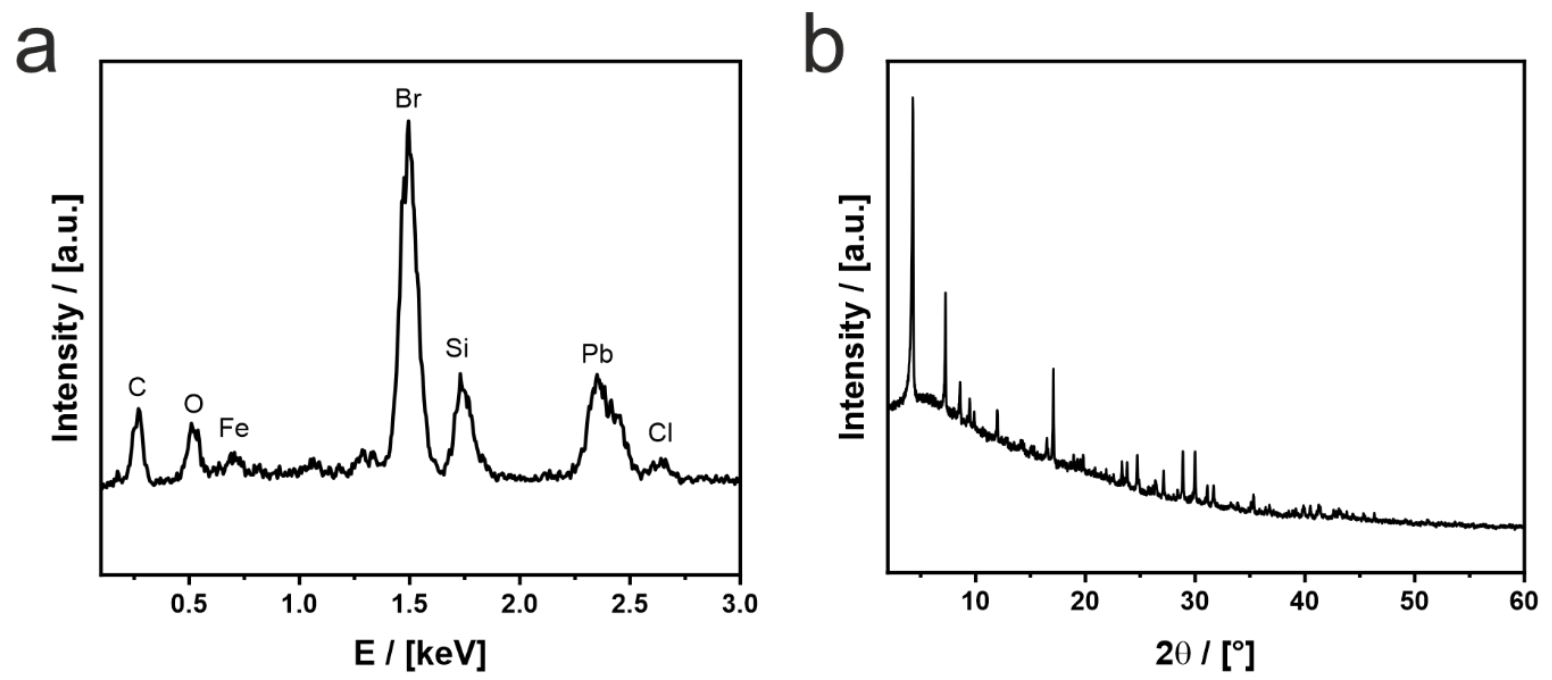

Figure S18. a) Energy dispersive X-ray (EDX) spectrum and b) PXRD of particles after oxidation with 2.0 eq $\mathrm{Fe}\left(\mathrm{ClO}_{4}\right)_{3}$. The composition detected with EDX is listed below in Table S4.

Table S4. (Composition of particles after oxidation with 2.0 eq $\mathrm{Fe}\left(\mathrm{ClO}_{4}\right)_{3}$ according to EDX)

\begin{tabular}{lccccccc}
\hline Atom & $\mathrm{C}$ & $\mathrm{O}$ & $\mathrm{Si}^{\mathrm{a})}$ & $\mathrm{Cl}$ & $\mathrm{Fe}$ & $\mathrm{Br}$ & $\mathrm{Pb}$ \\
\hline [at\%] & 51.0 & 15.6 & 7.6 & 1.7 & 3.8 & 15.4 & 4.7
\end{tabular}

a) $\mathrm{Si}$ originates from substrate
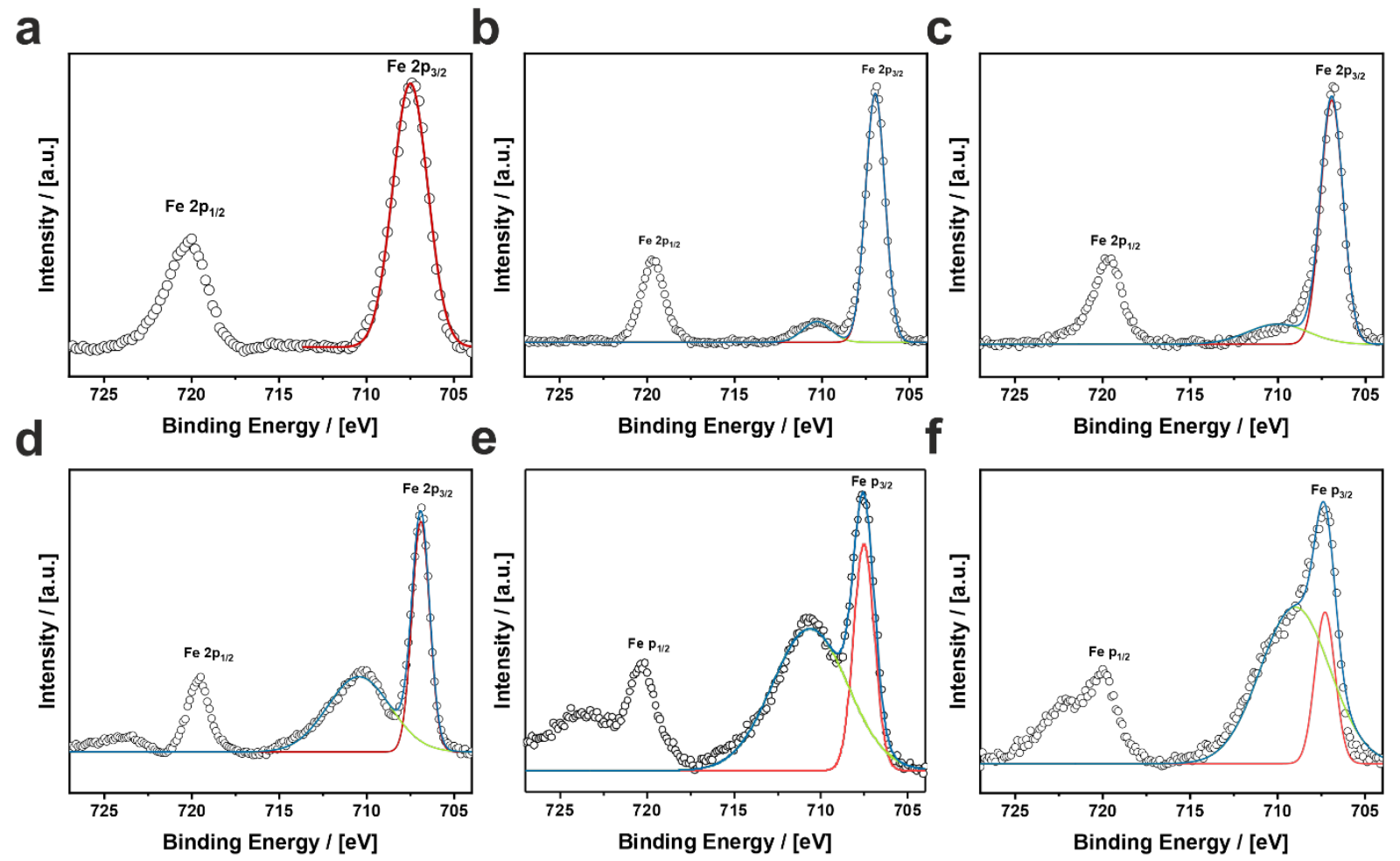
Figure S19. X-ray photon spectroscopy (XPS) fits of particles oxidized with a) 0 eq, b) 0.1 eq c) 0.2 eq, d) 0.5 eq e) 1.0 eq and f) 2.0 eq of $\mathrm{Fe}\left(\mathrm{ClO}_{4}\right)_{3}$. For detailed procedures of the oxidation, please refer to the experimental section. Evaluation of the XPS-spectra is provided in Table S5.

Table S5. (Content of $\mathrm{Fe}^{3+}$ of the particles after oxidation)

\begin{tabular}{lcccccc}
\hline$\left[\mathrm{Fe}\left(\mathrm{OCl}_{4}\right)_{3}\right]$ & $0.0 \mathrm{eq}$ & $0.1 \mathrm{eq}$ & $0.2 \mathrm{eq}$ & $0.5 \mathrm{eq}$ & $1.0 \mathrm{eq}$ & $2.0 \mathrm{eq}$ \\
\hline $\mathrm{Fe}^{3+}$-content & $0 \%$ & $10.8 \%$ & $18.2 \%$ & $46.4 \%$ & $57.8 \%$ & $63.3 \%$
\end{tabular}
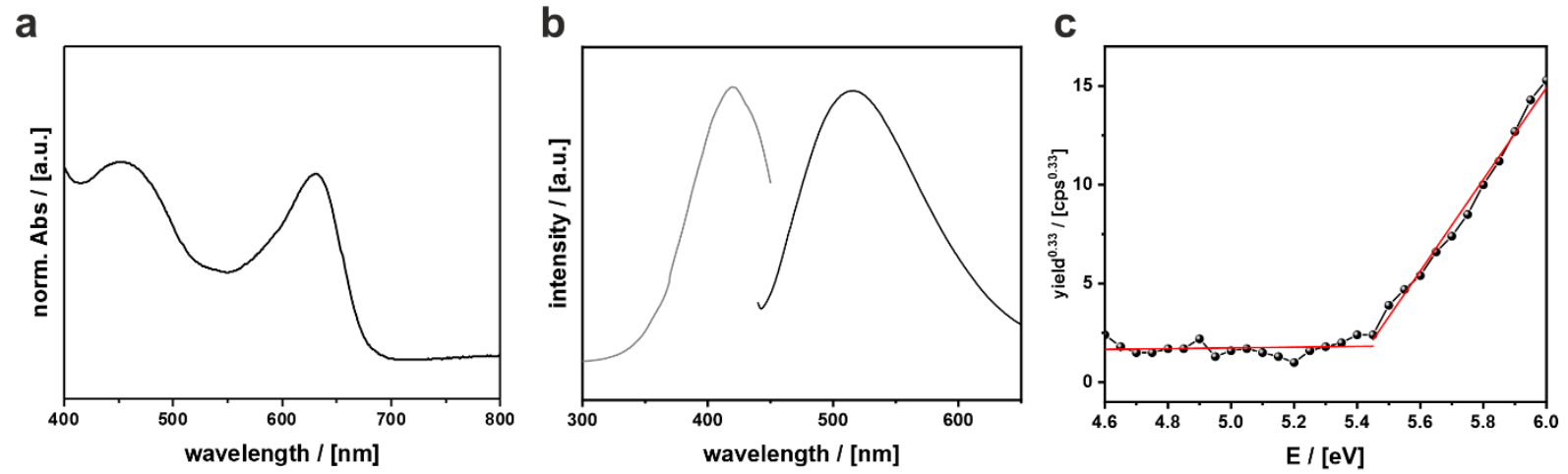

Figure S20. a) UV/Vis of $\left[\mathrm{FcC}_{2} \mathrm{Br}\right]^{+}$oxidized with $\mathrm{Ce}\left(\mathrm{SO}_{4}\right)_{2}$ b) Excitation at measured $515 \mathrm{~nm}$ emission (grey) and emission measured at $415 \mathrm{~nm}$ excitation of $\left[\mathrm{FcC}_{2} \mathrm{Br}\right]^{+}$oxidized with $\mathrm{Ce}\left(\mathrm{SO}_{4}\right)_{2}$. c) PESA measurement of $\mathrm{FcC}_{2} \mathrm{Br}$ before oxidation with $\mathrm{E}_{\mathrm{HOMO}}=-5.44 \mathrm{eV}$.
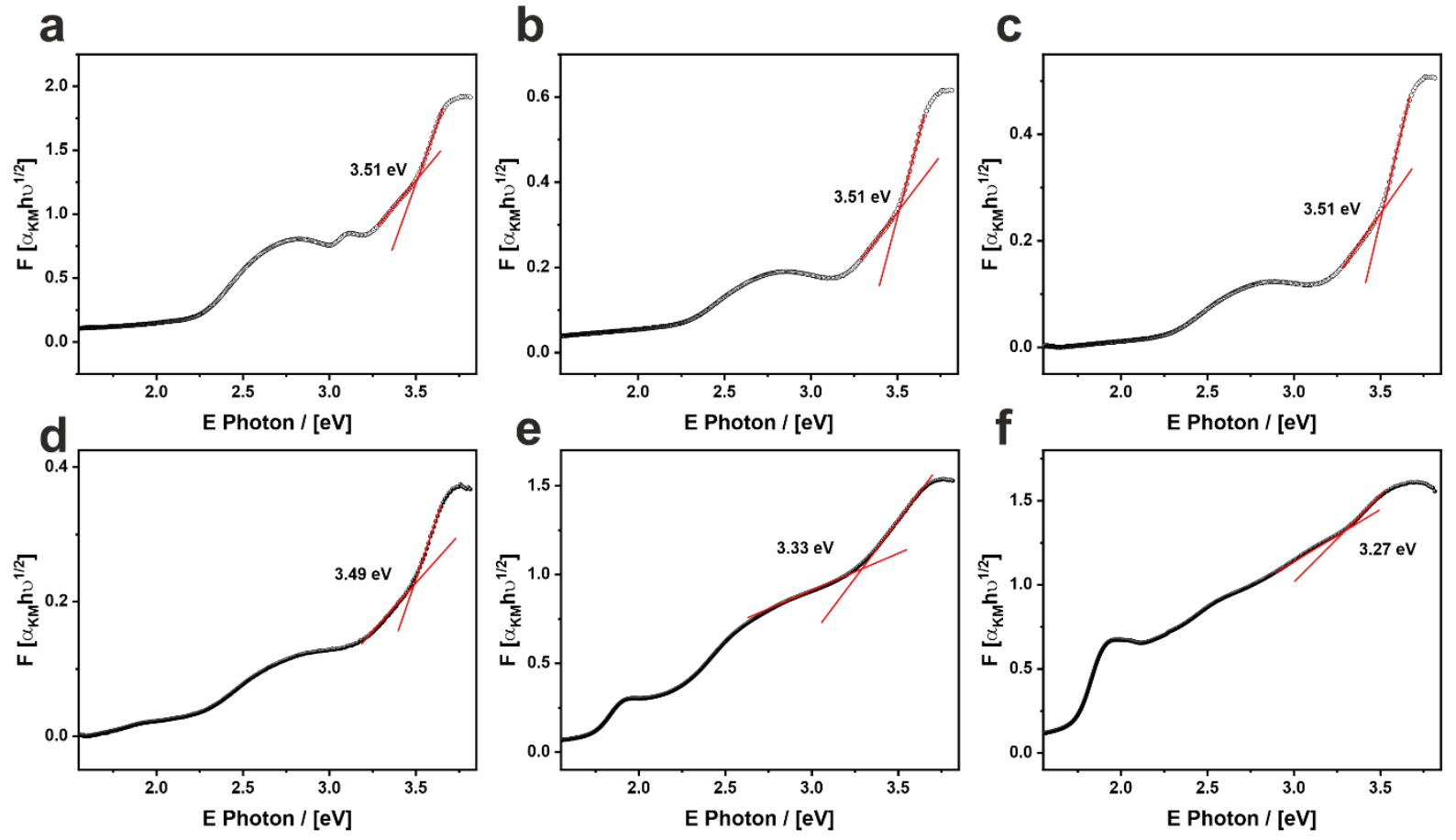

Figure S21. Kubelka-Munk plots of $\left(\mathrm{FcC}_{2}\right) \mathrm{PbBr}_{3}$ oxidized with a) $0.0 \% \mathrm{Fe}^{3+}$, b) $10.8 \% \mathrm{Fe}^{3+}$, c) $18.2 \% \mathrm{Fe}^{3+}$, d) $46.4 \% \mathrm{Fe}^{3+}$, e) $57.8 \% \mathrm{Fe}^{3+}$ and f) $63.3 \% \mathrm{Fe}^{3+}$. 


\section{Electrochemical oxidation of $\left(\mathrm{FcC}_{2}\right) \mathrm{PbBr}_{3}$}

To verify the chemical oxidation results, $\left(\mathrm{FcC}_{2}\right) \mathrm{PbBr}_{3}$ was electrochemically oxidized. For this purpose, an ITO substrate was coated with $\left(\mathrm{FcC}_{2}\right) \mathrm{PbBr}_{3}$ and oxidized in the same electrolyte as for the CV by applying a voltage of $0.65 \mathrm{~V}$ for $1800 \mathrm{sec}$. In Figure $4 \mathrm{a}, 0.65 \mathrm{~V}$ was identified as the oxidation potential. The sample was characterized using a combination of PXRD, SEM optical reflectance and PL spectroscopy.
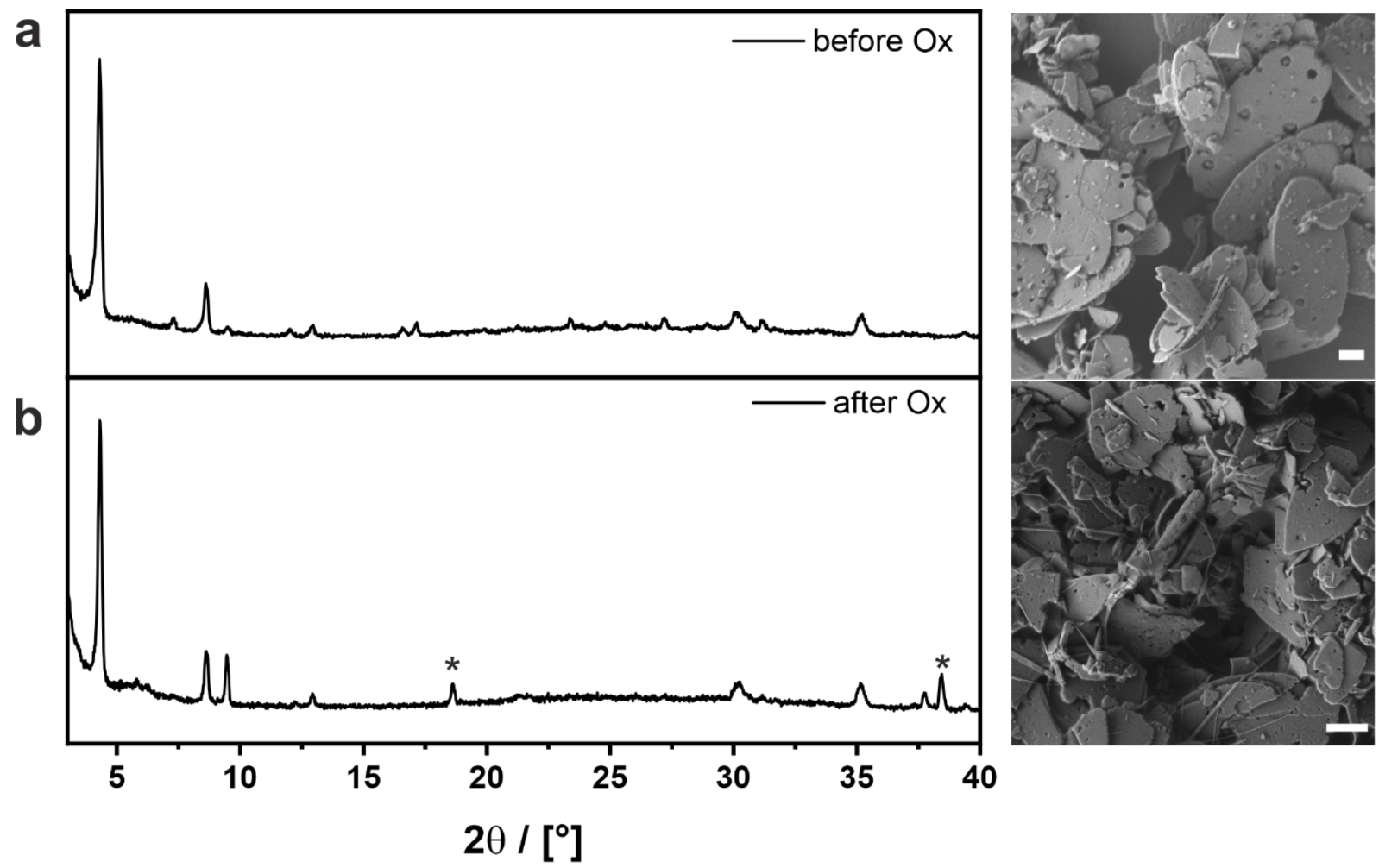

Figure S22. a) PXRD and scanning electron microscopy (SEM) image of $\left(\mathrm{FcC}_{2}\right) \mathrm{PbBr}_{3}$ on ITO before electrochemical oxidation and b) PXRD and SEM image of $\left(\mathrm{FcC}_{2}\right) \mathrm{PbBr}_{3}$ on ITO after oxidation at $0.65 \mathrm{~V}$ for $1800 \mathrm{sec}$. Realignment of the particles lead to changed intensities of the reflexes. In addition, typical reflections of $\mathrm{PbBr}_{2}$ are found after oxidation, which are marked with $(*)$.; Scalebar $=1 \mu \mathrm{m}$.
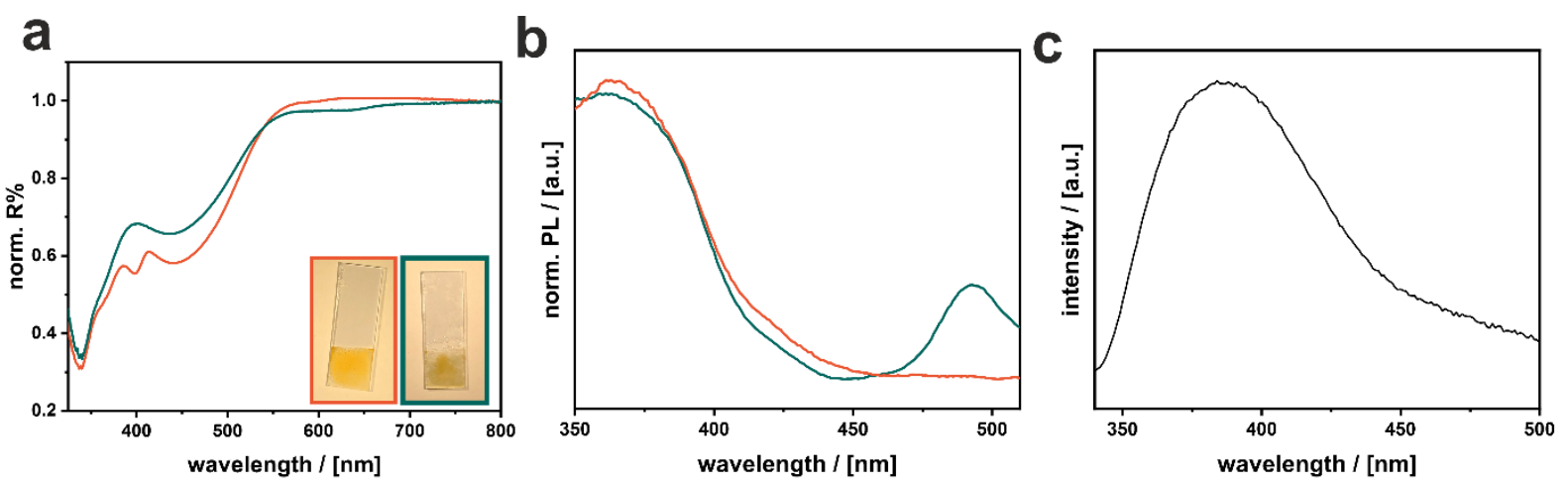
Figure S23. a) Normed reflectance spectra and photographs of $\left(\mathrm{FcC}_{2}\right) \mathrm{PbBr}_{3}$ before (orange) and after electrochemical oxidation (green). A decrease of the reflectance at $630 \mathrm{~nm}$ and the increase between $400 \mathrm{~nm}$ and $500 \mathrm{~nm}$ confirms the presence of the oxidized species $\mathrm{Fc}^{+} \mathrm{b}$ ) PL spectra of the particles before (orange) and after (green) electrochemical oxidation. c) PL spectra of the ITO substrate. By electrochemically oxidizing $\left(\mathrm{FcC}_{2}\right) \mathrm{PbBr}_{3}$ an emission at $494 \mathrm{~nm}$ with excitation at $310 \mathrm{~nm}$ is observed. The luminescence below $440 \mathrm{~nm}$, which occurs even before oxidation, is due to the ITO substrate (Figure S23c) 


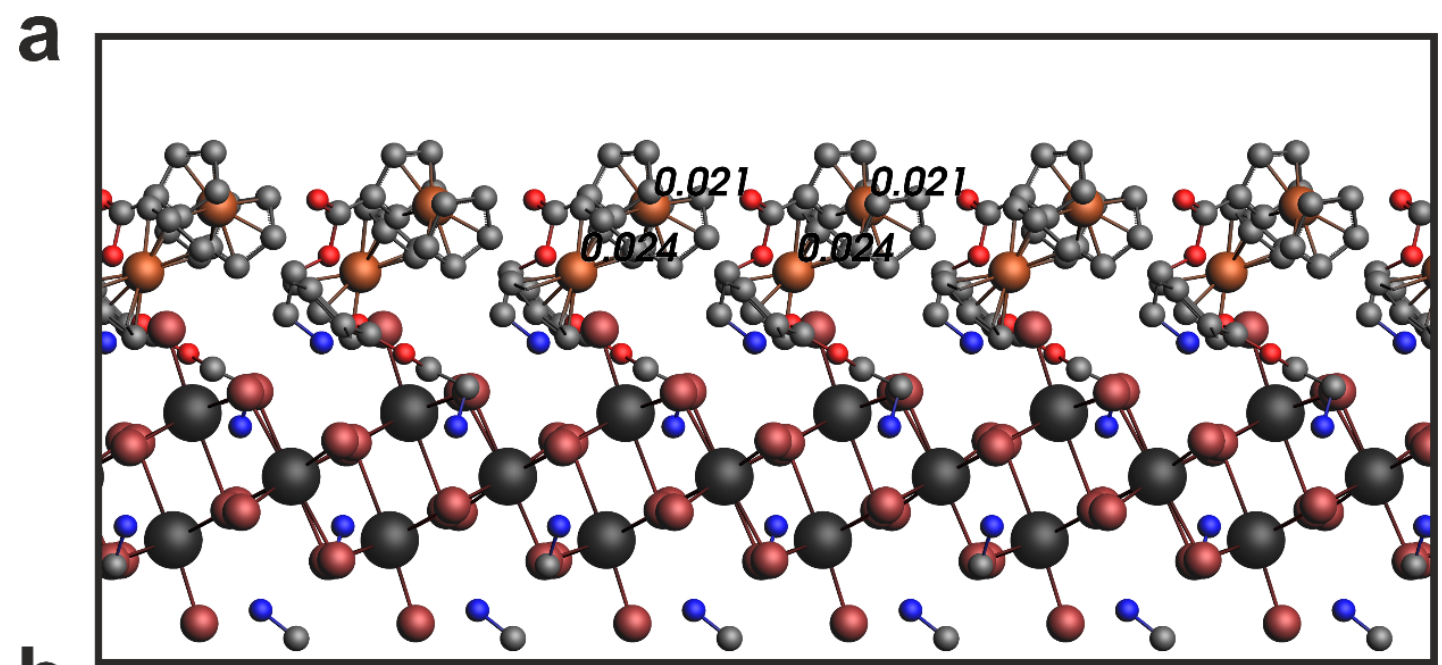

b

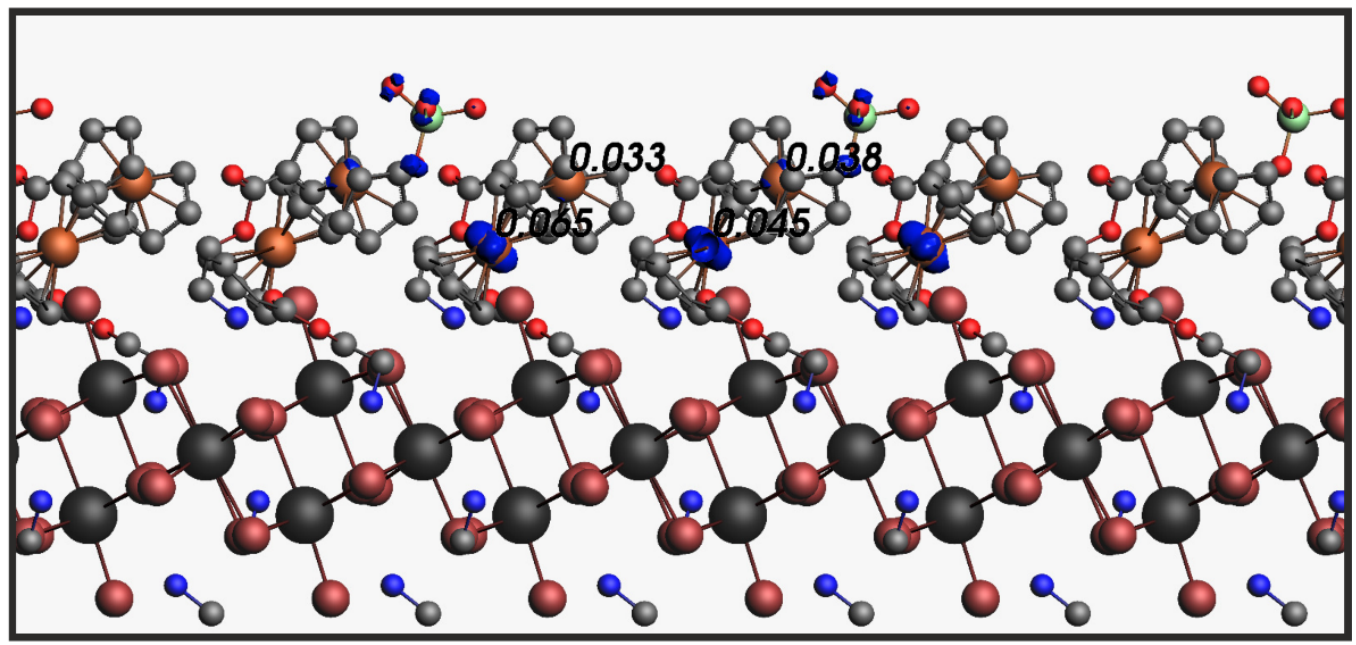

C

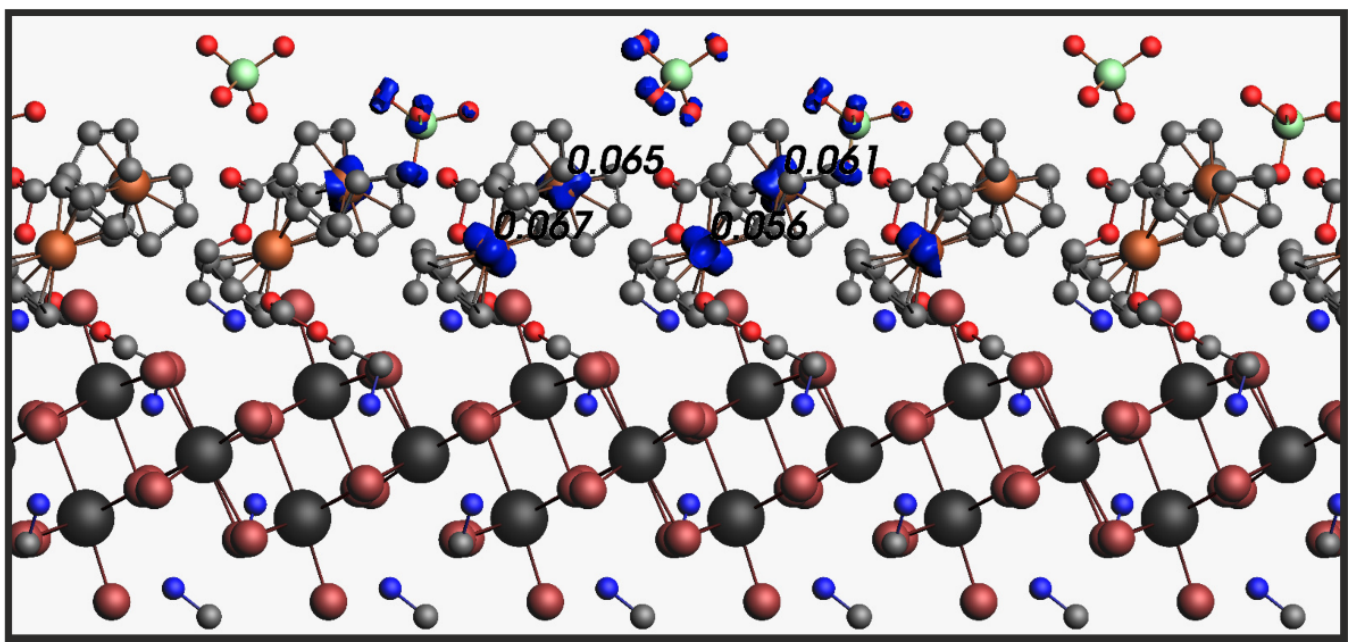

Figure S24. Representation of the calculated $\left(\mathrm{FcC}_{2}\right) \mathrm{PbBr}_{3}$ structures with Hirshfeld charges for a) the intrinsic state, b) the oxidized state with one $\left(\mathrm{ClO}_{4}\right)^{-}$anion $(25 \%)$ and c) the oxidized state with two $\left(\mathrm{ClO}_{4}\right)^{-}$anions $(50 \%)$. 